OSWALDO DE ALMEIDA PASTORE

A INFLUÊNCIA DA TEMPERATURA NA EFICIÊNCIA DE FILTROS MECÂNICOS COM CARGA ELETROSTÁTICA USADOS EM RESPIRADORES EM AMBIENTE DE MINERAÇÃO 
OSWALDO DE ALMEIDA PASTORE

\section{A INFLUÊNCIA DA TEMPERATURA NA EFICIÊNCIA DE FILTROS MECÂNICOS COM CARGA ELETROSTÁTICA USADOS EM RESPIRADORES EM AMBIENTE DE MINERAÇÃO}

Dissertação apresentada à Escola Politécnica da Universidade de São Paulo para o título de Mestre em Engenharia 
OSWALDO DE ALMEIDA PASTORE

A INFLUÊNCIA DA TEMPERATURA NA EFICIÊNCIA DE FILTROS PARA PARTICULADOS COM CARGA ELETROSTÁTICA USADOS EM RESPIRADORES EM AMBIENTE DE MINERAÇÃO

Dissertação apresentada à Escola Politécnica da Universidade de São Paulo para o título de Mestre em Engenharia

Área de concentração:

Engenharia de Minas e Petróleo

Orientador: Prof. Doutor

Wilson Siguemasa Iramina

São Paulo 
Este exemplar foi revisado e alterado em relação à versão original, sob responsabilidade única do autor e com a anuência de seu orientador.

São Paulo, de novembro de 2008.

Assinatura do autor

Assinatura do orientador

FICHA CATALOGRÁFICA

Pastore, Oswaldo de Almeida

A influência da temperatura na eficiência de filtros para particulados com carga eletrostática usados em respiradores em ambiente de mineração / O.A. Pastore. -- ed.rev. -- São Paulo, 2008.

$102 \mathrm{p}$.

Dissertação (Mestrado) - Escola Politécnica da Universidade de São Paulo. Departamento de Engenharia de Minas e de Petróleo.

1.Segurança em mineração 2.Prevenção de acidentes 3.Equipamento de proteção individual I.Universidade de São Paulo. Escola Politécnica. Departamento de Engenharia de Minas e de Petróleo II.t. 


\section{AGRADECIMENTOS}

A Deus, por ter me dado saúde, força e ricas oportunidades de crescimento nesta vida.

À minha esposa, pela ajuda prática e incentivo constante e incondicional.

Aos meus filhos, pela compreensão por minha ausência e apoio nas minhas longas horas de estudo.

Ao meu cunhado, Álvaro, pela sua incansável ajuda numa madrugada interminável. Ao meu orientador, Wilson Shiguemasa Iramina, pela paciência e praticidade de seus conselhos.

Aos professores Sérgio Médice de Eston e Ivo Torres de Almeida, pelos primeiros conselhos e apoio no início desta jornada.

À MSA do Brasil, por deixar à disposição seu laboratório, equipamentos e infraestrutura para a realização das diversas análises contidas neste estudo.

À colega Lucila Marcomini, da MSA, pela ajuda com os testes dos filtros.

À colega Sueli Garcia Perez Alvarenga, da MSA, que com seu perfeccionismo colaborou na revisão do texto e formatação.

Ao colega Antonio Wladimir Vieira, da Fundacentro, pelo incentivo no início do Mestrado e pelas constantes e valiosas trocas de informações técnicas.

A Maria Cristina Martinez Bonesio, da biblioteca da Engenharia de Minas pela revisão da formatação da bibliografia.

A Maria Estela, pelo excelente atendimento e palavras de ânimo.

Ao amigo e pai da proteção respiratória no Brasil, Mauricio Torloni, que esteve sempre disposto a ajudar e a dividir seu enorme conhecimento. 
Dedico este trabalho à minha querida e amada esposa Mara, por seu apoio incansável, paciência e amor que dedica a mim e nossos queridos filhos, sem a qual não teria conseguido superar este e outros desafios desta vida. 


\section{RESUMO}

O uso de filtros contra particulados é extremamente comum em ambiente de mineração. As normas nacionais e internacionais, utilizadas para a aprovação destes filtros, definem critérios de testes e aprovação que visam garantir que os filtros continuem eficientes ao longo do tempo. Os fatores como: tipo, tamanho, velocidade, carga da partícula e temperatura, são considerados nos testes de aprovação. O objetivo desta dissertação é verificar o comportamento de filtros para particulados tipo eletreto usados em respiradores, expostos a condições térmicas semelhantes às encontradas em ambiente de mineração, simulando, em laboratório, a temperatura e tempo de exposição a que os mesmos podem estar sujeitos, medindo e comparando os resultados obtidos no sentido de atenderem as recomendações normativas, tanto nacionais como internacionais. Filtros e peças faciais de diferentes fabricantes foram expostos a diferentes temperaturas, sendo mantidos nestas temperaturas por no mínimo 24 horas. Testes de penetração utilizando partículas de $\mathrm{NaCl}$ com ajuste da vazão em $85 \mathrm{l} / \mathrm{min}$ foram realizados antes e depois de cada período de exposição. O equipamento utilizado foi um gerador de partículas tipo impactador, que gera partículas da ordem de 0,3 a 0,6 considerados os Tamanhos Mais Penetrantes de Partículas (MPPS). Como esperado, ocorreu um aumento da penetração de partículas de $\mathrm{NaCl}$ à medida que o tempo de permanência na temperatura e/ou a própria temperatura aumentaram. $O$ fator temperatura foi predominante, em relação ao tempo de exposição, no decaimento da performance dos filtros. Este efeito variou de fabricante para fabricante, sendo, em alguns casos, inexpressivos. A variação encontrada nos testes de penetração após acondicionamento térmico foi entre $2,53 \%$ e $18 \%$. Não se observou um aumento ou diminuição significativa da resistência ao fluxo de ar. Testes repetitivos em amostras sem acondicionamento térmico demonstraram uma diminuição da penetração do aerossol e um aumento da resistência ao fluxo de ar. Acredita-se que o aumento da resistência ao fluxo ocorra devido ao efeito de entupimento por deposição das partículas de $\mathrm{NaCl}$ ao longo do tempo em função da repetição dos testes no mesmo filtro.

Palavras chave: Segurança em mineração, prevenção de acidentes, equipamento de proteção individual. 


\section{ABSTRACT}

The use of particle filters is extremely usual in mining environment. The national and international standards used for the approval of these filters define tests and approval criteria which look forward guaranteeing the efficiency of the filters along the time. Facts such as: type, size, speed, particle charge and temperature are considered on approval tests. The objective of this dissertation is to check the behavior of the eletrect filters for particulated used in respirators, when exposed to similar thermal conditions found in mining environment, by simulation, in lab, of the temperature and time of exposition beyond the respirators could be exposed, measuring and comparing the obtained results in order to attend the standards recommendations such National as International ones. Facial filters and pieces of different manufactures were exposed to different temperatures and maintained under these conditions for at least 24-hours. Penetration tests using $\mathrm{NaCl}$ particles and adjusted to a flow of $85 \mathrm{l} / \mathrm{min}$ were done before and after each period of exposition. The equipment used was a particle generator, impactor type which generates particles of the order of 0.3 to $0.6 \mu \mathrm{m}$, considered the Most Penetrant Particles Size (MPPS). As expected, an increase of $\mathrm{NaCl}$ particle penetration occurred as long as time and temperature increased too. The temperature factor was predominating in relation to time of exposition in the decrease of performance of the filters. This effect varied from one manufacture to another and in some cases it was expressionless. The variation found after conditioning at high temperature was from $2.53 \%$ to $18 \%$. It wasn't observed a significant increase or decrease in the air flow resistance. Repetitive tests in samples without thermal packing showed a decrease of aerosol penetration and an increase of air flow resistance. Apparently, the increase of flow resistance happens because of the glog for $\mathrm{NaCl}$ particles deposition throughout the time, due to the test repetition over the same filter.

Key-words: Safety in mining, accidents prevention, personal protection equipment. 


\section{LISTA DE ILUSTRAÇÕES}

Figura 1 - Classificação dos equipamentos de proteção respiratória .............. 21

Figura 2 - Peça um quarto facial..................................................... 25

Figura 3 - Peça semi-facial........................................................... 26

Figura 4 - Peça facial inteira......................................................... 26

Figura 5 - Peça facial filtrante...................................................... 27

Figura 6 - llustração da captura de partículas neutras e carregadas por uma fibra carregada.......................................................... 30

Figura 7 - Simulação de deposição de partículas sobre fibras sem carga elétrica. a) vista frontal e b) vista oposta.

Figura 8 - Simulação de deposição de partículas sobre fibras com carga elétrica. a) vista frontal e b) vista oposta.................................. 32

Figura 9 - Partícula interceptada no espaço entre fibras........................... 33

Figura 10 - Representação esquemática dos mecanismos de captura das partículas de um filtro....................................................... 36

Figura 11 - Mecanismos de captura versus tamanho da partícula................. 37

Figura 12 - Ilustração esquemática do arranjo das fibras em um tecido e um TNT, respectivamente.

Figura 13 - Ilustração esquemática do arranjo das fibras em um tecido e um TNT, respectivamente.................................................. 38

Figura 14 - Ilustração da quantidade de fibras por metro quadrado.................. 40

Figura 15 - Comparação entre o cabelo humano e uma trama de nanofibras... 41

Figura 16 - Esporo de pólen capturado em uma trama de nanofibras.............. 41

Figura 17 - Imagens de fibras produzidas pelos processos: a) Meltblown, b) Spunbonded e c) ElectroSpin........................................ 42

Figura 18 - Corte transversal de um filtro........................................... 43

Figura 19 - Vista superior de um filtro................................................ 44

Figura 20 - Filtro para particulado P3 e vista interna em corte....................... 44

Figura 21 - Filtros e respiradores para particulados de diversas formas e tamanhos.......................................................................... 45

Figura 22 - Superfície de um filtro tipo P1 ampliado 250x......................... 46 
Figura 23 - Secção transversal de um filtro eletreto, classificação P1, ampliação 650x

Figura 24 - llustração esquemática da configuração da carga eletrostática de materiais filtrantes: (A) fibra unitária de lã resinada. (B) mistura de fibras (vários materiais). (C) fibra separada de material eletreto.

(D) feltro eletreto carregado.................................................. 50

Figura 25 - Fibra eletreto...................................................................... 51

Figura 26 - Equipamento automático de teste de filtros - Modelo TDA 100...... 55

Figura 27 - Equipamento de teste de filtros Modelo 1150 Sodium Flame Photometer

Figura 28 - Equipamento automático de teste de filtros Modelo AFT 8130....... 56

Figura 29 - Esquema simplificado do equipamento de teste Modelo 8130....... 59

Figura 30 - Atomizador 8110............................................................... 60

Figura 31 - Vista frontal interna do equipamento TSI 8130............................ 62

Figura 32 - Placa de orifícios para calibração da vazão e perda de carga......... 63

Figura 33 - Identificação de filtros de fibra de vidro padrão............................ 65

Figura 34 - Filtros de fibra de vidro padrão................................................. 65

Figura 35 - Verificação do gerador de sal com uma folha (disco).................... 66

Figura 36 - Verificação do gerador de sal com duas folhas (disco)................ 66

Figura 37 - Verificação do gerador de sal com três folhas (disco).................... 67

Figura 38 - Verificação do gerador de sal com quatro folhas (disco)................ 67

Figura 39 - Verificação do gerador de sal com cinco folhas (disco)................ 68

Figura 40 - Penetração em um filtro versus tamanho da partícula................... 69

Figura 41 - Penetração em um filtro versus desvio geométrico padrão............. 70

Figura 42 - Estufa utilizada para condicionamento dos filtros........................... 71

Figura 43 - Posicionamento dos filtros no interior da estufa............................. 71

Figura 44 - Medição da temperatura em diferentes pontos no interior da estufa 


\section{LISTA DE GRÁFICOS}

Gráfico 1 - Variação da penetração e perda de carga em amostras de filtros classe $\mathrm{P} 1$ testadas 10 vezes consecutivas

Gráfico 2 - Variação da penetração e perda de carga em amostras de filtros classe P2 testadas 10 vezes consecutivas......

Gráfico 3 - Filtros de controle testados nos mesmos intervalos das primeiras 7 medições

Gráfico 4 - Amostras condicionadas a $75^{\circ} \mathrm{C}$ depois de mergulhadas em isopropanol.

Gráfico 5 - Variações da penetração nas 26 amostras selecionadas em função do tempo de exposição a $75^{\circ} \mathrm{C}$

Gráfico 6 - Médias das variações da penetração por fabricante em função do tempo de exposição e incremento da temperatura. Os resultados das amostras de controle também estão representados.

Gráfico 7 - Variações da penetração nas 26 amostras em função do tempo de exposição e incremento da temperatura.

Gráfico 8 - Variações da resistência à respiração medida nas 26 amostras em função do tempo de exposição e incremento da temperatura.

Gráfico 9 - Variações da penetração em cada uma das 26 amostras expostas condicionadas em temperatura de até $90^{\circ} \mathrm{C}$ 


\section{LISTA DE TABELAS}

Tabela 1 - Comparação simplificada entre os requisitos das normas EN e $\mathrm{NIOSH}$ com relação à penetração..

Tabela 2 - Área superficial da fibra por massa para diferentes tamanhos de fibras.

Tabela 3 - Comparação entre normas EN 143/149, 42 CFR 84 e NBR 13697/13698 e requisitos de pré-condicionamento com relação à temperatura e umidade relativa (UR).

Tabela 4 - Medição da penetração em função da temperatura tempo de exposição e umidade 77

Tabela 5 - Quantidades e tipos de filtros utilizados. 80 


\section{LISTA DE ABREVIATURAS E SIGLAS}

\begin{tabular}{|c|c|c|}
\hline ABNT & - & Associação Brasileira de Normas e Técnicas \\
\hline ATI & - & Air Techniques International \\
\hline BSI & - & British Standard Institute \\
\hline CFR & - & Code of Federal Regulation (Estados Unidos da América) \\
\hline DOP & - & Di-octil phthalate (Ftalato de 2-(dietil hexila)) \\
\hline EM & - & Européen Norm (Norma Européia) \\
\hline EPI & - & Equipamento de Proteção Individual \\
\hline EPR & - & Equipamento de Proteção Respiratória (respiradores) \\
\hline ES & - & Electrospining \\
\hline HEPA & - & High Efficiency Particulate Air \\
\hline IDHL & - & Immediately Dangerous to Health and Life \\
\hline INDA & - & Association of the Nonwoven Fabrics Industry \\
\hline IPVS & - & Imediatamente Perigosos à Vida e à Saúde \\
\hline MB & - & Melt Blown \\
\hline MMAD & - & Diâmetro Médio Mássico Aerodinâmico \\
\hline MPPS & - & Tamanho de Partículas mais Penetrantes \\
\hline $\mathrm{NIOSH}$ & - & The National Institute for Occupational Safety and Health \\
\hline NR9 & - & Norma Regulamentadora 9 \\
\hline PE & - & Polietileno \\
\hline PFF & - & Peça Facial Filtrante \\
\hline PP & - & Polipropileno \\
\hline PPR & - & Programa de Proteção Respiratória \\
\hline RBC & - & Rede Brasileira de Calibração \\
\hline SB & - & Spunbonds \\
\hline SFP & - & Sodium Flame Photometer \\
\hline TNT & - & Tecido Não Tecido \\
\hline WHO & - & World Health Organization \\
\hline
\end{tabular}




\section{LISTA DE SÍMBOLOS}

$\begin{array}{lll}\% & - & \text { porcentagem } \\ \mu \mathrm{g} / \mathrm{m}^{3} & - & \text { micrograma por metro cúbico } \\ \mu \mathrm{m} & - & \text { micrometro } \\ \mathrm{kPa} & - & \text { kilopascal } \\ \mathrm{l} / \mathrm{min} & - & \text { litro por minuto } \\ \mathrm{m}^{2} / \mathrm{g} & - & \text { metro quadrado por grama } \\ \mathrm{mbar} & - & \text { milibar } \\ \mathrm{mg} / \mathrm{m}^{3} & - & \text { miligrama por metro cúbico } \\ \mathrm{mmH}{ }^{2} \mathrm{O} & - & \text { milímetros de coluna d'água } \\ \mathrm{NaCl} & - & \text { cloreto de sódio } \\ \mathrm{nm} & - & \text { nanômetro } \\ { }^{\circ} \mathrm{C} & - & \text { temperatura Celsius } \\ \sigma \mathrm{\sigma g} & - & \text { distribuição geométrica padrão }\end{array}$




\section{SUMÁRIO}

1 INTRODUÇÃO ...................................................... 14

1.1 CONCEITUAÇÃO DO TEMA....................................................... 14

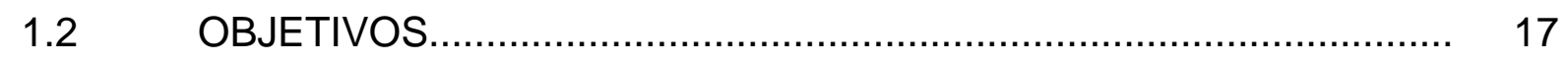

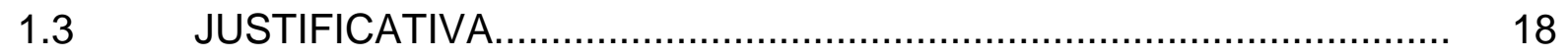

2 LEVANTAMENTO BIBLIOGRÁFICO .......................... 20

2.1 DOS EPR

2.2 DOS FILTROS MECÂNICOS PARA PARTÍCULAS............................ 22

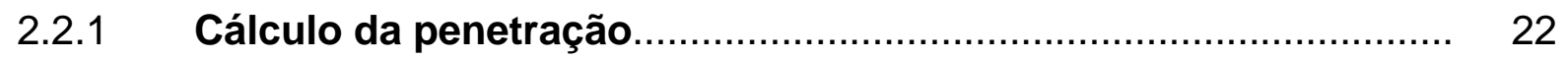

2.2.2 Termos e definições de filtros usados na proteção respiratória.... 23

2.3 RESPIRADORES PURIFICADORES DE AR PARA

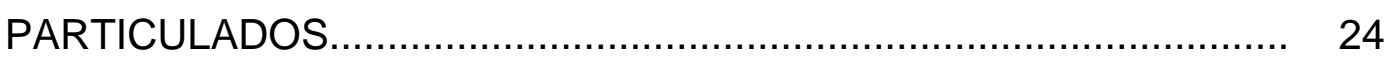

2.3.1 Respiradores purificadores de ar motorizados............................... 24

2.3.2 Respiradores purificadores de ar não motorizados........................ 25

2.3.3 Classificações normativas dos filtros e das PFF............................ 27

$2.4 \quad$ MECANISMOS DE CAPTURA DAS PARTÍCULAS.......................... 28

2.4.1 Captura por atração eletrostática .............................................. 29

2.4.2 Mecanismos de captura de partículas por ações mecânicas......... 32

2.4.2.1 Interceptação direta................................................................... 34

2.4.2.2 Impactação inercial.................................................................. 34

2.4.2.3 Deposição por difusão................................................................ 34

2.4.2.4 Deposição gravitacional.......................................................... 35

2.4.3 Mecanismos de captura versus tamanho das partículas............... 36

$2.5 \quad$ FABRICAÇÃO DOS FILTROS....................................................... 37

2.5.1 Materiais utilizados na fabricação de filtros mecânicos tipo

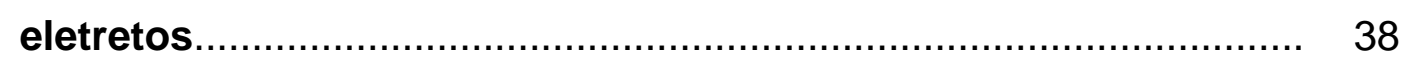

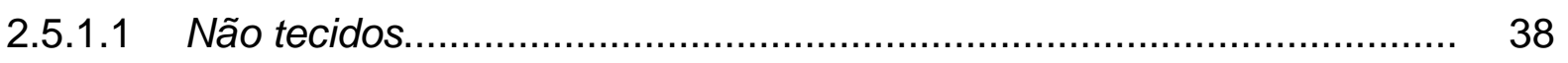

2.5.1.2 Processos de fabricação de não tecido............................................ 40

2.5.1.3 Estrutura do filtro para partículas usado em EPR ............................... 42

2.6 FILTROS COMERCIAIS PARA PARTICULADO................................ 44

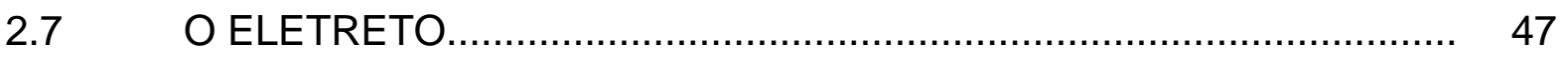


2.7.1 Origem do filtro eletreto e princípios de funcionamento.............. 49

2.7.2 Filtros eletretos ou eletrostáticos........................................... 50







3.2 INSTRUMENTOS DE MEDIDA UTILIZADOS ............................... 54

3.2.1 Características técnicas do equipamento CERTITEST® modelo

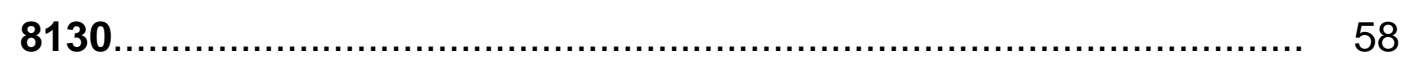

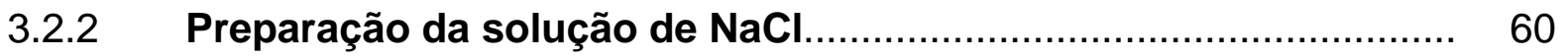

3.2.3 Calibração dos equipamentos............................................... 61

3.2.4 Calibração do CERTITEST ${ }^{\circledR}$ modelo 8130................................. 61

3.2.5 Procedimento de calibração do equipamento de teste.................. 62

3.2.6 Verificação da vazão e perda de carga...................................... 63

3.2.7 Verificação da penetração................................................... 64

3.2.7.1 Parâmetros de maior influência na repetibilidade na medição da penetração...................................................................... 68

3.2.8 Estufa usada para condicionamento térmico............................ 70

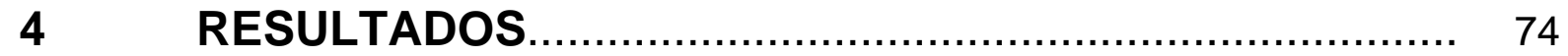

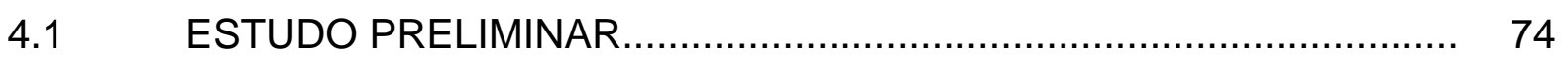

4.2 DEFINIÇÃO DE PARÂMETROS PARA NOVOS TESTES................. 77

4.3 DESCRIÇÕES DAS AMOSTRAS USADAS NOS TESTES FINAIS..... 79

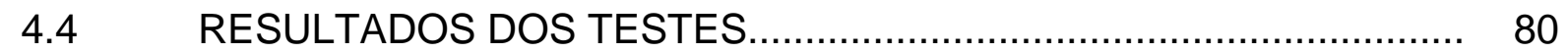

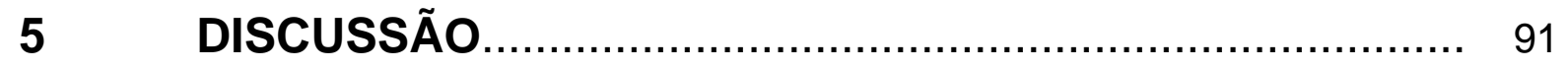

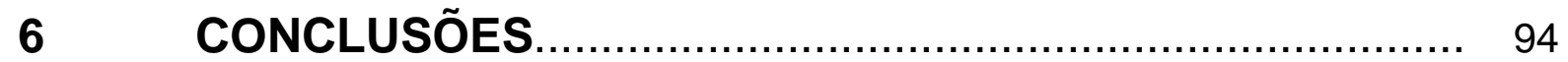

6.1 DIFICULDADES ENCONTRADAS NA REALIZAÇÃO DA PESQUISA. 95

6.2 PROPOSTAS PARA FUTUROS TRABALHOS .............................. 96






\section{INTRODUÇÃO}

\subsection{CONCEITUAÇÃO DO TEMA}

Os ambientes de trabalho, em particular o da mineração, podem, por vezes, serem extremamente inadequados à presença do homem. A própria natureza do trabalho, seja por processamento, armazenamento ou transformação, pode gerar contaminantes nocivos que afetam a saúde do trabalhador.

Para que o trabalhador adentre ou permaneça em ambientes contaminados são utilizadas técnicas ou equipamentos que proporcionam uma proteção adequada à saúde do mesmo. Entre os profissionais de saúde e segurança ocupacional, sabe-se bem que a primeira medida a ser tomada para dar condições de trabalho a alguém é minimizar a contaminação do local de trabalho. Isso pode ser feito por meio das medidas de controle de engenharia, como por exemplo: ventilação, enclausuramento, substituição de substâncias por outras com menor toxidez e outras mais (TORLONI, 2002). Estas medidas de controle também são uma regulamentação para o Brasil, conforme a Norma Regulamentadora NR9 (Brasil, 1994).

Os Equipamentos de Proteção Individual (EPI) somente devem ser utilizados quando não for viável a aplicação das medidas de controle de engenharia ou enquanto a avaliação e implementação das mesmas estiverem em curso, situações de emergência, para fuga ou em operações não rotineiras como a de manutenção. Concluindo, os EPI devem somente ser utilizados em última circunstância.

Apesar da recomendação da aplicação das medidas de controle de engenharia como primeiro recurso, o uso dos EPI para proteção respiratória é largamente utilizado e acaba sendo, em muitos casos, o único e principal recurso para proteger a saúde do trabalhador. 
Obs.: o termo proteger a vida não está sendo usado pelo fato dos EPR não serem recomendados para o uso em ambientes considerados Imediatamente Perigosos à Vida e à Saúde (IPVS).

No caso desta pesquisa, os EPI estudados são específicos para a proteção respiratória e particularmente utilizados na proteção contra particulados em suspensão. Estes tipos de EPI são comumente chamados de máscaras, sendo tecnicamente e genericamente definidos como Equipamentos de Proteção Respiratória (EPR) ou, simplesmente, respiradores.

Garantir que os EPR atendam aos objetivos pretendidos é de suma importância para se preservar a saúde do trabalhador. As especificações técnicas para a aprovação dos EPR estão definidas em normas técnicas nacionais e internacionais específicas para cada tipo de respirador. Estas normas, no caso de filtros contra partículas, definem basicamente o tipo de partícula ou névoa a ser utilizado, o tamanho, velocidade, pré-acondicionamento, limites de resistência à inalação e penetração/eficiência do filtro.

Além das especificações técnicas, o EPR deve ser usado corretamente e ter o tamanho e formato que melhor se ajustem ao rosto do usuário, permitindo a melhor selagem possível; isto é feito obedecendo ao Programa de Proteção Respiratória (PPR), obrigatório desde 1994 (BRASIL, 1994).

A penetração ou a eficiência é medida pela capacidade do filtro em reter uma dada porcentagem da quantidade de partícula a qual o filtro foi exposto.

A penetração e a eficiência são parâmetros por meio dos quais se define o desempenho de um filtro na captura de partículas suspensas no ar. A penetração é a relação entre a porcentagem da concentração do aerossol de ensaio, medida a jusante e a montante de um filtro para particulados e a eficiência é a redução porcentual da concentração do aerossol medida a montante em relação a jusante (TORLONI e VIEIRA 2003). 
São por meio destes dois parâmetros, aliados as outras especificações contidas no PPR, que se pode determinar se um filtro irá ou não oferecer a proteção adequada ao trabalhador. Na prática, o usuário do filtro terá somente dois parâmetros para saber se o seu filtro está realmente filtrando os contaminantes: o aumento da resistência à respiração e/ou o odor. No caso dos particulados em específico, a questão do odor é raramente percebida. Deste modo, o trabalhador pode desapercebidamente estar utilizando um filtro que não irá ajudar a proteger a sua saúde. Daí a importância das empresas terem um programa adequado de substituição programada dos filtros, sempre zelando pela qualidade dos produtos utilizados, sem falar nas questões de ajuste à face e uso adequado do equipamento.

No caso de filtros contra particulados, diferentes materiais podem ser empregados na fabricação dos mesmos, como lã de carneiro, poliéster, poliuretano, polipropileno, entre outros. Estas fibras, quando entrelaçadas ou depositadas aleatoriamente umas sobre as outras, formam uma manta que pode ser utilizada como filtro. Estas mesmas fibras, quando carregadas eletrostaticamente, aumentam significativamente a eficiência da filtração. Os filtros carregados eletrostaticamente são chamados de filtros eletretos ou elétricos. Nos casos em que a carga eletrostática exerce um papel preponderante nos mecanismos de captura das partículas, a perda ou diminuição desta, pode levar um filtro, outrora eficiente, à uma condição de inapropriado para a proteção do trabalhador.

Diversos autores como Moyer e Bergman (2000), Motyl e Lowkis (2006), Fjeld (1988) e Brown (2001) descreveram que o decaimento da carga eletrostática pode ocorrer por motivos como, por exemplo, exposição à alta umidade, radiação ionizante, aerossóis carregados eletricamente, partículas oleosas, alta temperatura, exposições intermitentes com cloreto de sódio ( $\mathrm{NaCl}$ ) e em função do tempo de exposição à uma destas condições.

Considerando que o gradiente geotérmico ocasiona um acréscimo de 2 a $3^{\circ} \mathrm{C}$ a cada 100 metros de profundidade, minas subterrâneas com profundidades entre 1000 a 3000 metros podem apresentar temperaturas da ordem de $60^{\circ}$ a $110^{\circ} \mathrm{C}$ (notas de 
aula $)^{1}$, aliadas à presença de um alto grau de umidade e com isto gerar condições de degradação do filtro.

Na mineração a céu aberto existe ainda a condição onde veículos de transporte são constantemente expostos de às radiações solares, podendo elevar a temperatura interna da cabine destes veículos em até aproximadamente $95^{\circ} \mathrm{C}$ (informação de anotações pessoais) ${ }^{2}$. Apesar de estas condições extremas serem contornadas com um projeto adequado de ventilação de mina e ar condicionado, não se pode descartar a possibilidade de ter os equipamentos de proteção respiratória expostos a estas condições na mineração.

Sabendo-se, então, que os fatores temperatura elevada e umidade são comuns em ambientes de mineração, fica a preocupação do quanto estas condições poderão afetar a eficiência dos filtros para particulados tipos eletreto quando utilizados em ambientes de mineração com alta temperatura.

\subsection{OBJETIVOS}

O objetivo deste trabalho é verificar, por meio de testes em laboratório, o comportamento dos filtros tipo eletretos, quanto à penetração de $\mathrm{NaCl}$, mediante permanência em estufa com temperaturas similares às encontradas em ambiente de mineração e variando o tempo de exposição.

Também será avaliado se os resultados de penetração obtidos com o aumento da temperatura ainda satisfazem as exigências normativas brasileiras e estrangeiras, fazendo ainda, uma comparação dos resultados obtidos entre diferentes fabricantes e classes de filtros.

\footnotetext{
1 Disciplina Higiene Industrial na Mineração, USP 2005.

2 Palestra de Degradação de Polímeros por Intemperismo, CIBA 2008.
} 


\subsection{JUSTIFICATIVA}

A utilização de filtros contra particulados fabricados com fibras poliméricas carregadas eletrostaticamente que possuem alta eficiência, baixa resistência à respiração, baixo custo e maior conforto, é cada vez mais freqüente e popular. Conseqüentemente, seu mercado está em expansão.

Normas nacionais e internacionais indicam as condições de pré-condicionamento dos filtros antes de os aprovarem para uso comercial, visando assim, verificar a degradação dos mesmos. Entretanto, essa medida por si só não previne ou alerta sobre qualquer problema de degradação das características de filtração que se pode ter no futuro.

Muitas vezes, o único meio de proteção do trabalhador é o uso do respirador, portanto, se o filtro, por uma razão ou outra, deixar de proporcionar a proteção adequada, o trabalhador terá uma falsa impressão de segurança e, conseqüentemente, isso poderá resultar em sérios danos à sua saúde.

Vale lembrar que os meios que o usuário tem para avaliar a eficiência do seu respirador são por meio do aumento da resistência à respiração e/ou odor percebidos pelo próprio usuário.

Apesar de pouco provável que as condições desfavoráveis (alta temperatura, umidade e tempo de exposição) para a perda da eficiência de filtração ocorram simultaneamente e sistematicamente em um ambiente de mineração. Não se pode descartar a possibilidade de que, em momentos onde o sistema de ventilação e/ou ar condicionado sejam desligados por questões de manutenção ou entre intervalos de turnos, os filtros que permanecerem dentro da mina, seja na sua embalagem original ou após o uso diário, fiquem expostos às elevadas temperaturas.

Não existem recomendações, tanto por exigência de norma ou mesmo por iniciativa dos próprios fabricantes, quanto aos cuidados que se deve ter com o 
armazenamento e exposição dos EPR à temperatura elevada, nem quanto aos seus efeitos potenciais em filtros tipo eletretos.

Finalmente, considerando que a degradação da carga eletrostática afeta diretamente a eficiência do filtro e, conseqüentemente, pode acarretar em dano à saúde do trabalhador, o estudo proposto pode ter um caráter relevante para futuras revisões de normas e orientações para os EPR atuais e, também, em desenvolvimentos de novos materiais filtrantes. 


\section{LEVANTAMENTO BIBLIOGRÁFICO}

Apesar da grande quantidade de literatura disponível que tratam dos aspectos da degradação da carga eletrostática de fibras carregadas e filtros tipo eletreto, pouquíssimos estudos relatam com mais profundidade a influência da temperatura no referido processo de perda das propriedades de filtração.

Baseando-se, então, nas inúmeras pesquisas e seus resultados, foi feito um levantamento bibliográfico que serviu como o importante recurso e ferramenta na elaboração desta pesquisa.

Por falta de publicações no âmbito nacional, o levantamento bibliográfico foi baseado na literatura internacional, tendo como fonte de pesquisa "sites" dos organismos internacionais como o National Institute for Occupational Safety and Helth (NIOSH), World Health Oraganizaion (WHO), "sites" de fabricantes e associações especializadas, a biblioteca do Departamento de Engenharia de Minas e Petróleo da Escola Politécnica (EP) da Universidade de São Paulo (USP), a biblioteca do grupamento da química da USP, Biblioteca da Engenharia Química da EP - USP, aquisição de livros e artigos internacionais, Rede de Serviços do SIBI/USP, acessando principalmente as seguintes bases de dados: SCOPUS, Science Direct, PubMed, Compendex e publicações eletrônicas atuais e disponíveis por meio da rede de computadores da USP.

\section{$2.1 \quad$ DOS EPR}

Os EPR podem ser classificados segundo o seu modo de operação e modo de uso. A NBR 12543 ABNT (1999) divide os respiradores em dois grupos: os de adução de ar, que são independentes do ar ambiente e os purificadores de ar, que são dependentes do ar ambiente (figura 1). 
Em outras palavras, pode-se dizer que um respirador de adução de ar supre o usuário por uma fonte de ar respirável vindo de uma atmosfera independente do ar ambiente. Já nos respiradores purificadores de ar, o ar ambiente passa através de um elemento filtrante que remove os contaminantes, sejam eles aerossóis, gases vapores ou ambos simultaneamente.

Os respiradores purificadores de ar não devem ser utilizados em ambientes com insuficiência de oxigênio, ou seja, concentração abaixo de 18\%. Não devem também ser utilizados em ambientes cuja contaminante possua fracas propriedades de alerta e ou quando a concentração seja IPVS.

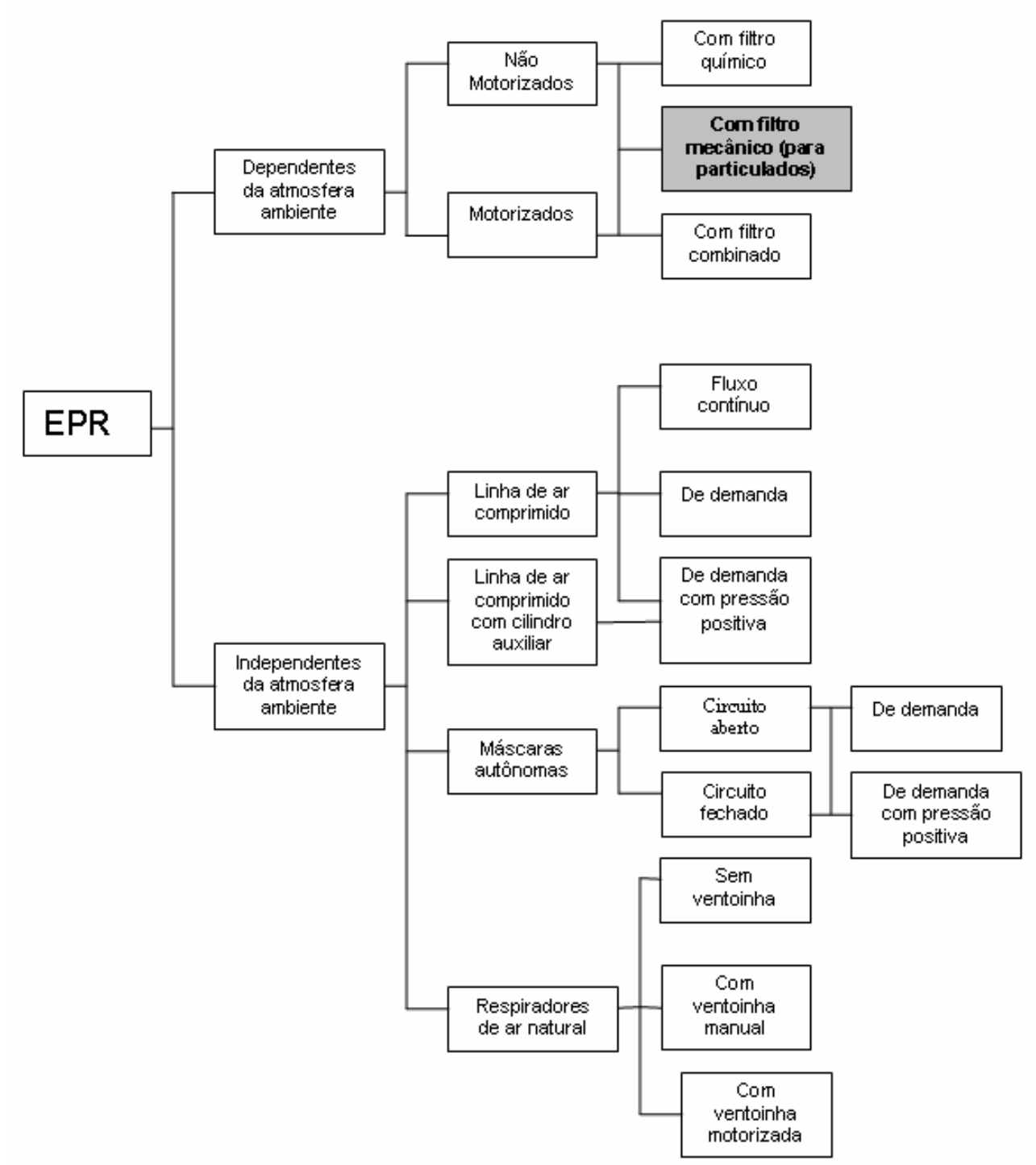

Figura 1 - Classificação dos equipamentos de proteção respiratória.

Fonte: (ABNT, 1999). 
Devido ao objetivo desta pesquisa, será dado um foco especial nos respiradores purificadores de ar com filtro para particulados.

\subsection{DOS FILTROS MECÂNICOS PARA PARTÍCULAS}

Os filtros para partículas, em geral, são classificados quanto à sua eficiência de filtração e tipo de particulado, sólido ou oleoso. Os níveis de penetração variam conforme a norma de aprovação, podendo ser 99,98\%, 95\%, 96\% ou $80 \%$.

Para objeto deste estudo foram utilizadas partículas sólidas de $\mathrm{NaCl}$ com diâmetro médio mássico aerodinâmico (MMAD) de 0,3 $\mu \mathrm{m}$, que é considerado como MPPS.

A norma 42 CFR 84 (ESTADOS UNIDOS, 1995) publicada pelo NIOSH classifica os filtros da seguinte forma: séries $N$, R e $P$, com três níveis de eficiência para cada classe: $95 \%$, 99\%, e 99.97\%, Todos testados com partículas consideradas tamanho de partículas mais penetrantes (MPPS), com o diâmetro de $0.3 \mu \mathrm{m}$, diâmetro médio mássico aerodinâmico (MMAD). As séries $\mathrm{N}$ são testadas contra leve degradação por $\mathrm{NaCl}$ e as séries $\mathrm{R}$ e $\mathrm{P}$ contra severa degradação de DOP.

\subsubsection{Cálculo da penetração}

O desempenho de um filtro para particulados é medido em função da sua capacidade de permitir que partículas sólidas ou oleosas, de tamanho e concentração conhecidos, passem por ele (penetração) ou que nele fiquem retidas (eficiência).

A medição da eficiência do filtro é expressa em termos porcentuais, e indica a quantidade da massa das partículas que este retém ou deixa passar. Portanto, é comum, além do termo penetração ( $\%$ que transpassou o filtro), usar o termo eficiência (\% que o filtro reteve). Sendo assim, se, por exemplo, for obtida a leitura 
no equipamento de teste de filtros, o valor de $20 \%$, pode-se dizer que o filtro teve uma penetração de $20 \%$, ou que sua eficiência é de $80 \%$. As normas brasileiras e da União Européia utilizam o termo penetração, enquanto as normas norte-americanas usam o termo eficiência.

Independente da nomenclatura utilizada, a penetração ou eficiência consiste na seguinte relação:

$$
P=(\mathrm{Cj} / \mathrm{Cm}) \times 100 \quad \text { ou } \quad E=\mathrm{Cm}-(\mathrm{Cj} / \mathrm{Cm}) \times 100 \quad \text { equação (1) }
$$

Onde:
$\mathrm{P} \quad=$ Penetração (\%)
$\mathrm{E}=$ Eficiência (\%)
$\mathrm{Cm}=$ Concentração a montante
Cj = Concentração a jusante

A relação entre a eficiência e penetração é a seguinte:

$E=100-P$

\subsubsection{Termos e definições de filtros usados na proteção respiratória}

As seguintes definições foram obtidas do Programa de Proteção Respiratória (TORLONI, 2002, p.53-58):

Aerossol: suspensão de partículas sólidas ou líquidas no ar. O mesmo que aerodispersóide.

Contaminante: agente químico ou biológico, em suas diversas formas (gases, vapores, aerodispersóides), presente em um determinado ambiente que tenha algum potencial de causar efeito adverso direto ou indireto a um sistema biológico, dependendo de sua concentração no ambiente.

Diâmetro aerodinâmico: diâmetro de uma partícula esférica com densidade unitária que possui a mesma velocidade terminal que a partícula considerada.

Diâmetro aerodinâmico médio mássico: ponto na distribuição de tamanho das partículas, na qual a metade da massa das partículas tem diâmetro menor que o diâmetro aerodinâmico médio mássico, e a outra metade tem diâmetro maior.

Filtro: parte do equipamento de proteção respiratória destinado a purificar o ar inalado.

Filtro Mecânico: filtro destinado a reter partículas em suspensão no ar. Pode ser classe P1, P2, ou P3, conforme a ABNT/NBR 13697/96. 
Fumos: aerodispersóides, gerados termicamente, constituídos por partículas sólidas formadas por condensação de vapores, em geral após volatilização de substância fundida (por exemplo, solda), freqüentemente acompanhada de reação química, tal como a oxidação.

IPVS (Imediatamente Perigoso à Vida ou à Saúde): condição considerada imediatamente perigosa à vida ou à saúde. Refere-se a exposição respiratória aguda, que supõe uma ameaça direta de morte ou conseqüências adversas irreversíveis à saúde, imediatas ou retardadas, ou exposição aguda aos olhos que impeça a fuga da atmosfera perigosa. Os valores de concentração IPVS são obtidos sob o título IDHL (Immediately Dangerous to Health and Life) apresentados pelo NIOSH na publicação Pocket Guide to Chemical Hazards.

Névoa: aerodispersóide, gerado mecanicamente, constituídos por partículas líquidas formadas pela ruptura mecânica de um líquido.

Peça facial: parte do equipamento de proteção respiratória que cobre as vias respiratórias, podendo, ou não, proteger os olhos.

Peça facial inteira: peça facial que cobre a boca e o nariz e os olhos.

Peça semifacial: peça facial que cobre a boca e o nariz, e se apóia sob o queixo.

Peça semifacial filtrante (PFF): peça facial constituída, parcial ou totalmente, de material filtrante. O mesmo que máscara descartável. Pode ser classe PFF1, PFF2 ou PFF3, conforme ABNT/NBR 13698/96.

Peça um quarto facial: peça facial que cobre a boca e o nariz, e se apóia sobre o queixo.

Poeira: aerodispersóide, gerado mecanicamente, constituído por partículas sólidas formadas por ruptura mecânica de um sólido.

Respirador: equipamento que visa a proteção do usuário contra a inalação de ar contaminado ou de ar com deficiência de oxigênio. O mesmo que máscara ou equipamento de proteção respiratória.

Respirador purificador de ar: respirador no qual o ar ambiente, antes de ser inalado, passa através do filtro para a remoção dos contaminantes.

Respirador de proteção negativa: respirador no qual a pressão, dentro da cobertura das vias respiratória, fica negativa, em relação ao ambiente externo, durante a inalação.

\subsection{RESPIRADORES PURIFICADORES DE AR PARA PARTICULADOS}

Os respiradores purificadores de ar podem ser do tipo:

- respiradores purificadores de ar motorizados.

- respiradores purificadores de ar não motorizados,

\subsubsection{Respiradores purificadores de ar motorizados}

Nos respiradores purificadores de ar motorizados, o ar é insuflado para dentro da cobertura das vias respiratórias por meio de uma ventoinha. Esta ventoinha força a passagem do ar por meio do elemento filtrante para que o ar seja purificado. 


\subsubsection{Respiradores purificadores de ar não motorizados}

Neste tipo de respirador, o ar contaminado é purificado quando é forçado a passar pelo elemento filtrante devido a pressão negativa que é gerada no interior do respirador. A pressão negativa é gerada pelo efeito da respiração do usuário.

Na maioria dos respiradores, válvulas de inalação e exalação são instaladas para facilitar o movimento do ar evitando que o ar exalado passe pelo elemento filtrante.

A seguir, são mostrados por meio de figuras os respiradores de ar com filtros para particulados mais comuns de serem usados em ambientes de mineração:

- peça um quarto facial (figura 2),

- semi-facial (figura 3),

- facial inteira (figura 4),

- peça facial filtrante (PFF) (figura 5).

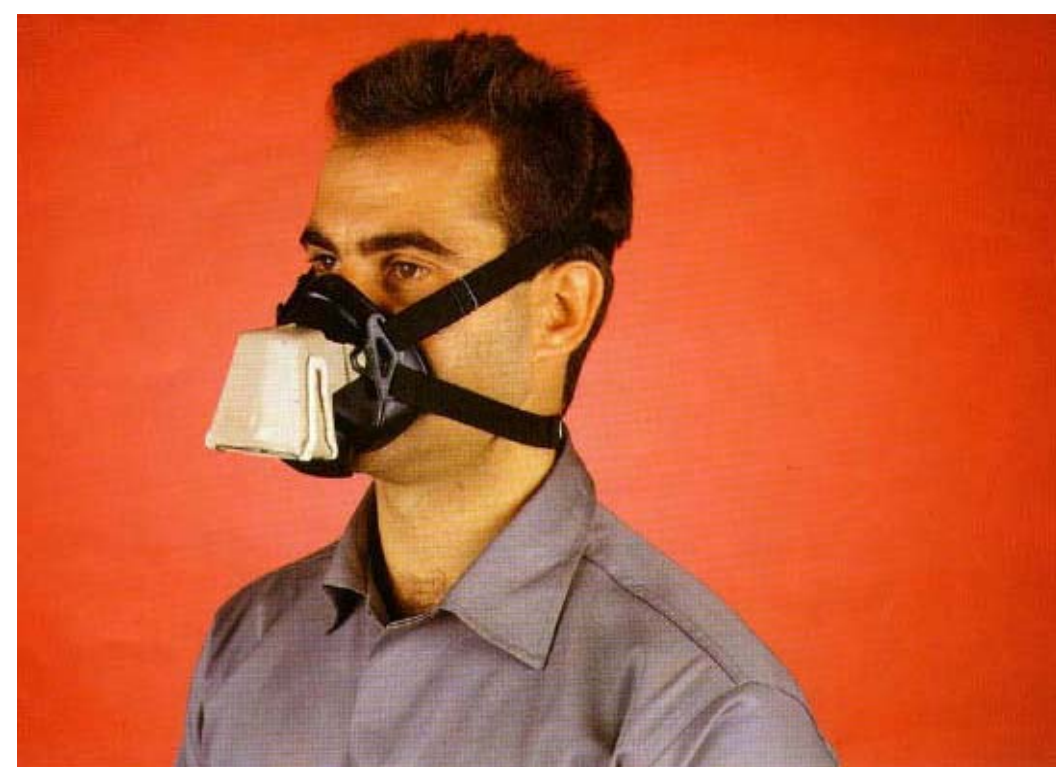

Figura 2 - Peça um quarto facial. Cortesia MSA. 


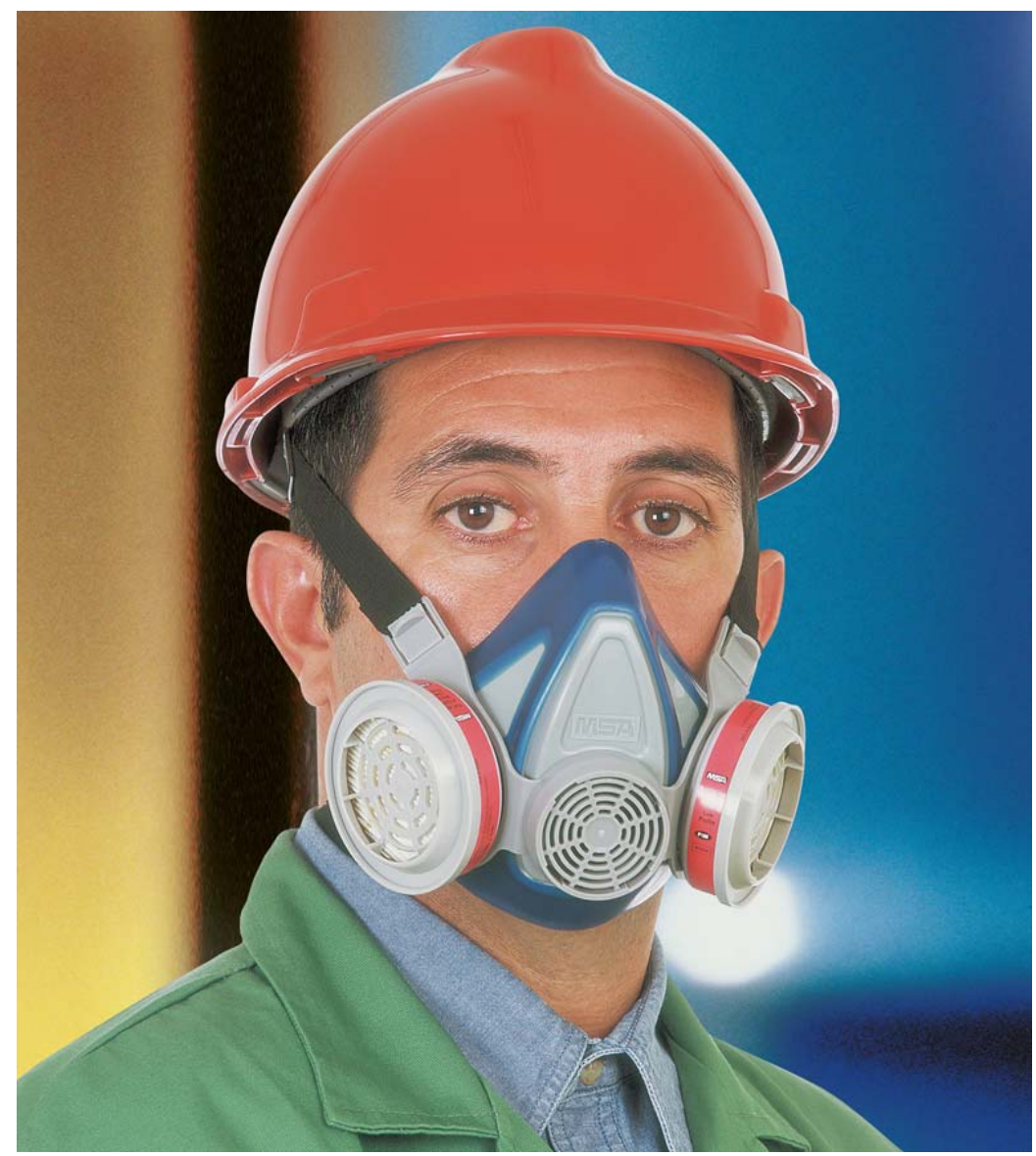

Figura 3 - Peça semi-facial. Cortesia MSA.

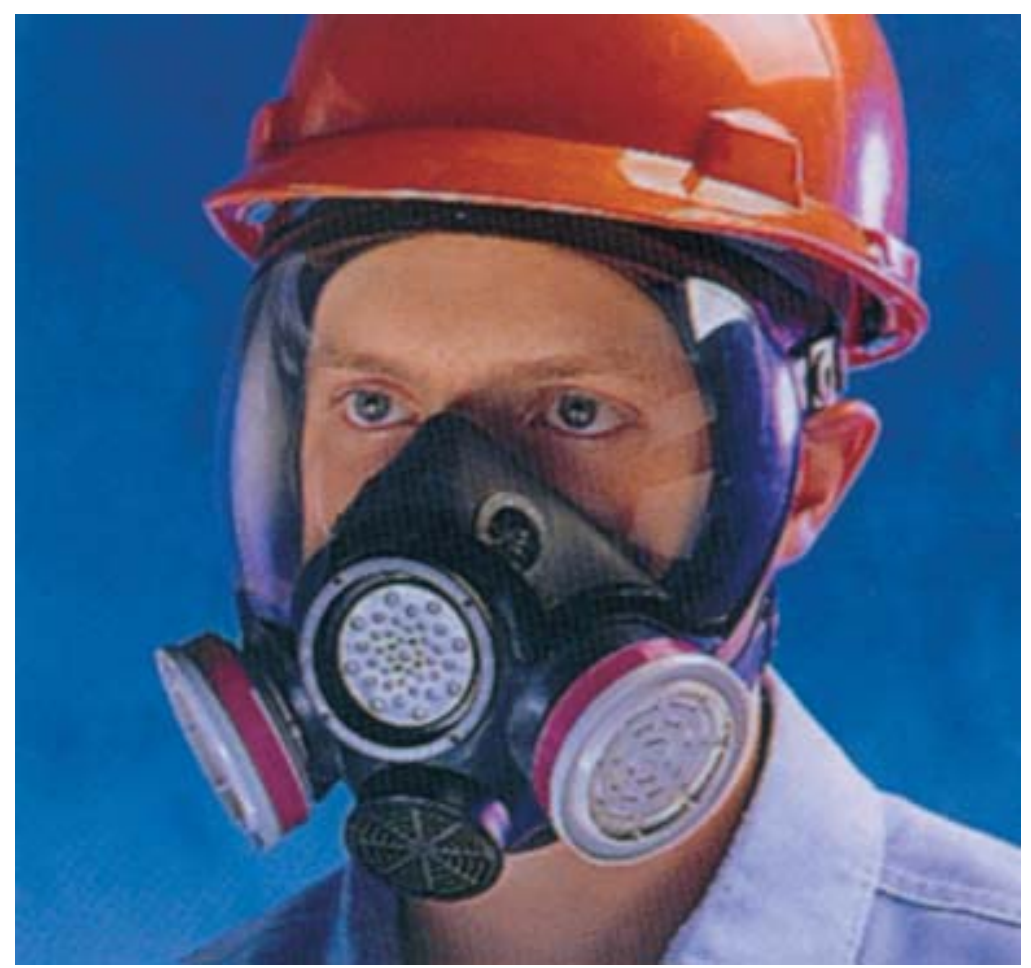

Figura 4 - Peça facial inteira. Cortesia MSA. 


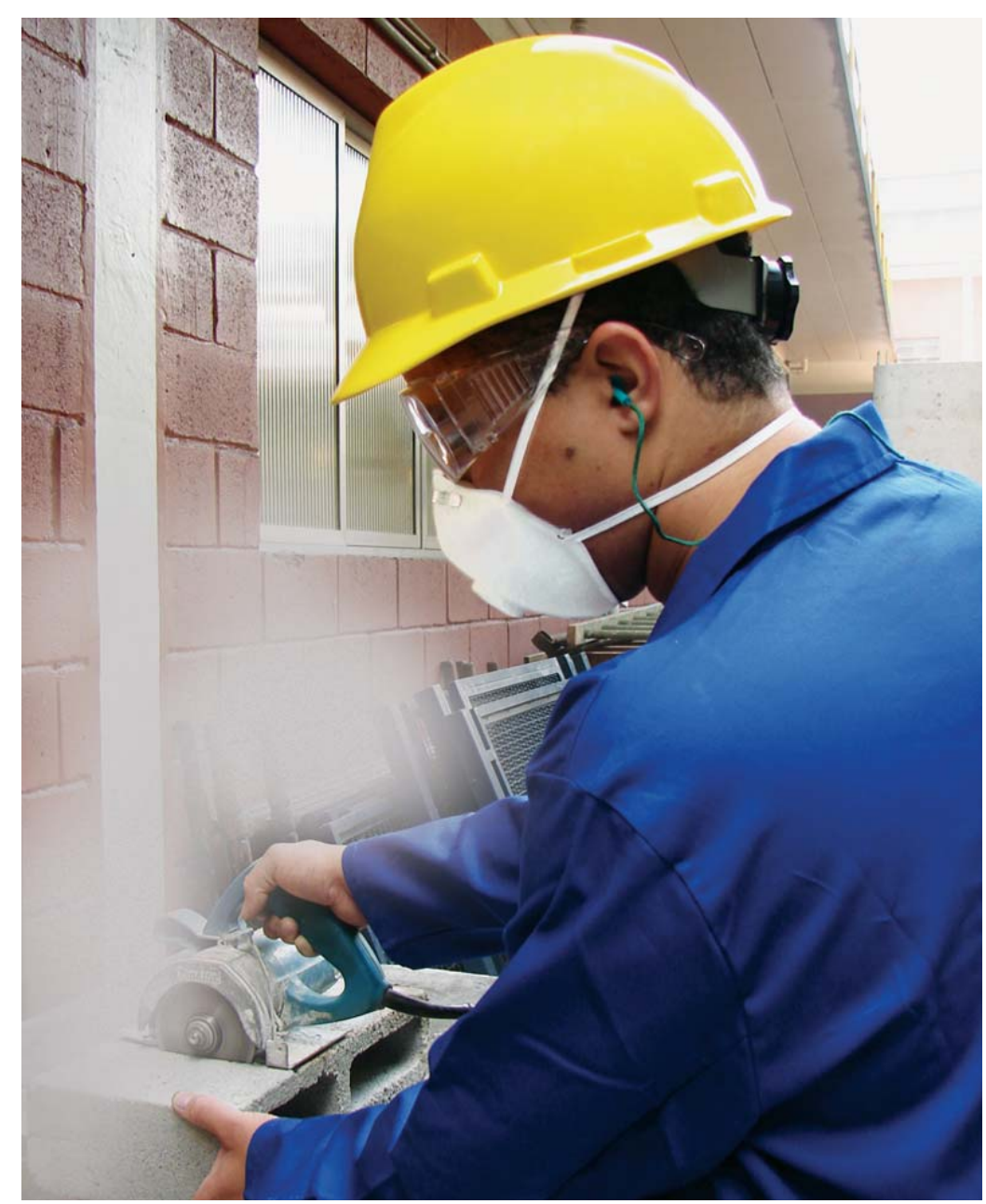

Figura 5 - Peça facial filtrante. Cortesia MSA.

\subsubsection{Classificações normativas dos filtros e das PFF}

Os filtros mecânicos, em geral, são classificados quanto à sua eficiência de filtração e tipo de particulado, sólido ou oleoso. Os níveis de penetração variam conforme a norma de aprovação, podendo ser $99,98 \%, 95 \%, 96 \%$ ou $80 \%$.

Para objeto deste estudo foram utilizadas partículas sólidas de $\mathrm{NaCl}$ com diâmetro

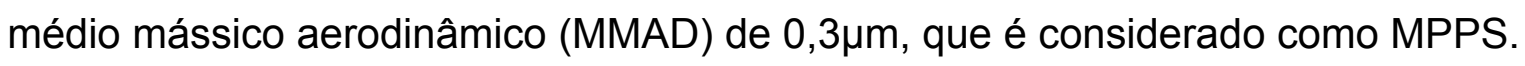

A norma 42 CFR 84 (ESTADOS UNIDOS, 1995) publicada pelo NIOSH classifica os filtros da seguinte forma: séries $N, R$ e $P$, com três níveis de eficiência para cada 
classe: 95\%, 99\%, e 99.97\%, Todos testados com partículas consideradas tamanho de partículas mais penetrantes (MPPS), com o diâmetro de $0.3 \mu \mathrm{m}$, diâmetro médio mássico aerodinâmico (MMAD). As séries $\mathrm{N}$ são testadas contra leve degradação por $\mathrm{NaCl}$ e as séries $\mathrm{R}$ e $\mathrm{P}$ contra severa degradação de DOP.

As normas nacionais e internacionais classificam os filtros ou PFF para partículas em função da sua capacidade de reter particulados de tamanho conhecido. A tabela 1 mostra uma comparação dos requisitos e classificação segundo as normas EN, praticamente idêntica às normas brasileiras (NBR) e norma 42 CFR 84 utilizada na América do Norte, pelo NIOSH.

Tabela 1 - Comparação simplificada entre os requisitos das normas EN e NIOSH com relação à penetração.

\begin{tabular}{|c|c|c|c|c|c|c|c|c|c|c|c|c|}
\hline \multirow{2}{*}{ 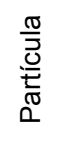 } & \multicolumn{3}{|c|}{ Penetração \% } & \multicolumn{3}{|c|}{$\begin{array}{c}\text { Diâmetro da. } \\
\text { Partícula** mícron }\end{array}$} & \multicolumn{3}{|c|}{$\begin{array}{l}\text { Vazão de teste } \\
(1 / \mathrm{min})^{*}\end{array}$} & \multicolumn{3}{|c|}{ Classificação } \\
\hline & EN & $\mathrm{NIOSH}$ & NBR & EN & $\mathrm{NIOSH}$ & NBR & EN & NIOSH & NBR & EN & $\mathrm{NIOSH}$ & NBR \\
\hline \multirow{3}{*}{$\begin{array}{l}\bar{W} \\
\bar{Z}\end{array}$} & 20 & & 20 & 0,6 & & 0,6 & 95 & & 95 & $\mathrm{P} 1$ & & $\mathrm{P} 1$ \\
\hline & 6 & 5 & 6 & 0,6 & 0,3 & 0,6 & 95 & 85 & 95 & $\mathrm{P} 2$ & N95 & $\mathrm{P} 2$ \\
\hline & 0,05 & 0,03 & 0,05 & 0,6 & 0,3 & 0,6 & 95 & 85 & 95 & P3 & P100 & P3 \\
\hline \multirow{2}{*}{ 웅 } & & 5 & & & 0,3 & & & 85 & & & P95 & \\
\hline & & 0,03 & & & 0,3 & & & 85 & & & P100 & \\
\hline \multirow{3}{*}{$\begin{array}{l}\overline{0} \\
z\end{array}$} & 20 & & 20 & 0,6 & & 0,6 & 95 & & 95 & PFF1 & & PFF1 \\
\hline & 6 & & 6 & 0,6 & & 0,6 & 95 & & 95 & PFF2 & & PFF2 \\
\hline & 1 & & 3 & 0,6 & & 0,6 & 95 & & 95 & PFF3 & & PFF3 \\
\hline \multirow{3}{*}{ 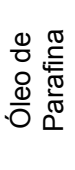 } & 20 & & & 0,6 & & 0,6 & 95 & & 95 & PFF1 & & PFF1 \\
\hline & 6 & & 2 & 0,6 & & 0,6 & 95 & & 95 & PFF2 & & PFF2 \\
\hline & 1 & & 1 & 0,6 & & 0,6 & 95 & & 95 & PFF3 & & PFF3 \\
\hline
\end{tabular}

* Quando o filtro for usado aos pares, a vazão deve ser dividida pela metade.

** Diâmetro médio mássico aerodinâmico.

\subsection{MECANISMOS DE CAPTURA DAS PARTÍCULAS}

Quando se fala em filtração é muito comum vir à mente algo semelhante a um peneiramento de partículas muito pequenas. Apesar de parte do processo de filtração ocorrer por um fenômeno muito semelhante, segundo Torloni e Vieira (2003), existe quase uma dezena de mecanismos que atuam simultaneamente na 
captura de partículas quando estas passam pelos vãos entre as fibras de uma camada do filtro.

Os filtros utilizados em proteção respiratória, quando em uso, obrigam por efeito da pressão negativa gerada pela respiração ou por ventilação forçada, que ocorra um arraste do ar contendo os contaminantes do ambiente, sendo este forçado a passar pelo filtro. As partículas se deslocam por uma trajetória extensa que é afetada pelo emaranhado das fibras. Neste longo trajeto, elas acabam se chocando com a parede das mesmas.

Após o choque, a retenção das partículas na superfície das fibras é provocada pelas forças de Van der Waals (TORLONI e VIEIRA, 2003).

\subsubsection{Captura por atração eletrostática}

A utilização de filtros carregados eletrostaticamente já vem de várias décadas. $\mathrm{Na}$ verdade, este tipo de material foi usado por muitos anos, antes mesmo que os mecanismos fossem entendidos.

Filtros com cargas eletrostáticas são bem conhecidos por serem muito eficientes na filtração de partículas muito finas e por, ainda, apresentarem uma perda de carga muito baixa. Característica paradoxal quando se trata de filtros mecânicos convencionais.

As fibras carregadas eletrostaticamente atraem tanto partículas carregadas quanto neutras. A captura das partículas com cargas negativas ocorre por meio da atração por forças Coulombianas. A captura de partículas neutras ocorre pela ação das forças de polarização. O campo elétrico das fibras induz um dipolo na partícula neutra, carregando-a e, então, atraindo-a. A força do dipolo induzido depende do volume da partícula e da constante dielétrica do material da partícula. As partículas mais próximas das fibras sofrem uma força de atração pouco maior que a força de repulsão, que age no sentido contrário. Este pequeno desequilíbrio faz com que a 
partícula seja atraída independentemente da carga da fibra ser positiva ou negativa (BROWN,1993).

Segundo Lowkis e Motyl (2001), as partículas carregadas têm a trajetória desviada quando passam pelo campo elétrico gerado pelas fibras também carregadas. Já as partículas neutras são polarizadas e se movem no sentido do campo elétrico e passam a ser atraídas pelas fibras. Ele acrescenta ainda que os filtros eletreto possuem uma vantagem em relação ao filtro mecânico, que é a captura de partículas submicrométricas sem causar entupimento ou aumento significativo da resistência à respiração; já no caso dos filtros puramente mecânicos, para filtrar partículas da mesma ordem de grandeza o mesmo teria que ser construído com malhas com aberturas micrométricas, configuração que facilitaria o entupimento por acúmulo de partículas, elevando rapidamente a resistência à respiração.

Na figura 6 é ilustrado o mecanismo de captura de partículas neutras e carregadas, por uma fibra carregada de um filtro.

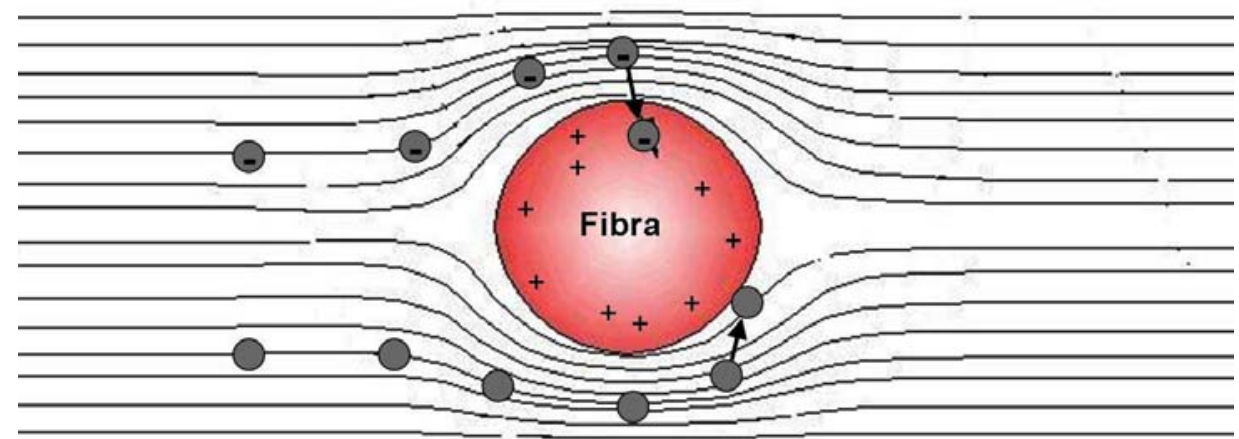

Figura 6 - llustração da captura de partículas neutras e carregadas por uma fibra carregada. Fonte: (adaptado de BROWN, 1993).

Em resumo, fatores como tamanho da partícula, constante dielétrica do material da partícula, velocidade da mesma e o quociente da variação da velocidade da partícula sob a influência da força elétrica, definirão a eficiência de filtração. Conseqüentemente, para que todos estes fenômenos possam ocorrer, quanto mais baixa for a velocidade de filtração, mais eficientes serão os filtros eletrostáticos. 
Para um melhor entendimento do porque os filtros com carga eletrostática proporcionam alta eficiência e baixa resistência à respiração, pode-se observar o comportamento da deposição das partículas sobre as fibras nas figuras 25 e 26, onde por simulação foram projetadas partículas em condições idênticas sobre os mesmos arranjos das fibras, diferenciando somente a condição das mesmas (sem cargas e carregadas). Na figura 7, a quantidade de partículas retidas é bem inferior e, na parte oposta do filtro quase não houve captura das mesmas. Já na figura 8 , a concentração de partículas é bem maior em ambos os lados, demonstrando uma capacidade muito maior de reter as partículas que passaram pelo filtro. Considerando o grande espaço existente entre as fibras nos dois casos, fato que possibilita a passagem do fluxo do ar com pouca restrição, o aumento da capacidade de reter as partículas, no segundo caso, transforma o filtro de baixa eficiência em um de alta eficiência.

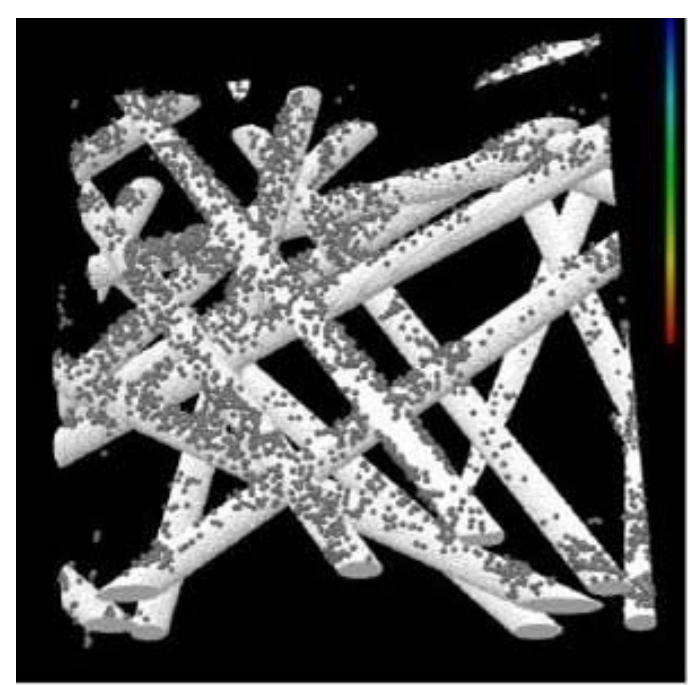

a)



b)

Figura 7 - Simulação de deposição de partículas sobre fibras sem carga elétrica. a) vista frontal e b) vista oposta. Fonte: (Rief, et al.). 


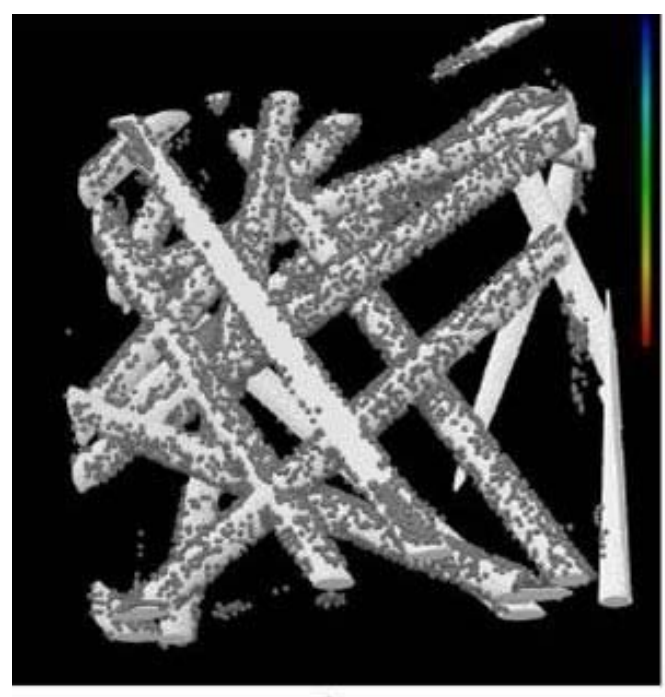

a)

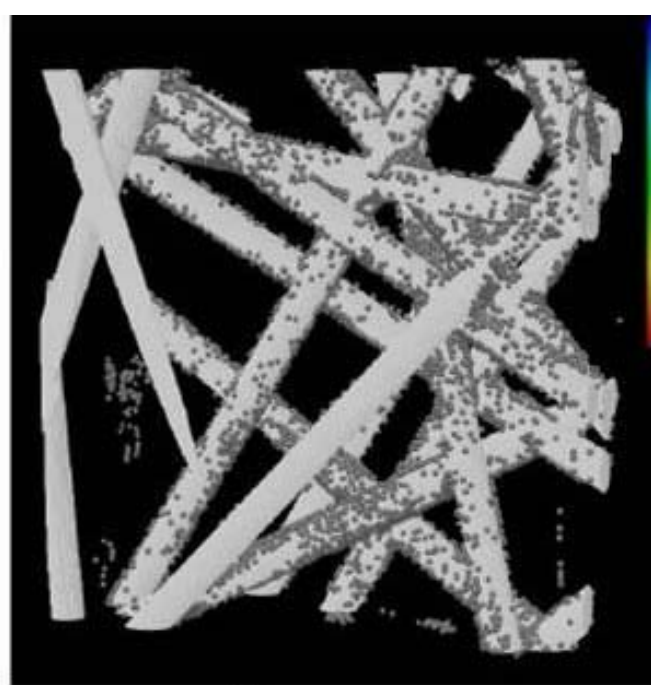

b)

Figura 8 - Simulação de deposição de partículas sobre fibras com carga elétrica. a) vista frotal e b) vista oposta. Fonte: (Rief, et al.).

\subsubsection{Mecanismos de captura de partículas por ações mecânicas}

Mecanismos de captura mecânica ocorrem independentemente da influência das forças de atração entre as partículas transportadas pelo ar e as fibras do filtro (BROWN, 1993).

Filtros mecânicos são menos efetivos quanto à filtração de partículas menores que $1 \mu \mathrm{m}$; isto porque as fibras, tanto naturais como sintéticas, possuem um diâmetro da ordem de 20 $\mu$ m (DROUIN, 2000). Ainda que o uso de micro fibras ou fibra de vidro venha a aumentar a eficiência da filtração mecânica, isto acarretará em um grande aumento na resistência ou perda de carga do filtro, apresentando, ainda, um risco muito grande de entupimento. Nestes casos, seria como se houvesse uma peneiração, onde as partículas com dimensões maiores que a trama do meio filtrante seriam retidas por não conseguirem passar pelos orifícios da malha (figura 9). 


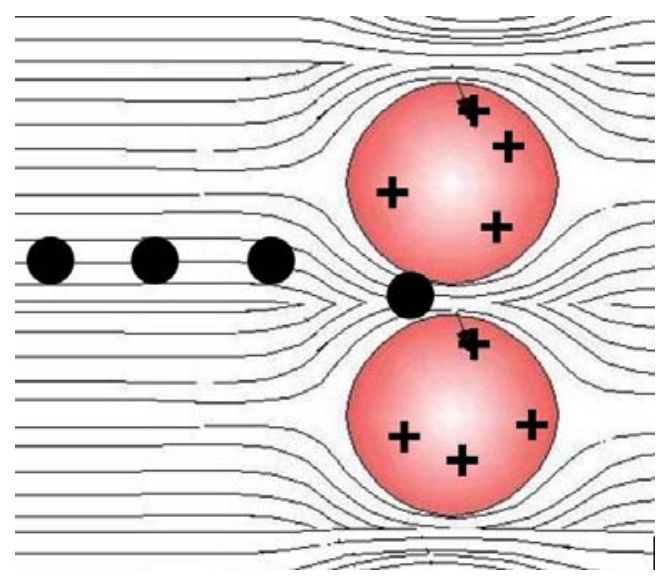

Figura 9 - Partícula interceptada no espaço entre fibras. Fonte: (adaptado de OBERTA, 2008).

O aumento muito rápido da perda de carga diminui a vida útil do filtro, seja ele usado para respiradores ou sistemas de ar condicionado. No caso específico de respiradores, com o aumento da dificuldade para respirar, o usuário tende a retirar o respirador do rosto, ficando exposto aos contaminantes do ambiente. Para respiradores motorizados, com o aumento da resistência ao fluxo de ar, o motor tem que trabalhar em um regime de carga mais elevado para poder compensar a vazão em razão do aumento da resistência. Conseqüentemente, o consumo da bateria aumenta, diminuindo o tempo de uso.

O termo perda de carga para o caso de respiradores é referido nas normas técnicas para aprovação como sendo resistência à respiração. Respiradores com uma baixa resistência à respiração tendem a ser mais confortáveis, aumentando o tempo de utilização do mesmo pelo trabalhador.

Os principais mecanismos de captura das partículas por meios mecânicos são:

- interceptação direta,

- impactação inercial,

- deposição por difusão,

- deposição gravitacional e

- peneiração. 
A teoria que recai sobre cada um destes mecanismos é bastante complexa, portanto faremos apenas um pequeno resumo das mesmas.

\subsubsection{Interceptação direta}

A partícula é capturada quando segue uma linha de fluxo de ar que a coloca em contato com a fibra, esse mecanismo inclui a peneiração (TORLONIN e VIEIRA, 2003). Brown (1993) explica que a Interceptação direta ocorre quando o comportamento da partícula transportada é totalmente passivo com relação ao fluxo do ar, ou seja, quando ela não está sujeita aos efeitos dos movimentos inercial e difusão, e também, não está agindo sob nenhuma força externa, incluindo a gravidade. Qualquer partícula transportada pelo ar nesta situação, deve seguir as linhas de fluxo do ar (figura 10).

\subsubsection{Impactação inercial}

A captura ocorre quando a partícula se desvia do fluxo de ar devido à sua própria inércia e colide com a parede da fibra. Qualquer convergência, divergência ou curvatura das linhas de fluxo envolve na aceleração do ar. Sob tais condições, a partícula poderá ser capaz de seguir as linhas do fluxo do ar (figura 10). O comportamento da partícula dependerá da sua inércia e massa. Partículas com inércia muito alta dificilmente mudarão a sua direção (BROWN, 1993).

\subsubsection{Deposição por difusão}

A ação combinada do fluxo de ar e movimentos Brownianos fazem com que a partícula entre em contato com a fibra. Os processos de captura indicados anteriormente são mais eficientes para partículas grandes. Um processo importante 
de captura das partículas pequenas ocorre por movimento difusor. A energia térmica de um gás em equilíbrio é distribuída entre suas moléculas, de modo que todo o grau de liberdade tenha associado a ele uma energia, que é igual à metade da constante de Boltzmann vezes a temperatura absoluta. As partículas suspensas no gás irão entrar rapidamente em equilíbrio térmico com o mesmo, de modo que elas também recebam a sua parte da energia térmica. A constante troca de energia entre as moléculas do gás e a partícula resulta no movimento microscópico bem conhecido como movimento Browniano (figura 10). Sendo que a equiparação de energia significa que a energia cinética média é uma constante, independentemente do seu tamanho, a média da velocidade das partículas pequenas, como resultado do seu movimento, será maior que a velocidade das partículas grandes.

\subsubsection{Deposição gravitacional}

As partículas do aerossol que ainda estiverem em suspensão no ar tendem a sedimentar-se devido à influência da gravidade. Este processo também irá ocorrer quando o ar que a sustenta passar através do filtro. Se, como resultado, a partícula entrar em contato com a fibra será capturada por deposição gravitacional (figura 10). O efeito da gravidade durante a filtração irá depender da direção do fluxo do ar, onde o resultado da sedimentação gravitacional pode tanto aumentar com diminuir o transporte da partícula em direção da fibra (BROWN, 1993). Vale lembrar que estes efeitos ocorrem simultaneamente. 


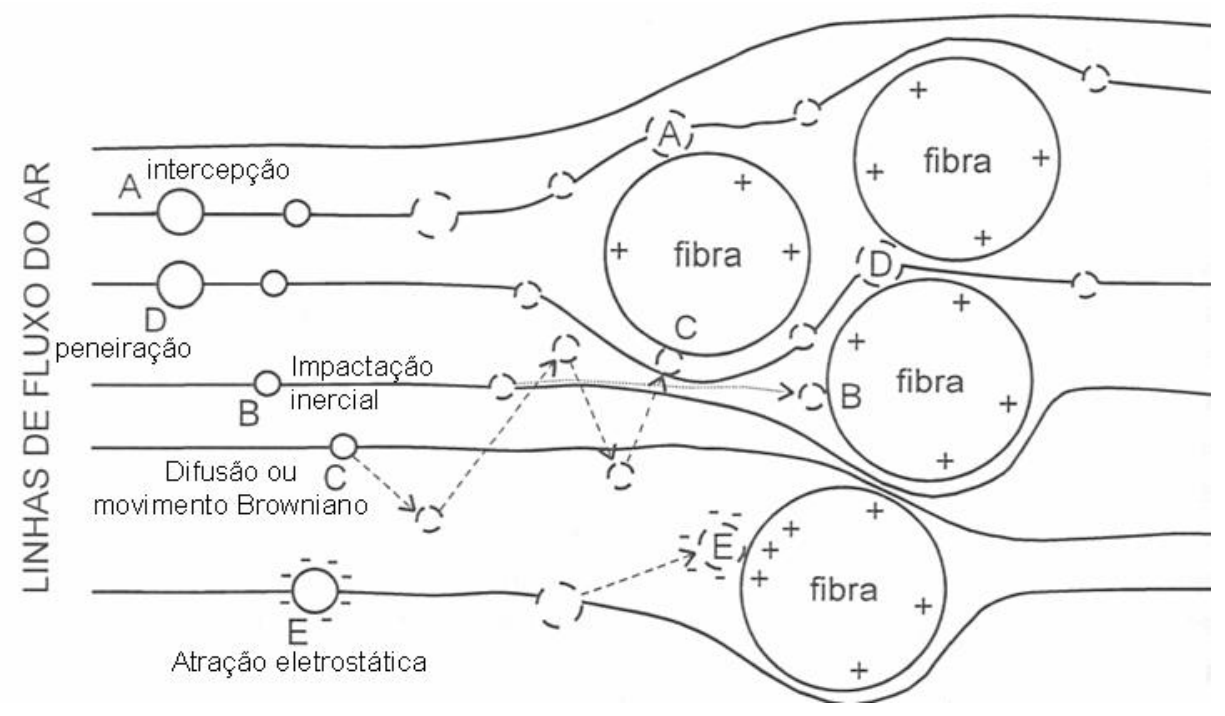

Figura 10 - Representação esquemática dos mecanismos de captura das partículas de um filtro. Fonte: (TORLONI e VIEIRA, 2003).

\subsubsection{Mecanismos de captura versus tamanho das partículas}

Os diversos meios atuam com intensidade diferente, dependendo da velocidade do ar, diâmetro da partícula, densidade do material, tamanho da fibra, presença ou não de carga elétrica.

Oberta (2008), por meio de equações, calculou para tamanhos de partículas de $0,01 \mu \mathrm{m}$ a $3 \mu \mathrm{m}$, qual seria a taxa que cada mecanismo teria na retenção destas partículas (figura 11). Nesta mesma figura pode se observar que a faixa de diâmetros de partículas mais penetrantes para os mecanismos de captura por interceptação, impactação e difusão variam entre de $0,3 \mu \mathrm{m}$ a $0,6 \mu \mathrm{m}$ sendo, portanto, os tamanhos de partícula médios mássicos utilizados nos equipamentos de teste de penetração em filtros. 


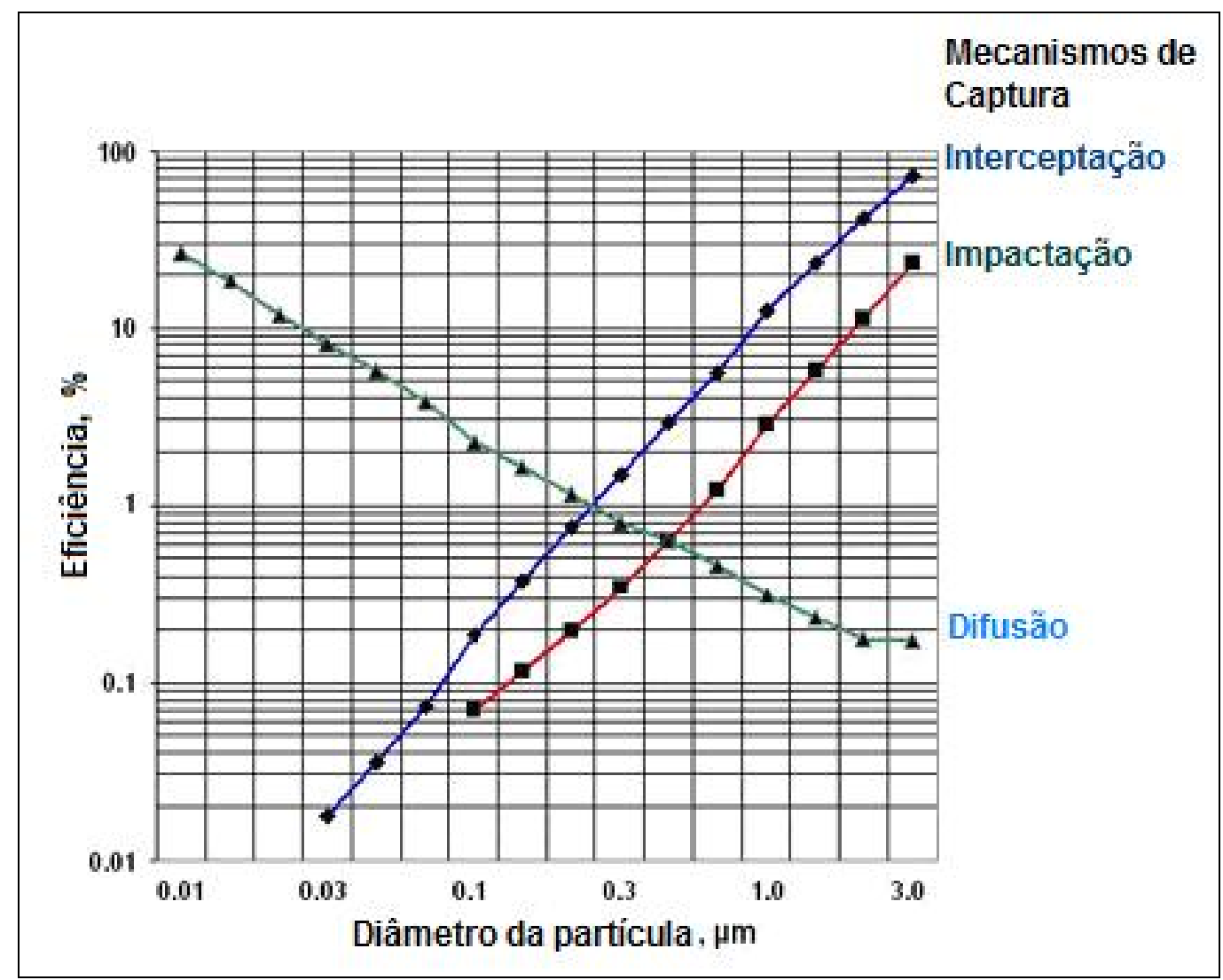

Figura 11 - Mecanismos de captura versus tamanho da partícula. Fonte: (Oberta, 2008).

\subsection{FABRICAÇÃO DOS FILTROS}

Materiais como o algodão e o feltro foram muito utilizados na fabricação de filtros, não mais de 10 anos atrás, era muito comum a utilização de mantas de lã (feltro) embebidas em resina, que após a calandragem passavam a apresentar características eletrostáticas.

A lã de carneiro foi drasticamente substituída por fibras sintéticas e, atualmente, não se tem notícia de que ainda sejam produzidos filtros com mantas de feltro, tanto no mercado nacional como no internacional. 


\subsubsection{Materiais utilizados na fabricação de filtros mecânicos tipo eletretos}

\subsubsection{Não tecidos}

Os não tecidos, conhecidos também como tecidos não tecidos (TNT), são formados com fibras sintéticas (figuras 12 e 13). O uso do TNT tem se popularizado e sua aplicação pode ser vista praticamente em todo o lugar, inclusive no uso de filtros e respiradores.

Tecido

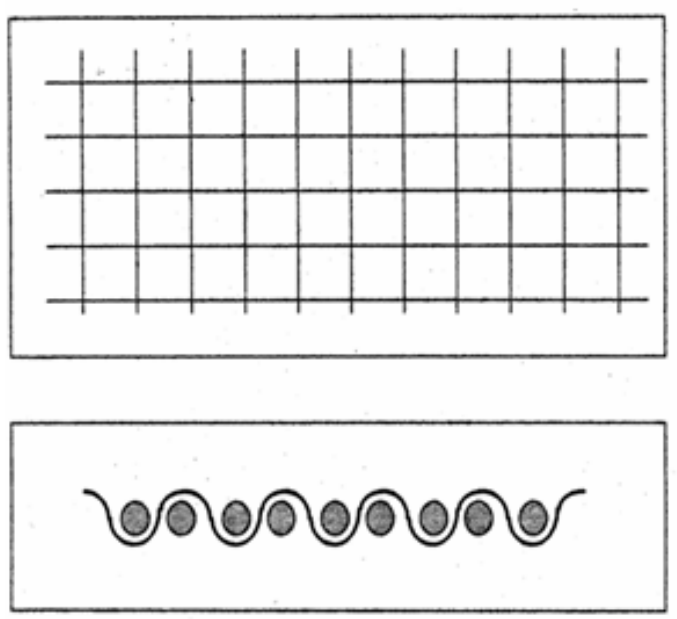

Não Tecido



Figuras 12 e 13 - llustrações esquemáticas do arranjo das fibras em um tecido e um TNT, respectivamente onde os losangos representam os pontos de contato entre as fibras.

A associação dos fabricantes de não tecidos, Association of the Nonwoven Fabrics Industry (INDA), define o não tecido como sendo uma folha, trama ou chumaço de fibras ou filamentos natural e ou sintético, exceto o papel, que foi convertido em fios e são aderidos uns aos outros por meio de um dos seguintes meios:

- adesivação,

- fusão térmica da fibra ou filamentos sobrepostos,

- dissolução, 
- resolidificação do material,

- criação de um emaranhado entre as fibras por meio de agulhameno, costurandoas entre si.

Dentre um grande número de fibras disponíveis no mercado, os materiais mais utilizados na fabricação de não tecido a saber são: poliolefinas, poliéster e rayon. Devido às aplicações cada vez mais técnicas dos não tecidos, os requisitos com relação às propriedades das fibras acabaram se tornando muito importantes. Parcerias entre fornecedores de fibras e fabricantes de produtos que utilizam não tecidos têm sido muito importantes para o avanço na utilização dos mesmos.

Fibras de olefinas é uma descrição genérica que abrange as fibras termoplásticas derivadas das olefinas, predominantemente os hidrocarbonetos alifáticos. As olefinas são produtos da polimerização de gases de propileno e etileno. $O$ polipropileno (PP) e o polietileno (PE) são os dois membros mais comuns da família das olefinas.

O PP em comparação com o PE é extremamente versátil no sentido de tornar-se fibras e tem sido usado com muito sucesso em vários produtos e mercados em todo o mundo.

A fibra de PP se funde entre 160 e $170^{\circ} \mathrm{C}$, caracterizando uma grande vantagem, pois elas podem se manter macias o suficiente mesmo após o processamento a quente. O processamento a quente é utilizado para unir as bordas dos filtros ou para conformá-los.

Vale lembrar que alguns tipos de filtros, dependendo da forma geométrica e/ou tipo de processo usado para a soldagem das suas bordas, geralmente por ultra som ou a quente, podem ficar expostos à temperaturas na faixa de 90 a $140^{\circ} \mathrm{C}$. 
2.5.1.2 Processos de fabricação de não tecido

Existem vários métodos de processamento das poliolefinas, mas neste estudo serão citados somente os mais utilizados para a fabricação de filtros para particulados usados em EPR. Os processos são Melt Blown (MB), Spunbonds (SB) e Electrospining (ES) (HEGDE et al, 2004).

As fibras produzidas pelo processo Spunbonded possuem os diâmetros entre 10 a $35 \mu \mathrm{m}$. As produzidas em Meltblown são descontínuas e muito finas, com diâmetros menores que 10 mícron. As nanofibras, em geral, possuem o diâmetro menor que um mícron (20 a 200 nano metro), fato que explica parcialmente o porquê as tramas fabricadas pelo Meltblow e Eletrospining possuem uma resistência mecânica menor que as fabricadas pelo processo Spundond. (figura 14).



Figura 14 - Ilustração da quantidade de fibras por metro quadrado. Cotesia: FITESA.

As nanofibras são fabricadas pelo processo eletrospining e, devido ao diâmetro diminuto destas fibras, é muito comum o seu uso em filtros e respiradores de alta eficiência. A trama gerada pelas nanofibras favorece os mecanismos mecânicos de captura das partículas em suspensão. 
É interessante observar a comparação do tamanho das nanofibras em relação a um fio de cabelo humano e um esporo de pólen (figuras 15 e 16).

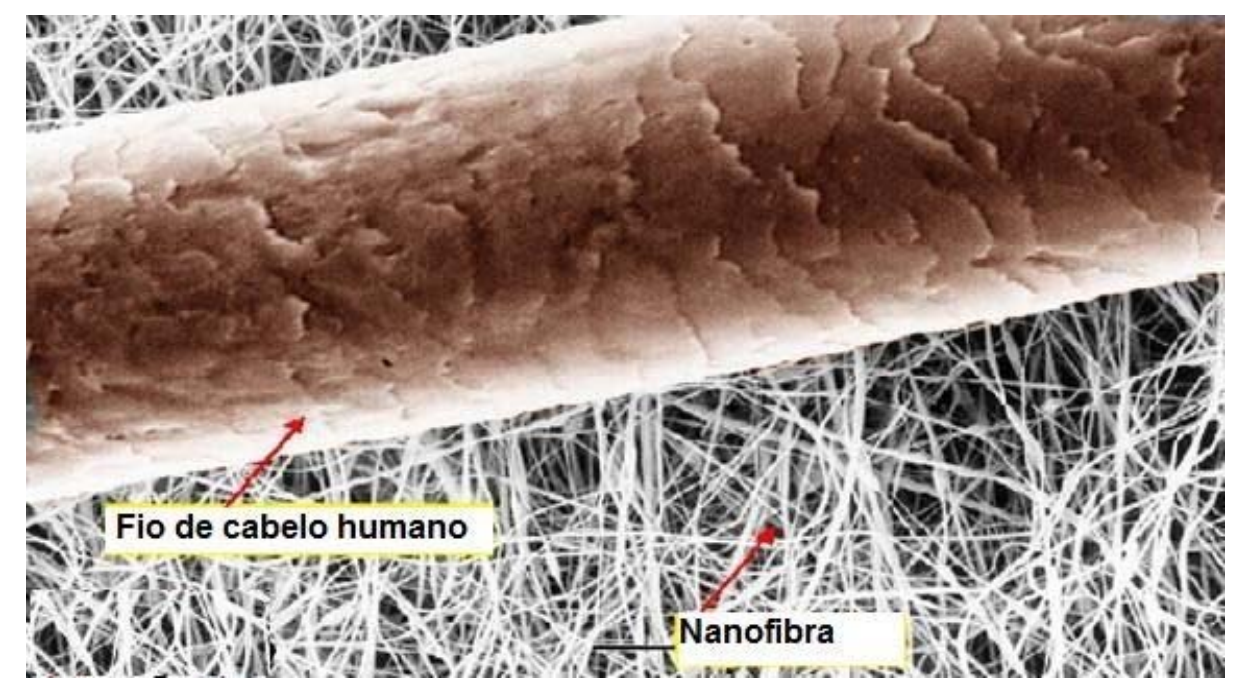

Figura 15 - Comparação entre o cabelo humano e uma trama de nanofibras. Fonte: Nonwovens, science and technology I. apud (WADSWORTH 2004).

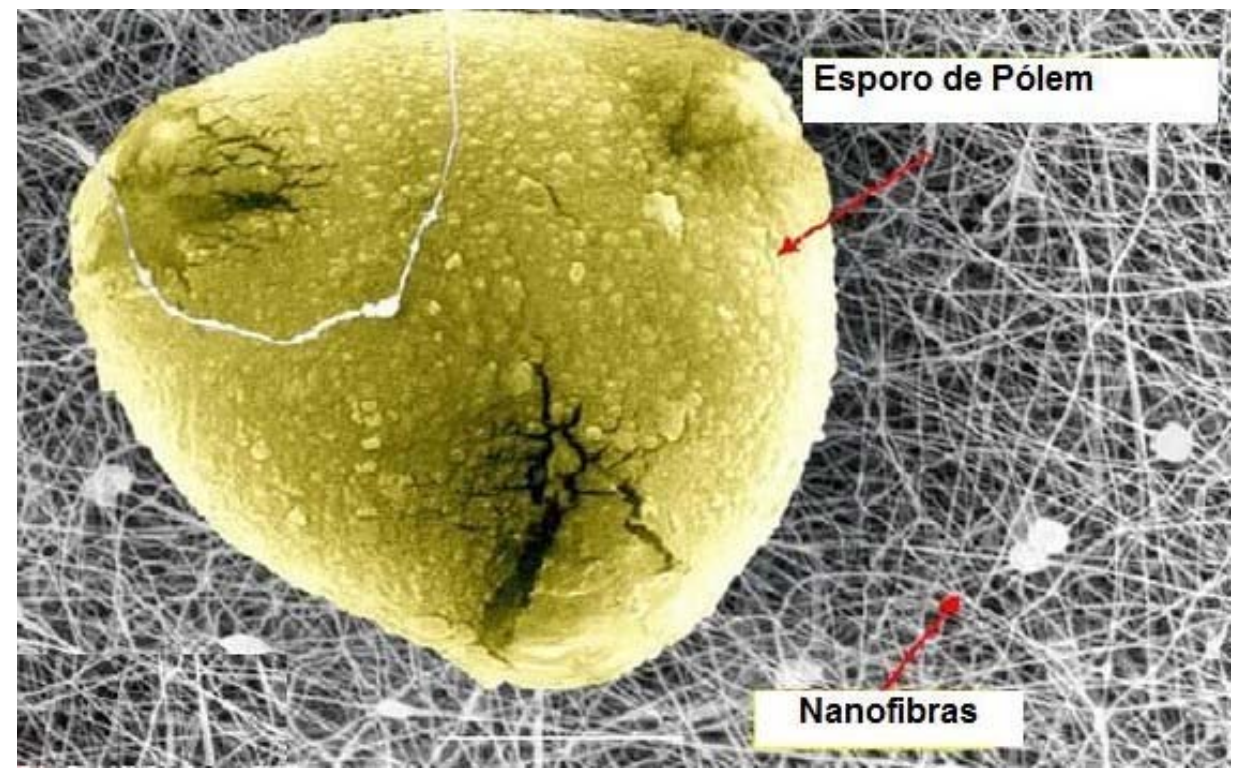

Figura 16 - Esporo de pólen capturado em uma trama de nanofibras. Fonte: Nonwovens, science and technology I. apud (WADSWORTH 2004).

A tabela 2 mostra uma comparação entre os tamanhos de fibras e seus processos de origem (DRUCKETT, 1999). 
A maior diferença entre as mantas fabricadas pelos processos de SB, MB e ES está no diâmetro das fibras, os quais são em média $20 \mu \mathrm{m}, 5 \mu$ e $0,5 \mu \mathrm{m}$, respectivamente (BEHNAM e HOOMAN, 2006).

Tabela 2 - Área superficial da fibra por massa para diferentes tamanhos de fibras (DRUCKETT, 2004).

\begin{tabular}{lcc}
\hline Tipo de fibra & $\begin{array}{c}\text { Tamanho da fibra em } \\
\text { mícron }\end{array}$ & $\begin{array}{c}\text { Área superficial da fibra por massa do material da } \\
\text { fibra } \mathbf{~ e m ~} \mathbf{~ m}^{2} / \mathbf{g}\end{array}$ \\
\hline Nanofibers* & 0.05 & 80 \\
Spunbond & 20 & 0.2 \\
Melt blown & 2.0 & 2 \\
\hline
\end{tabular}

${ }^{\text {* }}$ Fabricado pelo processo eletrospining.

A figura 17 mostra imagens de fibras produzidas pelos processos MB, SB e ES.

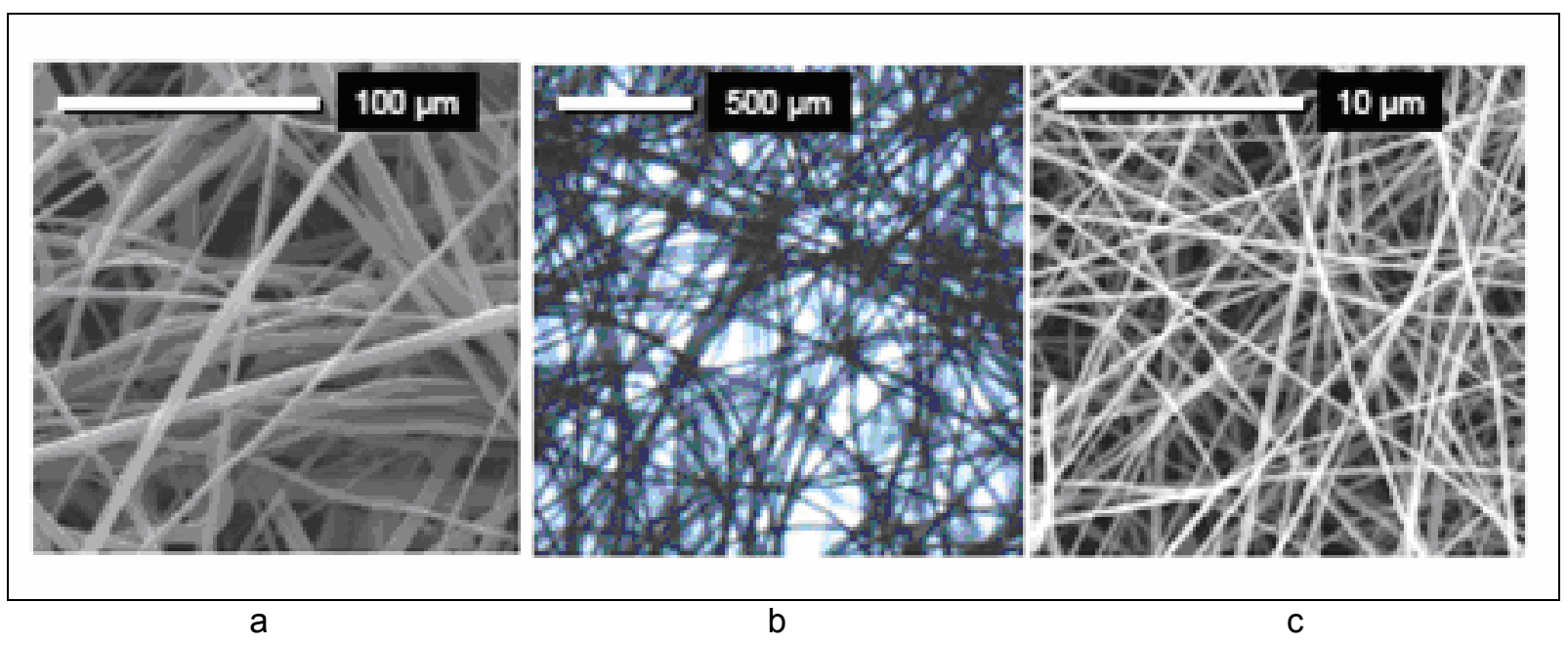

Figura 17 - Imagens de fibras produzidas pelos processos: a) Meltblown, b) Spunbonded e

c) ElectroSpin. Fonte: (Behnam e Hooman, 2006).

\subsubsection{Estrutura do filtro para partículas usado em EPR}

$\mathrm{Na}$ fabricação de filtros ou Peça Facial Filtrante (PFF) são usadas uma ou mais camadas de mantas de material filtrante, geralmente fabricadas pelo processo MB. A quantidade de mantas irá depender da espessura das fibras, densidade, e da carga elétrica das fibras. 
O material filtrante é geralmente protegido por duas camadas externas, fabricadas pelo processo SB, o qual possui maior resistência mecânica. As figuras 18 e 19 mostram uma estrutura de três camadas. As externas em SB e a interna em MB.

Em geral a parte externa do filtro não influencia na eficiência do filtro, tanto em termos de penetração quanto em resistência à respiração, porém, existem necessidades em que, para atender o binômio penetração $x$ resistência, faz-se necessário usar a camada externa como parte ativa do filtro.

A confirmação da condição prática indicada anteriormente é descrita por Behnam (2006), que explica que os filtros são compostos basicamente de duas camadas externas fabricadas pelo processo (SB) que protegem o material filtrante e, praticamente, não influenciam na eficiência de filtração. Contudo, as combinações destas camadas produzem um excelente filtro de nano partículas.

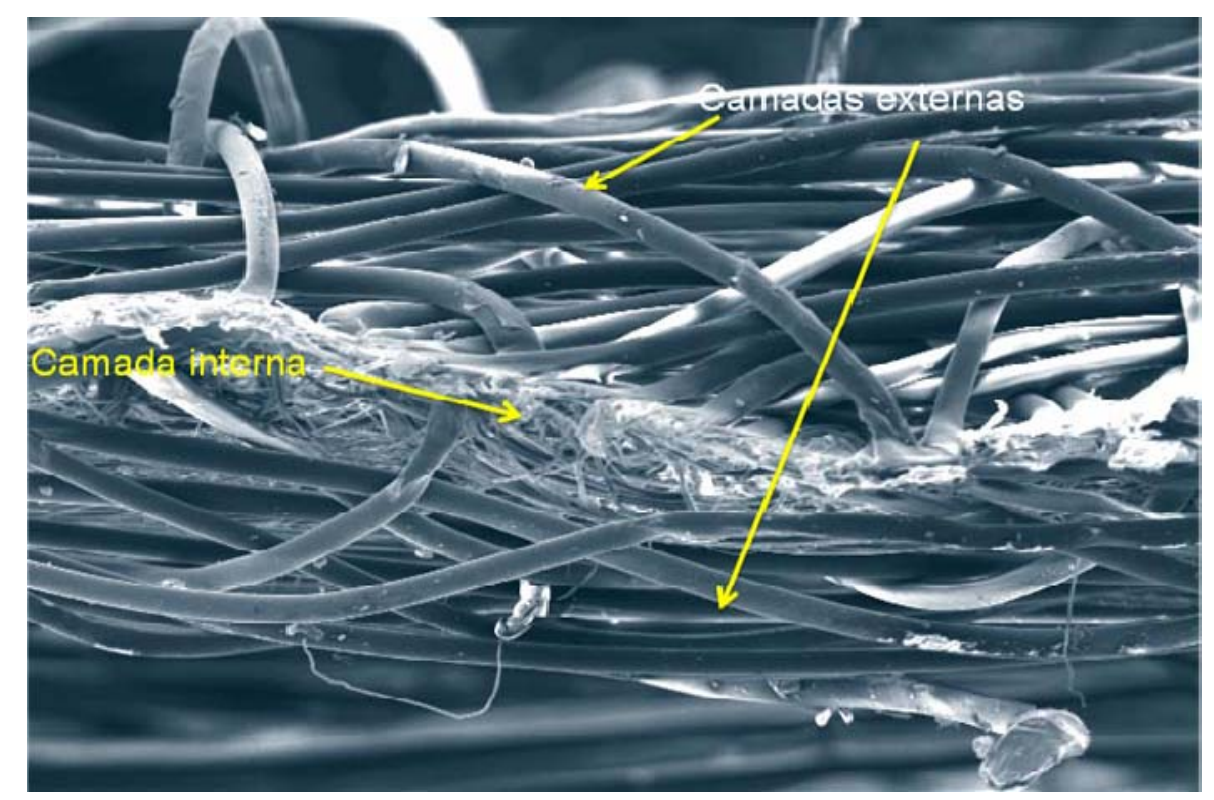

Figura 18 - Corte transversal de um filtro. Fonte: Cortesia FITESA. 


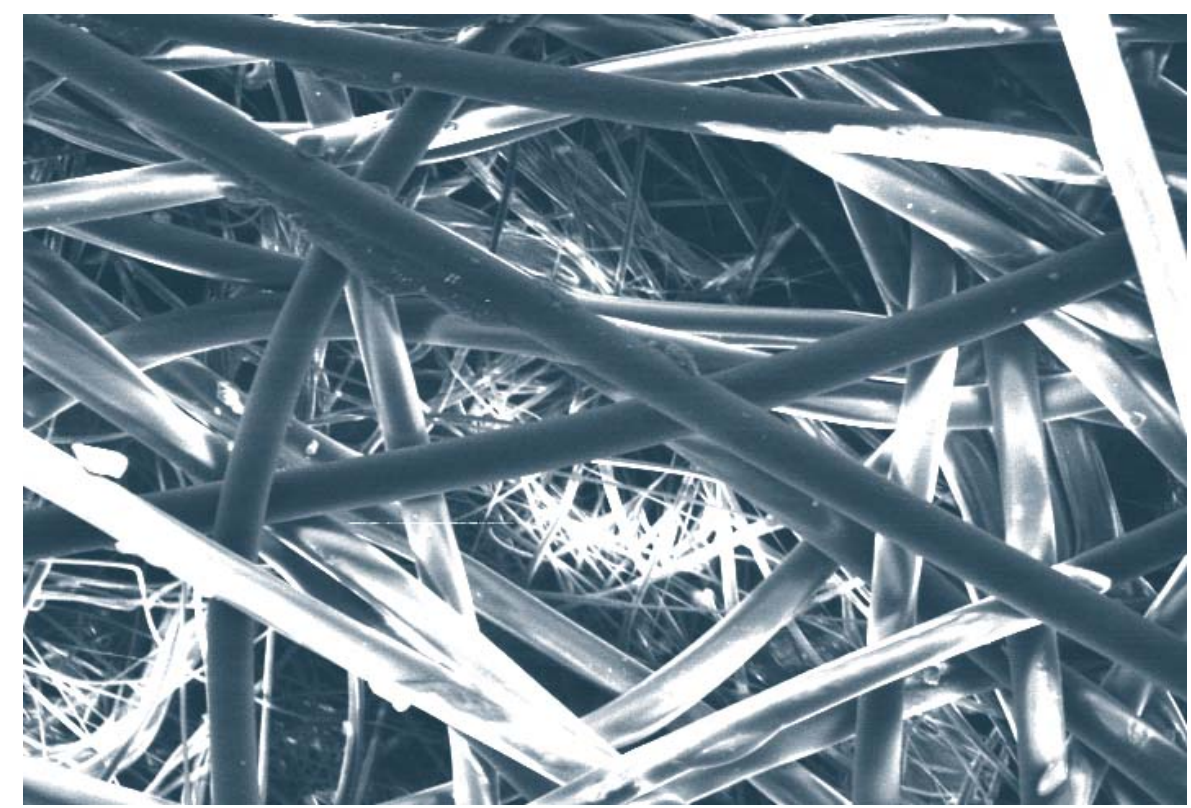

Figura 19 - Vista superior de um filtro. Fonte: Cortesia FITESA.

\subsection{FILTROS COMERCIAIS PARA PARTICULADO}

Os filtros mecânicos para partículas podem possuir diversas formas, como por exemplo, plano, plissado, ondulado; e podem ser fabricados com diversos tipos de materiais (figuras 20 e 21).


Figura 20 - Filtro para particulado P3 e vista interna em corte. Fonte: Arquivo pessoal. 


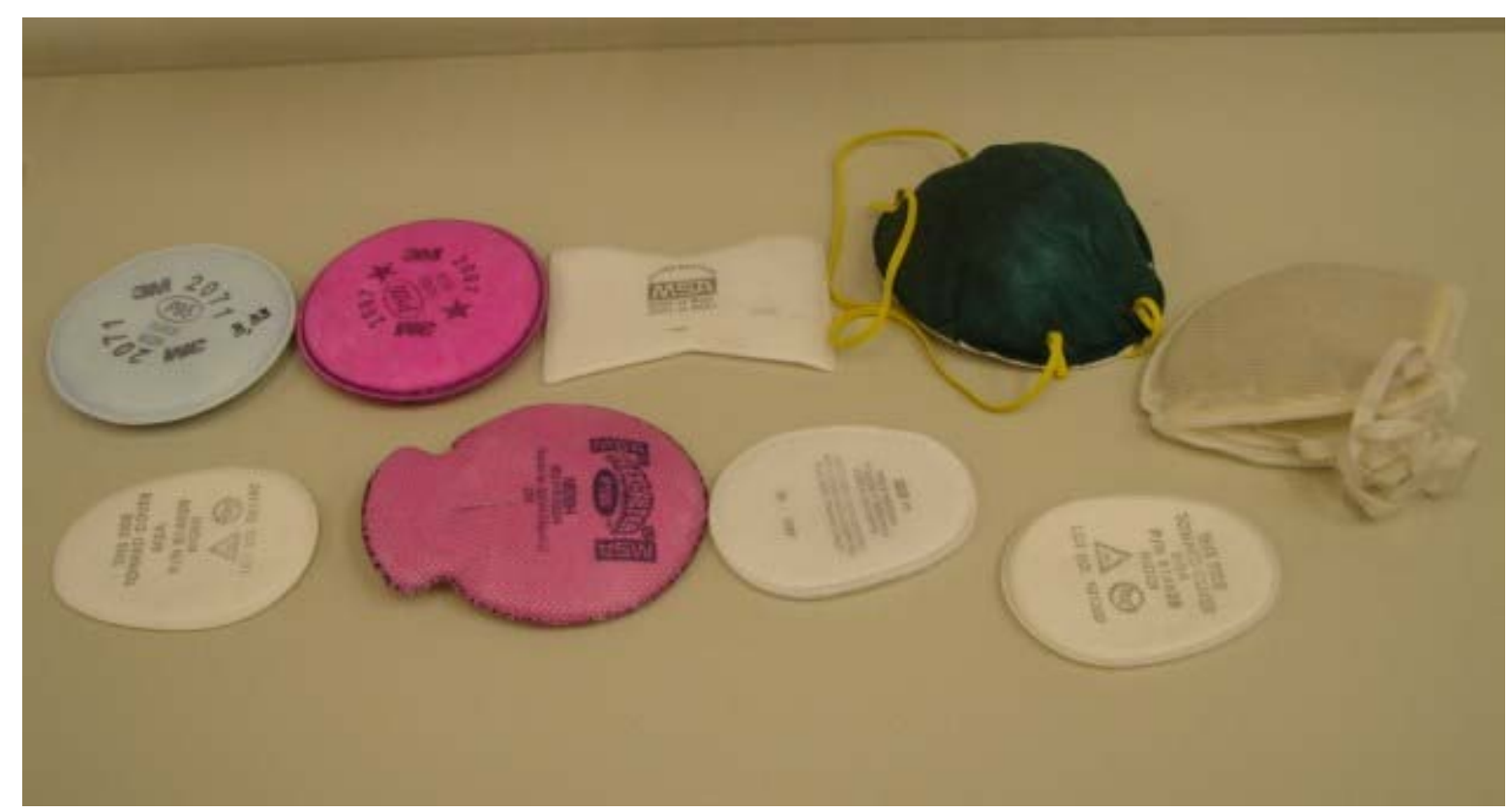

Figura 21 - Filtros e respiradores para particulados de diversas formas e tamanhos. Fonte: Arquivo pessoal.

Para fins deste estudo foram utilizados respiradores ou filtros fabricados a partir de mantas planas, por processos (MB) e carregadas eletrostaticamente. As gramaturas dos materiais filtrantes variaram entre 13 a $83 \mathrm{~g} / \mathrm{m}^{2}$.

Em seus estudos, Lowkis e Motyl (2001) descrevem que as fibras de PP dos filtros classe P2 são mais finas que as do filtro P1. Fotos da superfície e secção transversal de um filtro P1 são mostradas nas figuras 22 e 23 . O diâmetro das fibras varia entre $3 \mu \mathrm{m}$ e $20 \mu \mathrm{m}$ e as espessuras das mantas foram estimadas em $1,0 \mathrm{~mm}$ para o filtro $\mathrm{P} 1$ e $1,6 \mathrm{~mm}$ para o filtro $\mathrm{P} 2$. 


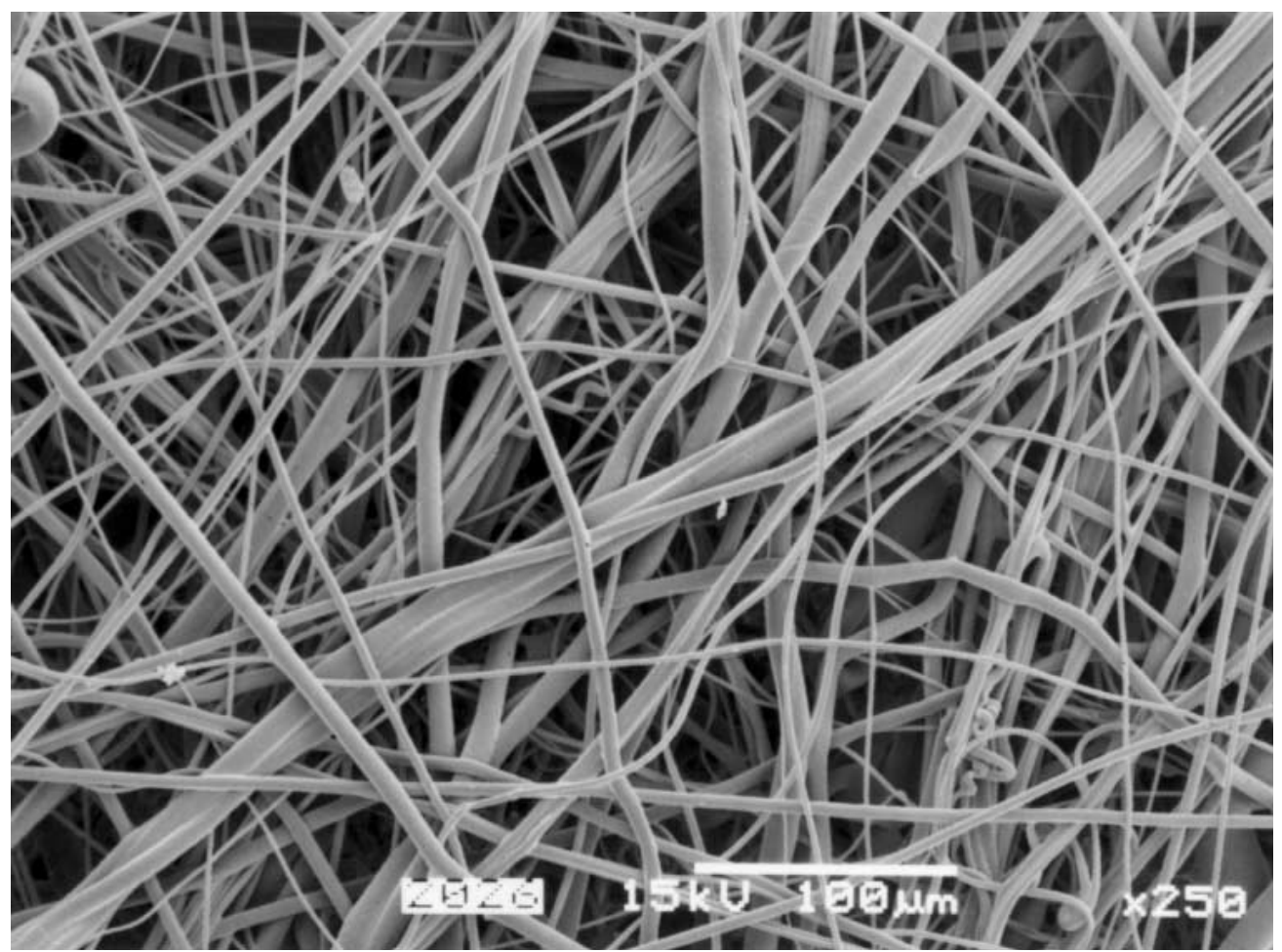

Figura 22 - Superfície de um filtro tipo P1 ampliado 250x. Fonte: (Lowkis e Motyl, 2001).



Figura 23 - Secção transversal de um filtro eletreto, classificação P1, ampliação 650X. Fonte: (Lowkis e Motyl, 2001). 


\subsection{O ELETRETO}

Eletreto é um material dielétrico que retém cargas elétricas de forma duradoura, passando a ter propriedades magnéticas (polarização).

Segundo Neto (1994), um eletreto pode ser produzido pelo emprego de distintas formas, como por exemplo:

- Termo-eletretos, produzidos mediante aquecimento ou derretimento do material, antes de sua formação.

- Radio-eletretos, produzidos por materiais expostos à radiações.

- Magneto-eletretos, formados enquanto o material está exposto a um campo magnético.

- Foto-eletretos, são feitos com determinados materiais expostos a um campo elétrico sob forte iluminação (como se procede com o enxofre). Esses, só mantém sua eletrização quando armazenados no escuro.

- Eletro-eletreto, o material é simplesmente exposto a um campo elétrico

- Corona-eletreto, o material é eletrizado com cargas provenientes de uma descarga.

- Corona, faísca ou eflúvio, atua sobre o elemento filtrante e é aplicado com a manta já acabada. O carregamento ocorre por meio de um conjunto de eletrodos polarizados a uma tensão muito alta. Esta polarização resulta na emissão de íons que são projetados contra a manta por meio do campo elétrico. Dependendo do método de produção o filtro poderá ser dipolar ou conter somente um tipo de carga.

- Triboelétrico, ocorre pela colocação de dois materiais com diferentes constantes dielétricas em estreito contato, polímeros no caso de filtros, de modo que eles 
troquem íons e criem assim que separados um balanço de cargas entre eles. Este desbalanceamento iônico cria um forte campo elétrico.

- Indução, envolve a própria carga eletrostática da fibra que ocorre durante o processo de extrusão do polímero. Cargas superficiais dipolares são induzida pela exposição do polímero, ainda líquido, a um campo elétrico.

Vários autores indicam que os principais métodos para obtenção do carregamento da fibra são por efeito corona, triboelétrico e por indução (BROWN, 1993; KRAVTSOV et al., 2000; TORLONI e VIEIRA, 2003).

Apesar do carregamento de fibras pelos meios indicados anteriormente serem os mais utilizados e a teoria de aplicação ser bem conhecida, foi observado que o processo está envolto à muita tecnologia adicionado à teoria básica. O assunto é, inclusive, tratado como um segredo industrial pelos fabricantes, não sendo permitido ao visitante se aproximar da sala por onde a manta do material filtrante passa para receber o carregamento elétrico por efeito corona (informação pessoal) ${ }^{1}$. Por se tratar de um mercado muito competitivo, informações tecnológicas que permitem produzir um elemento filtrante com maior estabilidade e carga elétrica, se tornam uma vantagem extremamente valiosa, pois afeta diretamente os resultados financeiros da empresa (informação verbal) ${ }^{2}$. O aspecto da diferença de tecnologia empregada na produção de materiais filtrantes não pode ser verificado visualmente comparando materiais de diferentes fornecedores, mas, ficou claro, pelos resultados obtidos neste estudo, que a tecnologia empregada reflete diretamente na capacidade do material filtrante em manter a carga elétrica quando expostos à temperaturas elevadas.

\footnotetext{
1 Visita a fabricante internacional, com sede nos Estados Unidos, de materiais não tecidos que produzem especificamente o material filtrante com carga eletrostática. Setembro. 2007.

2 Informações obtidas em conversa com o mesmo fabricante visitado nos Estados Unidos de materiais não tecidos. Setembro, 2007.
} 


\subsubsection{Origem do filtro eletreto e princípios de funcionamento}

A partir do entendimento dos mecanismos de captura das partículas pelas fibras devido à carga elétrica de uma ou ambas, começou-se a produzir filtros onde as fibras eram carregadas eletrostaticamente.

Em 1931, surgiu o filtro de lã carregado com resina que foi chamado de filtro Hansen. Para produzir este filtro, é necessário que ocorra primeiramente a impregnação da superfície das fibras da lã com pequenas partículas de resina. Então, por meio de ações mecânicas subseqüentes, como cardamento da lã, que as partículas de resina adquirem uma carga negativa e a lã, uma carga positiva. Estes filtros fazem uso de fibras de lã com aproximadamente $20 \mu \mathrm{m}$ de diâmetro e a resina utilizada é a base de fenolformaldeído e breu, produzido da resina secretada de certas árvores (TORLONI e VIEIRA, 2003).

Em 1975, surgiram os filtros feitos com fibras poliméricas, tipo eletreto, largamente utilizados até os dias de hoje (FELTHAN, 1976; TORLONI e VIEIRA, 2003).

A resina é um excelente isolante e sua baixa condutividade é suficiente para garantir que a carga no material filtrante fique estável. Já a lã, pode ser considerada como um condutor e, como tal, irá desenvolver qualquer que seja a carga necessária para reduzir a carga eletrostática do sistema ao mínimo, obtendo uma configuração que é a imagem elétrica das cargas elétricas da resina (BROWN, 1993).

A configuração da carga eletrostática sobre materiais filtrantes (figura 24) pode ser considerada, de modo simplificado, como uma configuração média das cargas nas fibras. 


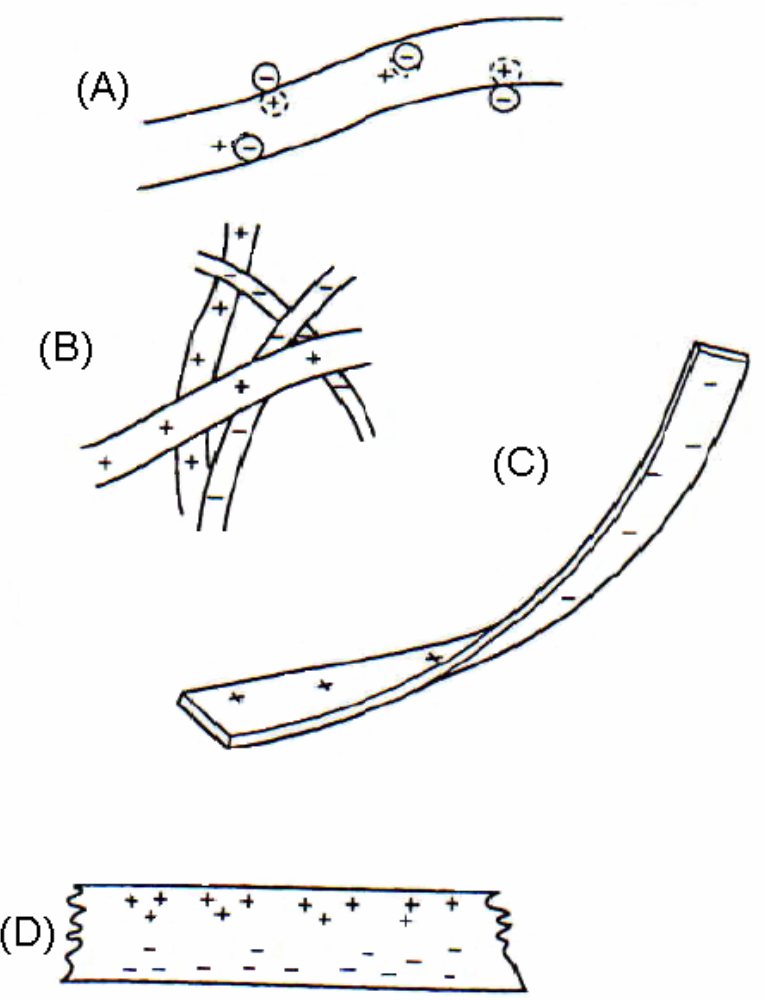

Figura 24 - Ilustração esquemática da configuração da carga eletrostática de materiais filtrantes: (A) fibra unitária de lã resinada. (B) mistura de fibras (vários materiais). (C) fibra separada de material eletreto. (D) feltro eletreto carregado. Fonte: (BROWN, 1993).

\subsubsection{Filtros eletretos ou eletrostáticos}

Filtros eletretos são usados largamente em aplicações que requerem alta eficiência de filtração e baixa perda de carga. Estes filtros se utilizam dos mecanismos eletrostáticos de captura de partículas em adição aos mecanismos mecânicos convencionais como interceptação direta, impactação inercial, deposição por difusão e deposição gravitacional. (ROMAY et al., 1998).

Desta forma, a solução mais efetiva e eficiente em resposta ao aumento da demanda de filtros de alta performance e que ao mesmo tempo tenham uma baixa perda de carga, é, sem dúvida, a filtração eletrostática.

Emi et al. (1987) classifica o filtro eletrostático em duas categorias: filtros com um campo elétrico externo e outro, com carga sobre as fibras. Este último é muito 
peculiar, pois carrega cargas positivas e negativas permanentes localizadas no interior de cada fibra (figura 25). A densidade destas cargas é extremamente alta. Esta divisão também é explanada por Brown (1993).

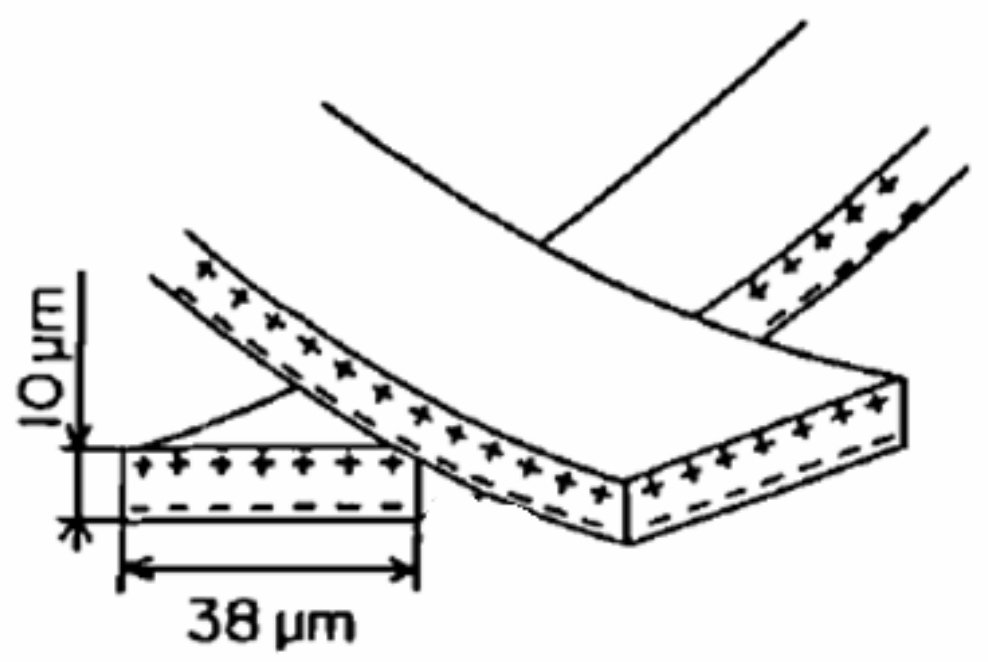

Figura 25 - Fibra eletreto. Fonte: (Emi,1987).

Apesar do esquema demonstrado na figura 25, Jasper (2007) esclarece que o local exato em que as cargas ficam presas no material filtrante de PP ainda é uma questão não respondida.

A eficiência de captura por interceptação de partículas micrométricas sobre uma única fibra, com diâmetro aproximado de $20 \mu \mathrm{m}$ (diâmetro típico de fibras animais, vegetais ou sintéticas), fabricada por processos de tecelagem, é extremamente baixa. Por exemplo: partículas de diâmetros entre 2 e $3 \mu \mathrm{m}$ possuem uma penetração entre 47 e $22 \%$. Esta mesma fibra, quando carregada eletrostaticamente, passa a ter uma penetração de 0,06 a $0,03 \%$. Os valores de penetração são aproximados. (BROWN, 1993). 


\subsection{PARTÍCULAS PRESENTES NA MINERAÇÃO}

As partículas em suspensão, também chamadas de aerodispersóides, são partículas sólidas ou líquidas, em geral menores que $100 \mu \mathrm{m}$, geradas mecanicamente ou termicamente, e podem manter-se por longo tempo em suspensão no ar. As poeiras, névoas e fumos são exemplos de aerodispersóides.

Willeke (1993) apud Santos (2001) define aerodispersóide como uma reunião de partículas, sólidas ou líquidas, suspensas em um meio gasoso pelo tempo suficiente para permitir a observação ou medição das mesmas. O tamanho das partículas presentes em um aerodispersóide varia na faixa de 0,001 a 100 $\mu \mathrm{m}$.

Fatores como tamanho, peso específico e velocidade do ar influenciam diretamente no tempo em que o aerodispersóide permanece suspenso no ar. As partículas com maior chance de serem inaladas são as que permanecem mais tempo em suspensão, consequentemente, podendo causar maior dano à saúde do trabalhador. Em função do seu tamanho, podem ser inaladas e depositadas no trato respiratório.

Almeida (1999) fez uma amostragem de particulados em mineradora de grande e pequeno porte, identificando a presença de pelo menos $10 \%$ das partículas amostradas dentro da fração respirável (partículas menores que $5 \mu \mathrm{m}$ ).

As partículas classificadas, pela origem, como mineral são: quartzo e misturas que contenham quartzo (carvão, caulim, quartzito, areia, argila), asbesto e misturas que contenham asbesto (asbesto bruto, crisotila, anfibólios, fibrocimento, talco), metais e compostos metálicos (alumínio, ferro, chumbo, manganês, berílio, cromo, cádmio) (FUNDACIÓN MAPFRE, 1991 apud SANTOS, 2001).

Baseando-se na classificação acima, verificamos que as partículas à base de sílica e asbesto são comuns nos ambientes de mineração, aumentando ainda mais a preocupação com a proteção do trabalhador que está constantemente exposto a estes tipos de particulados. 
As principais operações unitárias na mineração geradoras de partículas são:

- perfuração de rocha,

- detonações por explosivos,

- desmonte, escavação e carregamento do estéril e minério,

- britagem, moagem, peneiramento,

- transporte do estéril e do minério,

- deposição do estéril e do minério, entre outras.

Somando-se aos processos citados, máquinas e equipamentos que produzem particulados devido à combustão de motores a óleo Diesel, também contribuem para a contaminação do ambiente de trabalho. 


\section{MATERIAIS E MÉTODOS}

A metodologia empregada para o desenvolvimento desta pesquisa consta de levantamento bibliográfico (tanto para as condições de ambiente de mineração, como para os aspectos relacionados ao filtro), análise de resultados de testes em laboratório, busca de informações junto a um fabricante de EPI e fabricantes de matérias-primas utilizadas na fabricação de filtros tipo eletretos e parte experimental.

O laboratório e equipamentos utilizados foram cedidos pela empresa MSA do Brasil Equipamentos e Instrumentos de Segurança Ltda.

\subsection{COLETA DE DADOS}

A coleta de dados deu-se por meio da realização de testes de penetração inicial com $\mathrm{NaCl}$ em filtros mecânicos. Foram usados os parâmetros normativos de aprovação de filtros para particulados no que se refere à penetração e resistência à respiração. Tanto os testes realizados após condicionamento térmico, como a metodologia adotada para o condicionamento (tempo e temperatura), serão descritos posteriormente.

\subsection{INSTRUMENTOS DE MEDIDA UTILIZADOS}

Existem três fabricantes de equipamentos específicos para testes de filtros para particulados usados em EPR.

Os modelos mais conhecidos são: 
- ATI - Air Techniques International Modelo TDA 100P. 2008 (figura 26),

- SFP Services modelo Type 1150 Sodium Flame Photometer (figura 27),

- TSI Modelo AFT 8127 e Modelo 8130 (figura 28).

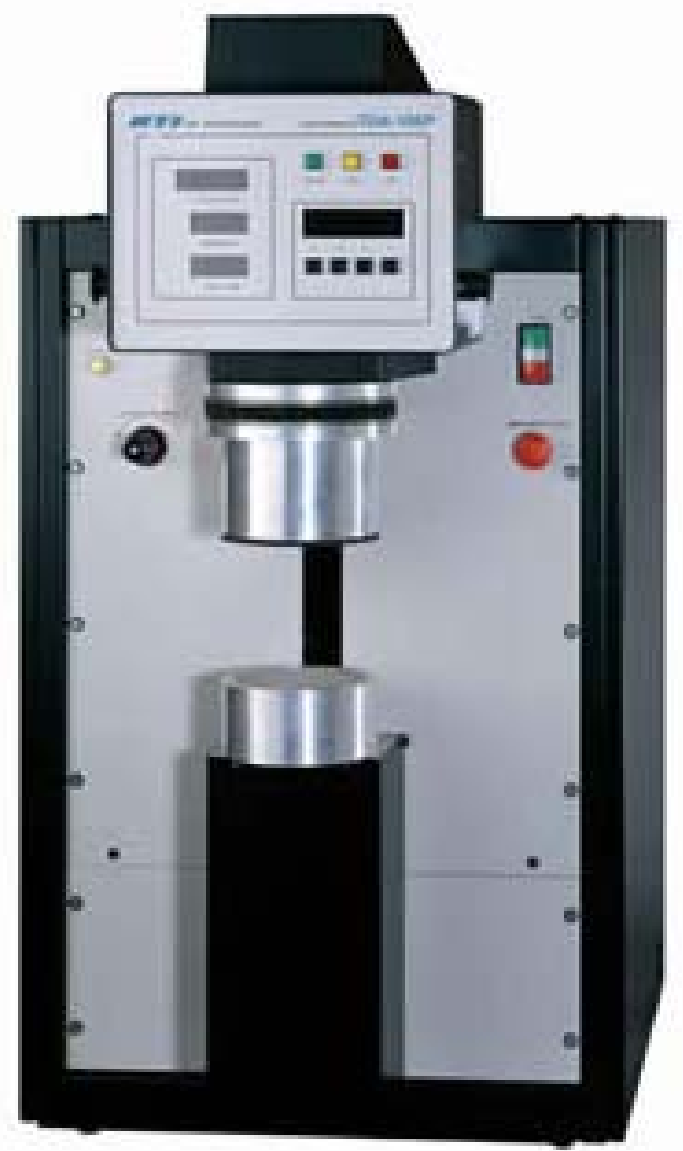

Figura 26 - Equipamento automático de teste de filtros - Modelo TDA 100. Fonte: ATI Air Techniques International.

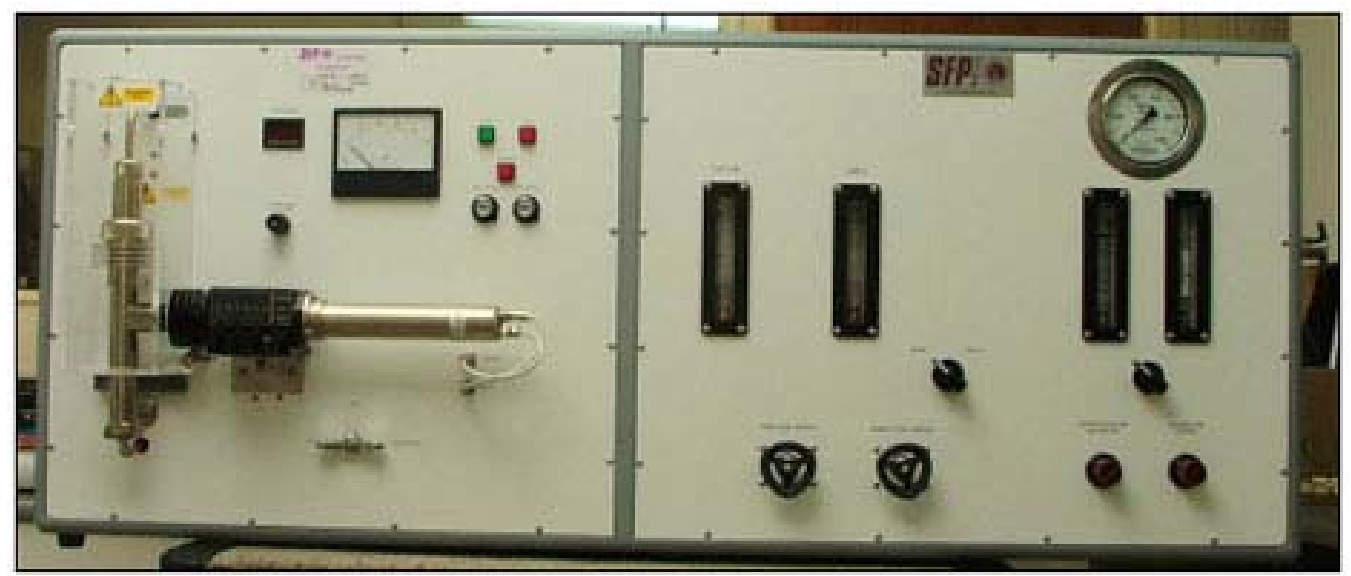

Figura 27 - Equipamento de teste de filtros Modelo 1150 Sodium Flame Photometer. Fonte: SFP. 


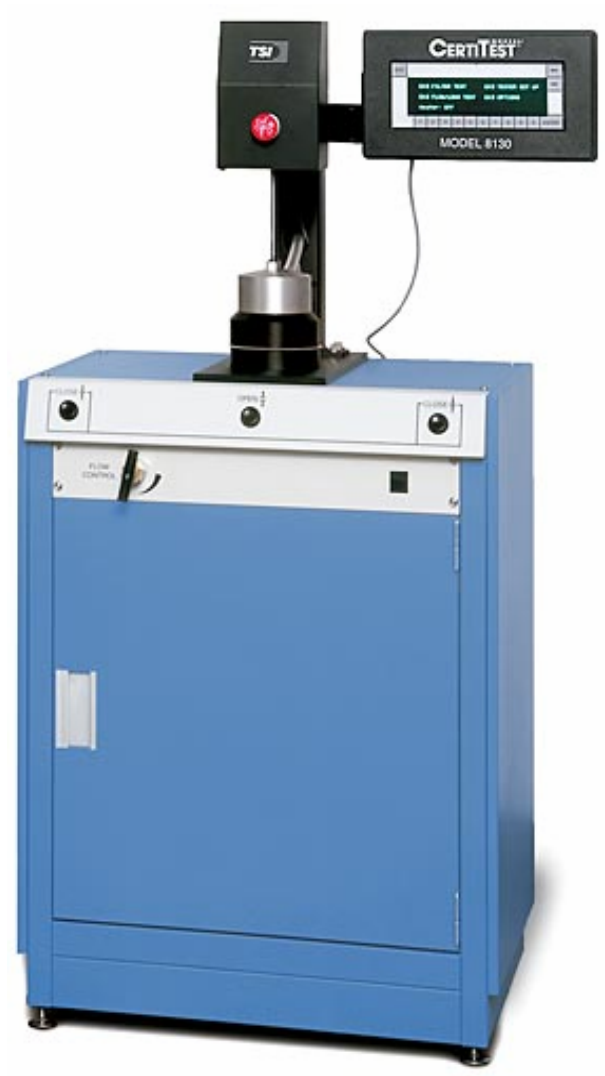

Figura 28 - Equipamento automático de teste de filtros Modelo AFT 8130.

Fonte: (TSI, $2008-b)$.

Apesar do fabricante ATI declarar em sua página da internet (ATI, 2008) que o Modelo TDA 100 atende aos requisitos da norma 42 CFR 84 (ESTADOS UNIDOS, 1995), o que se verifica entre os fabricantes e laboratórios que realizam testes em filtros para particulados, é que esse equipamento é utilizado para fins de controle da qualidade e não para submissão de amostras para aprovação junto aos organismos responsáveis. Isto é compreensível, pois este equipamento só realiza testes com partículas oleosas como Di Octil Ftalato (DOP) e, as principais normas de aprovação usadas mundialmente definem o uso de partículas de $\mathrm{NaCl}$ e oleosas.

Caso semelhante acontece com o equipamento fabricado pela empresa SFP que ao contrário dos modelos da empresa $\mathrm{ATI}$, somente utiliza partículas de $\mathrm{NaCl}$, este porém, paradoxalmente é bastante utilizado pelos laboratórios de aprovação do Brasil e na Europa. 
O modelo produzido pelo fabricante SFP, localizado na Inglaterra, foi originalmente fabricado pela empresa Moore's que deixou de produzir este equipamento desde 1998. A empresa SFP fornece uma família de equipamentos baseados na plataforma original do equipamento BS 4400 Moore's Tester Rig, por isso, é comum entre os fabricantes e laboratórios de testes referenciar os equipamentos da empresa SFP como equipamentos Moore.

Segundo Camargo (2007), a referência BS 4400 usada para identificar o modelo do equipamento de teste Moore é em função da norma British Standard Institute (BSI), BS 4400 de 1969, a qual está em desuso e foi substituída pela norma EN 143. Ainda em seu estudo comparativo entre as normas 42 CFR 84 (ESTADOS UNIDOS, 1995), EN 143 (INGLATERRA, 2006) e NBR 13697 (BRASIL, 1996) indica que, exceto pela duração do ensaio, onde o instante da medição da penetração na norma EN 143 é feita até que $120 \mathrm{mg}$ de $\mathrm{NaCl}$ tenha tocado a superfície do filtro e, na norma NBR 13697, a leitura deve ser feita em tempo máximo de um minuto; os parâmetros relativos à geração, detecção, concentração, neutralização do aerossol, e tamanho das partículas de $\mathrm{NaCl}$ ou oleosas são idênticos para as normas utilizadas no Brasil, NBR 13697, e Europa, EN 143. Já a norma utilizada nos Estados Unidos, 42 CFR 84, apesar dos parâmetros serem próximos, nenhum deles é igual aos dos outros dois países citados.

Por uma questão de praticidade, precisão e velocidade de operação para a realização dos testes de penetração em filtros para particulados, aliados ao objetivo de medir a variação dos resultados, optou-se pelo uso do equipamento TSI modelo 8130, dentre os equipamentos disponíveis, Moore`s e TSI, do laboratório da empresa MSA do Brasil. Vale destacar que este modelo foi homologado pela NIOSH para aprovação dos filtros para particulados, conforme a norma 42 CFR 84 (ESTADOS UNIDOS, 1995). 


\subsubsection{Características técnicas do equipamento CERTITEST® modelo 8130}

O equipamento de teste 8130 possui as seguintes características técnicas para detecção do aerossol e medição do fluxo de ar:

- pode usar geradores de aerossol tanto para $\mathrm{NaCl}$ como para óleo (DOP e óleo de milho),

- o aerossol é arrastado por um sistema de vácuo que confere maior precisão na medição da vazão e perda de carga (resistência),

- existe a opção de se neutralizar as cargas elétricas das partículas, ou não, por meio do acionamento do ionizador que é integrado ao equipamento, e

- a medição da penetração das partículas no filtro é feita por meio de dois fotômetros a laser, de dispersão de luz. Um dos fotômetros mede a concentração do aerossol a montante, o outro a jusante do filtro. Os fotômetros diferem entre si pelo tamanho e resolução. O fotômetro a montante possui uma baixa resolução e mede as altas concentrações. O fotômetro a jusante utiliza um diodo laser de alta potência para medir as concentrações muito baixas e possui uma sensibilidade para medir penetrações de até 0,001\%.

A figura 29 mostra o esquema simplificado dos equipamentos de testes Modelos TSI 8127 e 8130. Com o uso dos dois fotômetros, o instrumento tem a capacidade de medir a penetração de particulados na faixa de 0,001\% a 99,999\%. 


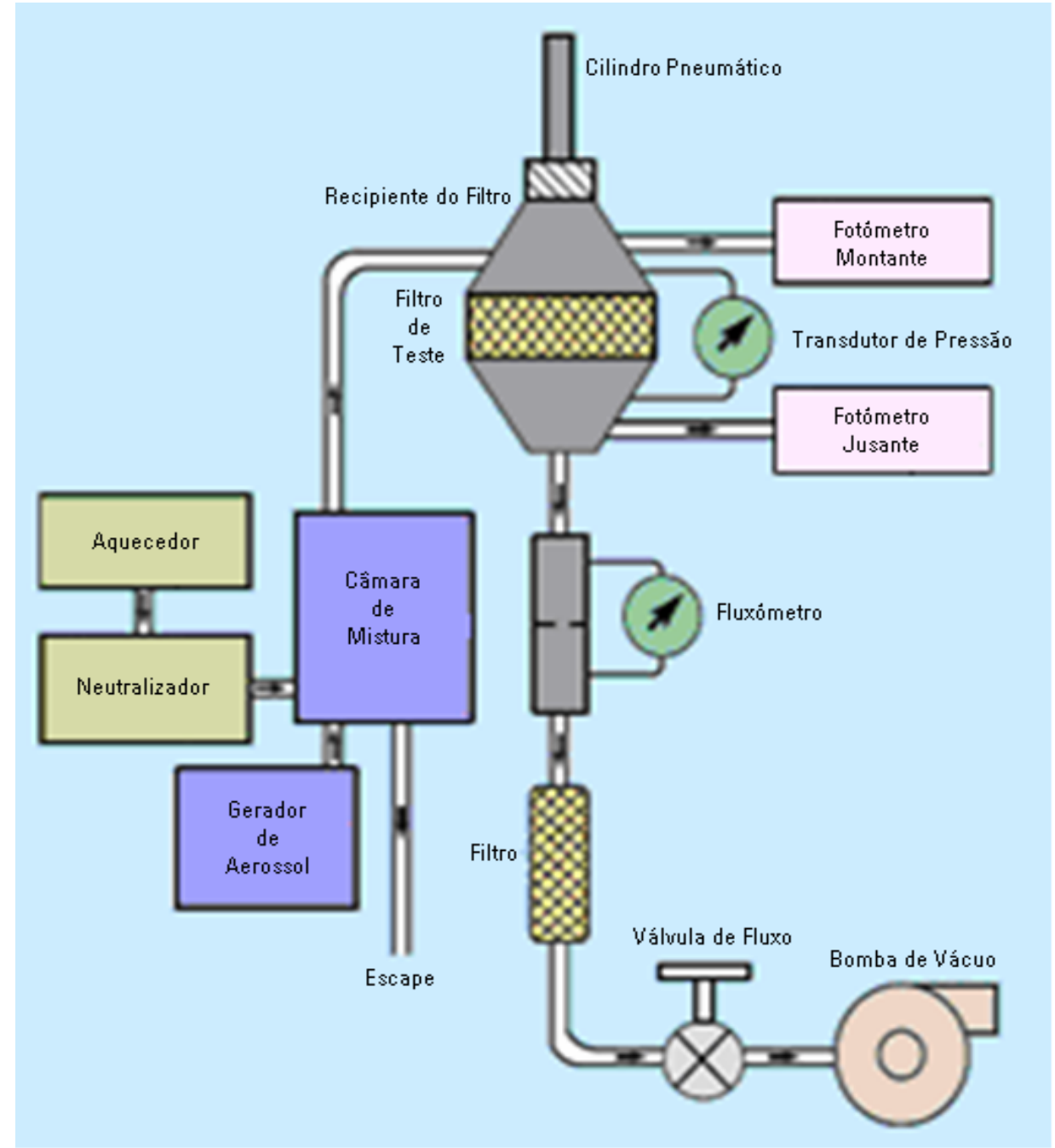

Figura 29 - Esquema simplificado do equipamento de teste Modelo 8130. Fonte: (TSI, 2007 - c).

A vazão é medida com orifício calibrado por diferencial de pressão, medido por meio de um transdutor eletrônico de pressão. A faixa de ajuste da vazão é de 15 a 100 $\mathrm{I} / \mathrm{min}$.

O atomizador é usado para gerar a névoa contendo as partículas de $\mathrm{NaCl}$ ou DOP. No caso do equipamento TSI 8130 foi utilizado o modelo $8110 \mathrm{~A}$, específico para solução de $\mathrm{NaCl}$, também do fabricante TSI Incorporated (figura 30). Este atomizador pode gerar aerossol em uma faixa de $1,0 \mu \mathrm{g} / \mathrm{m}^{3}$ a $200 \mathrm{mg} / \mathrm{m}^{3}$, o que favorece quando da necessidade de verificar o comportamento do filtro se submetido a períodos longos de deposição de partículas sobre a sua superfície. O atomizador 8118A usa um impactador que produz uma faixa estreita de distribuição do aerossol 
e possui uma distribuição geométrica padrão $\left(\sigma_{g}\right)$ menor que 1,86 , o aerossol de



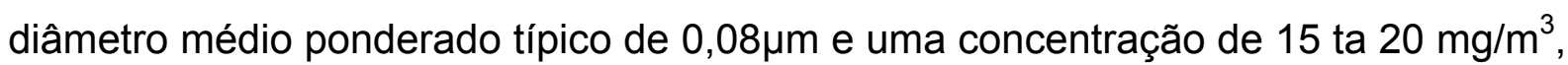
em diluição a 70 litros por minuto (I/m) (TSI INCORPORATED, 2004).



Figura 30 - Atomizador 8110. Fonte: TSI INCORPORATED, 2004.

\subsubsection{Preparação da solução de $\mathrm{NaCl}$}

A preparação da solução de $\mathrm{NaCl}$ foi feita utilizando-se água destilada, balança analítica e dessecador.

A solução salina com concentração de $2 \%$ de $\mathrm{NaCl}$ foi preparada diluindo-se dois gramas de $\mathrm{NaCl}$ em um balão volumétrico de um litro, cheio com água destilada; o sal foi seco previamente em estufa e mantido em dessecador, para evitar a absorção de água pelo sal, causando erro na preparação da concentração. 


\subsubsection{Calibração dos equipamentos}

Todos os equipamentos utilizados neste experimento, que forneçam a medição de qualquer tipo de grandeza, foram adequadamente calibrados contra padrões rastreáveis da Rede Brasileira de Calibração (RBC) e/ou padrões internacionais e, ainda, conforme padrões definidos pela empresa TSI Incorporated.

\subsubsection{Calibração do CERTITEST® modelo 8130}

Segue um maior esclarecimento sobre a metodologia utilizada para calibração do equipamento de teste de penetração para filtros, assim como, seu funcionamento.

Os equipamentos de teste de filtros medem basicamente a penetração do aerossol e a resistência à respiração ou perda de carga. As unidades destas medições são respectivamente porcentagem (\%) e milímetros de coluna d'água $\left(\mathrm{mmH}_{2} \mathrm{O}\right)$. Outra unidade extremamente importante e que afeta diretamente os resultados da medição é a vazão, que é medida em litros por minuto ( $/ / \mathrm{min}$.).

Para garantir que as leituras e ajustes obtidos durante os testes de penetração estejam corretos, são seguidos os procedimentos seguintes.

- Substituição da solução salina a cada 24 horas e/ou nivelamento conforme necessário, seguindo o indicador de nível do atomizador (figura 30).

- Pré-aquecimento do equipamento por, no mínimo, 20 minutos.

- Verificação do horímetro, localizado no painel traseiro do equipamento.

- Caso as horas em funcionamento atinjam os limites definidos conforme tabela de manutenção preventiva recomendada pelo fabricante, efetuar troca de filtros internos, limpeza de válvulas, mangueiras e conexões.

Uma visão geral da parte interna do equipamento pode ser observada na figura 31. 


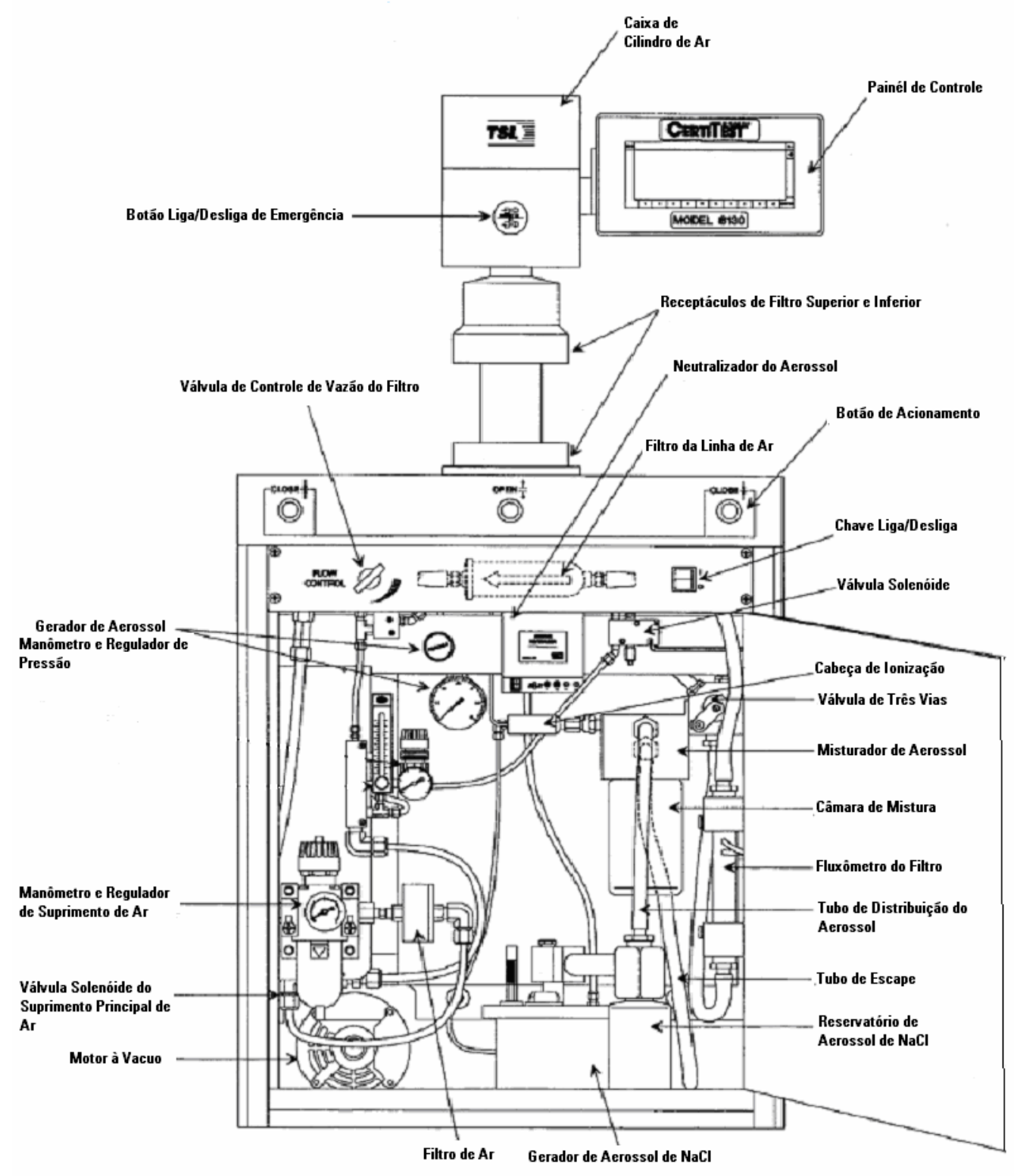

Figura 31 - Vista frontal interna do equipamento TSI 8130. Fonte: (TSI, 2008 - a)

\subsubsection{Procedimento de calibração do equipamento de teste}

A calibração foi feita diariamente seguindo o padrão estabelecido no manual do equipamento. Na verdade, o que ocorre é uma validação dos parâmetros chaves do sistema de medição, por meio de comparações contra padrões de referência para vazão, penetração e perda de carga, fornecidos pelo fabricante do equipamento. 


\subsubsection{Verificação da vazão e perda de carga}

A verificação da exatidão dos resultados da vazão e perda de carga é feita por intermédio do uso de uma placa de orifícios, que possui uma resistência conhecida para uma dada vazão.

A placa é posicionada no equipamento como se fosse realizar um teste de filtro, porém, a vazão é ajustada conforme indicado na placa. Neste caso, $32 \mathrm{l} / \mathrm{min}$. (figura 32). A leitura da perda de carga deve ser a mesma que foi indicada na placa e é obtida por leitura direta no painel do equipamento; caso a leitura divergir da indicada, pode significar que está havendo uma obstrução nos dutos de tomada da leitura, pressão ou falha na parte eletrônica do equipamento. No entanto o manual do equipamento descreve um passo a passo das ações a serem tomadas para cada tipo de falha, facilitando a correção do problema.

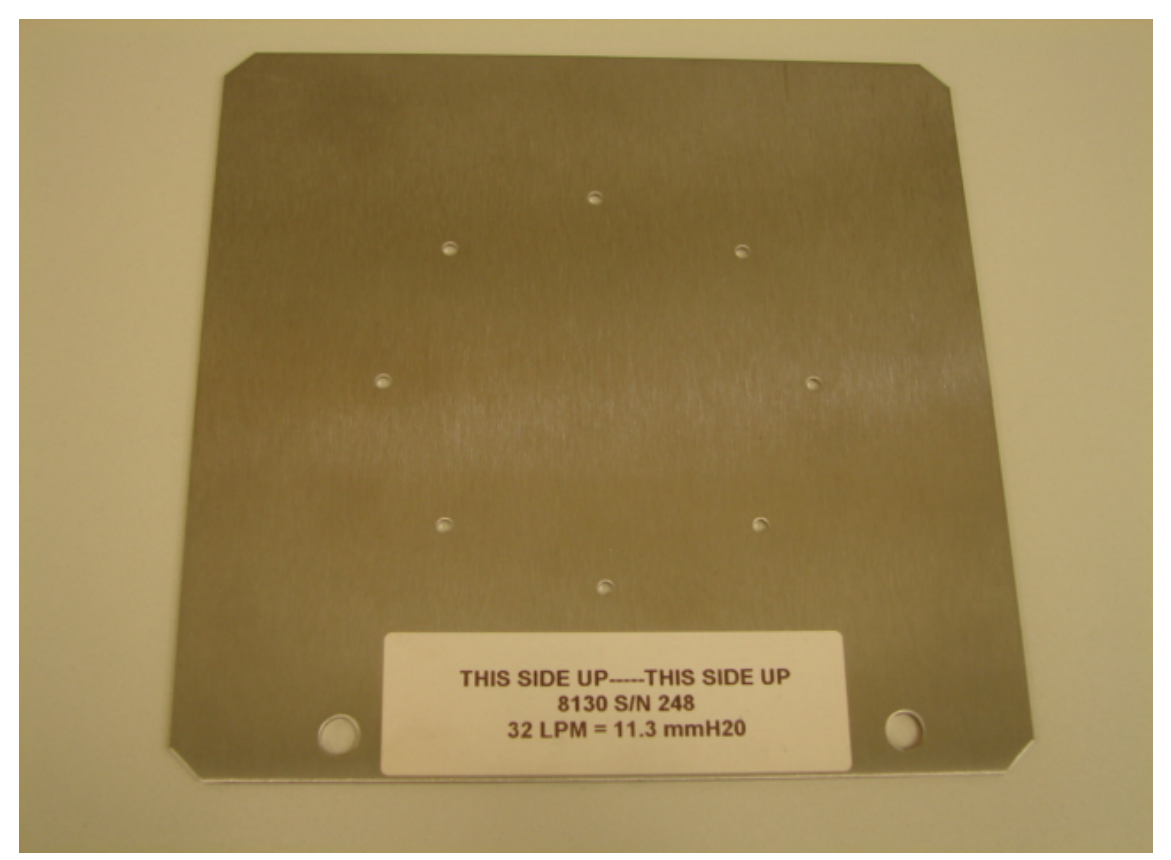

Figura 32 - Placa de orifícios para calibração da vazão e perda de carga. Fonte: Arquivo pessoal. 


\subsubsection{Verificação da penetração}

O procedimento de validação foi projetado para testar vários aspectos do equipamento de teste em filtros. Um deles é verificar o tamanho das partículas geradas, através da comparação dos resultados da medição da penetração em filtros, onde o nível de penetração do aerossol é conhecido. Adicionalmente, esta técnica provê a medição dos seguintes parâmetros: tamanho da distribuição do aerossol, medição da vazão, perda de carga, operação adequada dos fotômetros e operação geral do sistema.

Para tal validação (calibração) foram utilizadas folhas de filtros com uma faixa de penetração conhecida. Estes filtros são do tipo fibra de vidro e são fornecidos pela própria TSI, no formato de discos com 125mm (figuras 33 e 34).

Os discos são acompanhados de cinco gráficos (figuras $35,36,37,38$ e 39), os quais indicam a faixa de penetração esperada para cada combinação da quantidade de sobreposição dos discos. Desta forma, por exemplo, quando se submete um disco ao teste de penetração a uma vazão de $85 \mathrm{l} / \mathrm{min}$ e for obtido um resultado da resistência de $25 \mathrm{mmH}_{2} \mathrm{O}$, o valor nominal da penetração deve ser de $11,6 \%$, podendo estar no máximo dentro da faixa de 8,8 a 14,6 \%. Este procedimento deve se repetir sobrepondo-se os discos, obtendo desta forma, uma verificação em toda a faixa de medição do equipamento ou, pelo menos, na faixa mais utilizada para testes. Os gráficos cobrem uma faixa nominal de $22 \mathrm{mmH}_{2} \mathrm{O}$ de resistência e penetração de $14,4 \%$ a uma resistência de $140 \mathrm{mmH} 2 \mathrm{O}$ e penetração de $0,08 \%$. 


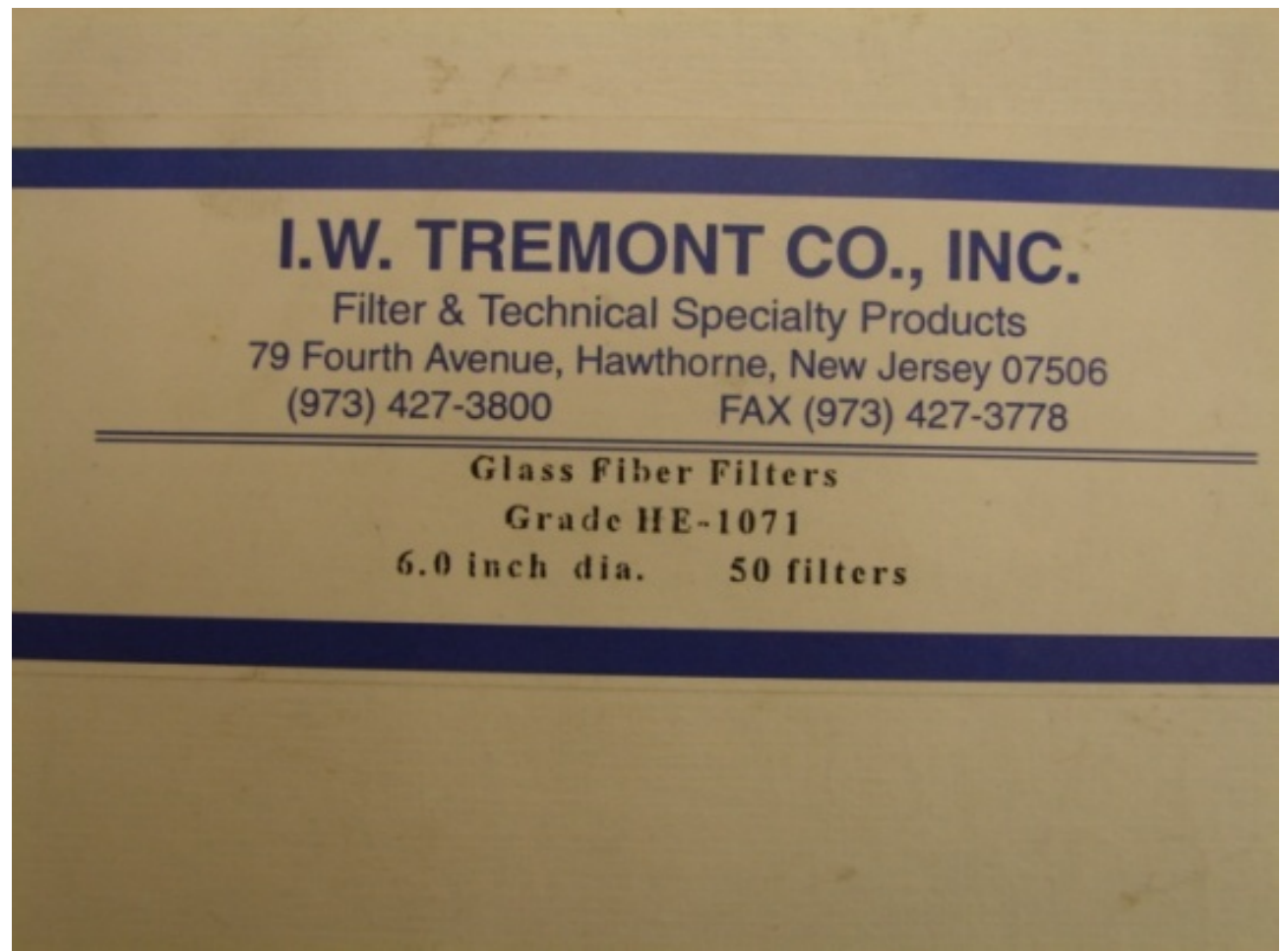

Figura 33 - Identificação de filtros de fibra de vidro padrão. Fonte: Arquivo pessoal.

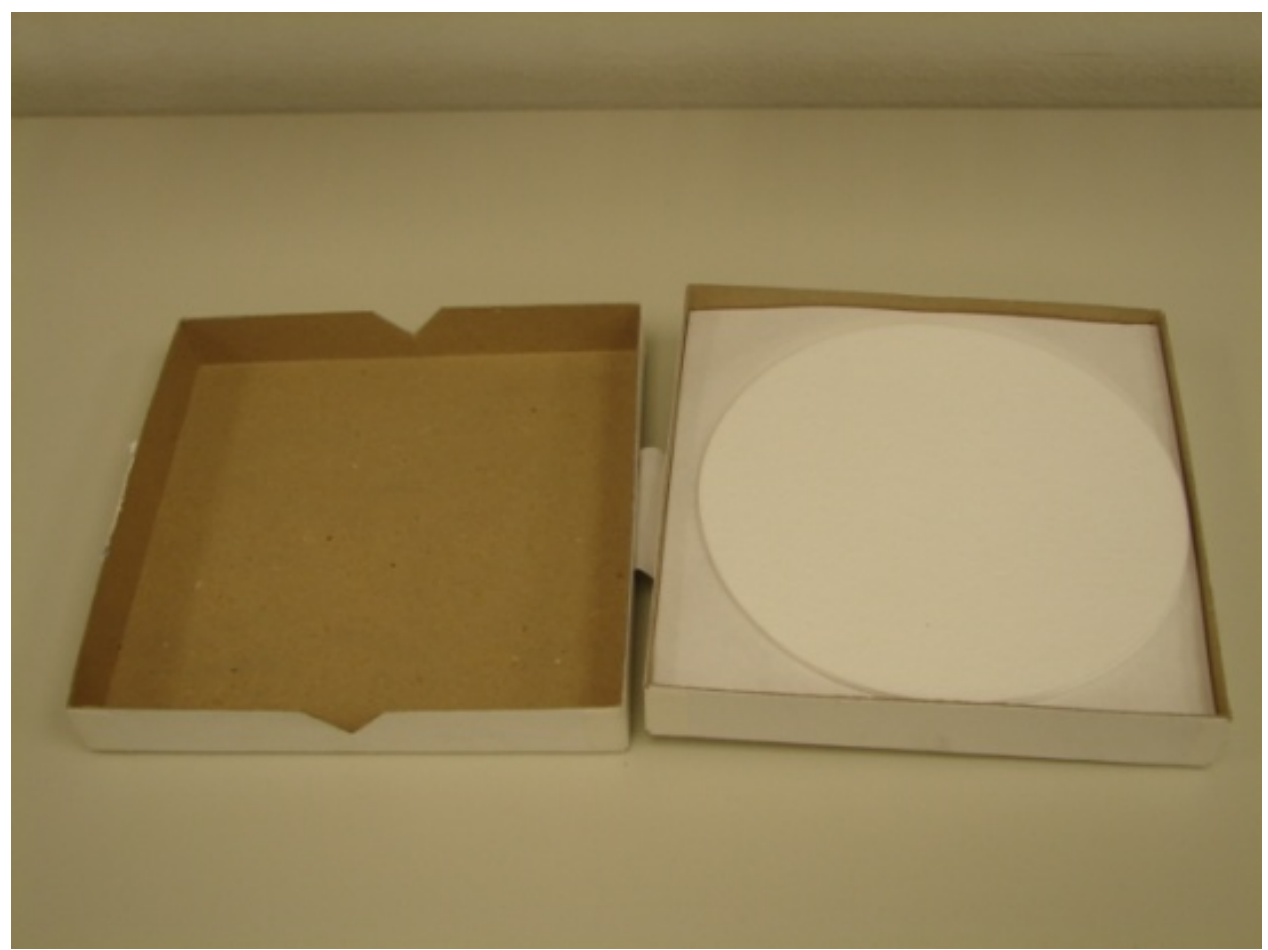

Figura 34 - Filtros de fibra de vidro padrão. Fonte: Arquivo pessoal. 




Figura 35 - Verificação do gerador de sal com uma folha (disco). Fonte: (TSI, 2001).



Figura 36 - Verificação do gerador de sal com duas folhas (disco). Fonte: (TSI, 2001). 


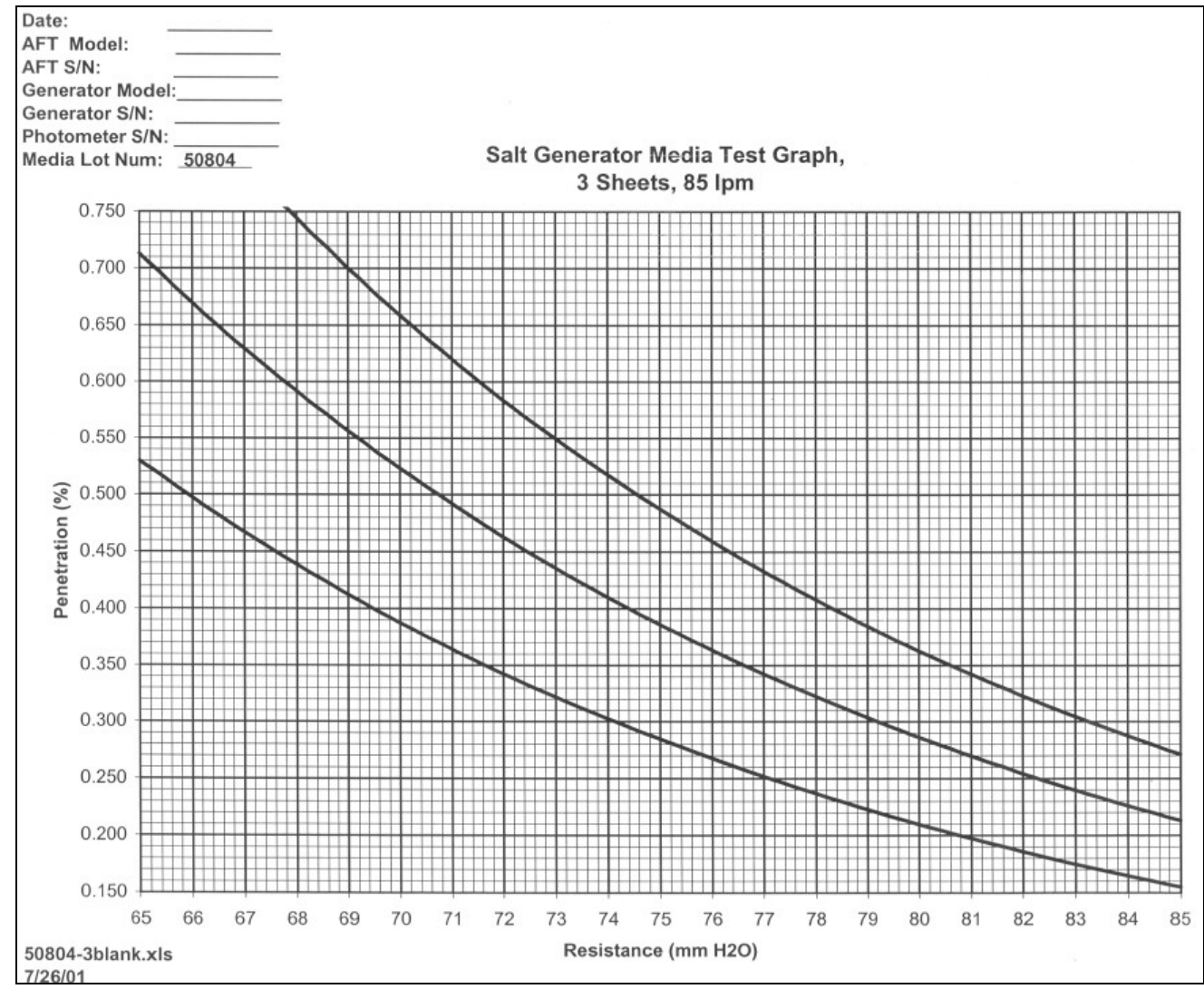

Figura 37 - Verificação do gerador de sal com três folhas (disco). Fonte: (TSI, 2001).

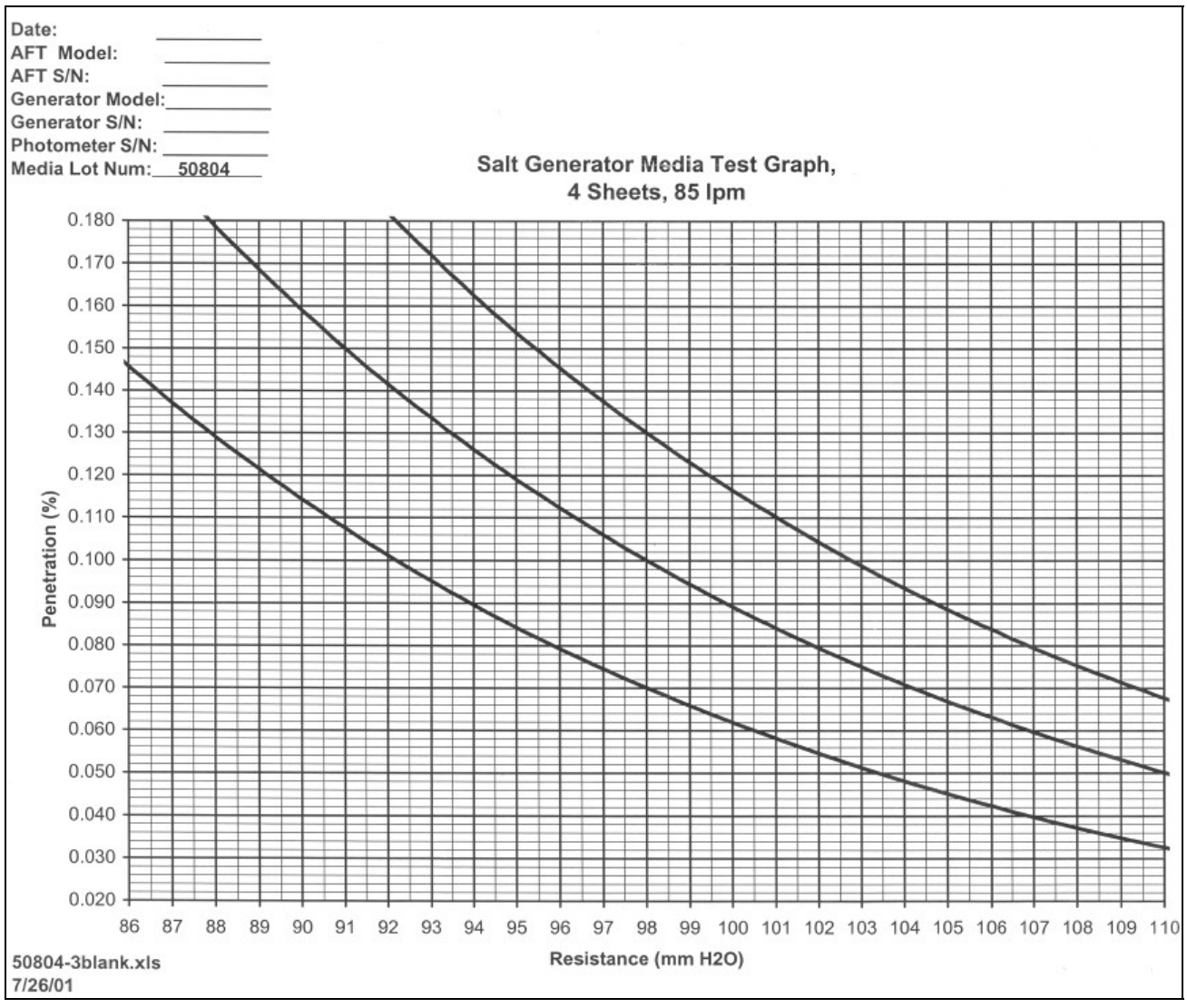

Figura 38 - Verificação do gerador de sal com quatro folhas (disco). Fonte: (TSI, 2001). 


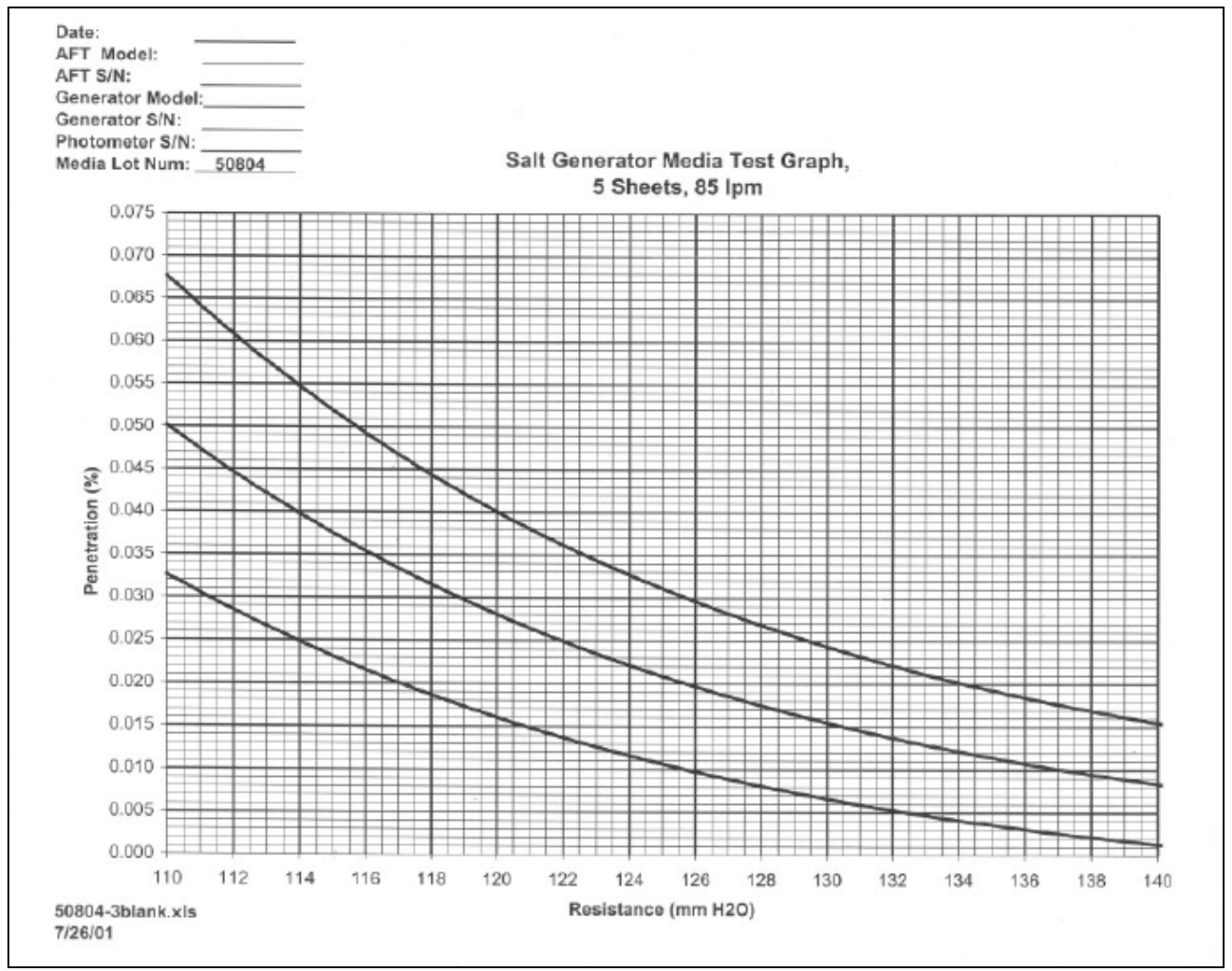

Figura 39 - Verificação do gerador de sal com cinco folhas (disco). Fonte: (TSI, 2001).

3.2.7.1 Parâmetros de maior influência na repetibilidade na medição da penetração

Basicamente, o resultado da penetração em um filtro é resultante de três parâmetros: o tamanho do aerossol, o tamanho da distribuição do aerossol e a vazão.

A figura 40 ilustra o relacionamento dos parâmetros, tamanho da partícula, vazão e penetração em um filtro. No filtro testado, as partículas com diâmetro de $0,1 \mu \mathrm{m}$ apresentaram a maior penetração ocorrendo um decaimento na penetração para as partículas de diâmetros maiores e menores que $0,1 \mu \mathrm{m}$. A variação da penetração em função da vazão/velocidade das partículas, apesar de não ser tão expressiva, pode ser verificada, sendo que a maior penetração ocorreu para a vazão de 54 l/min. 


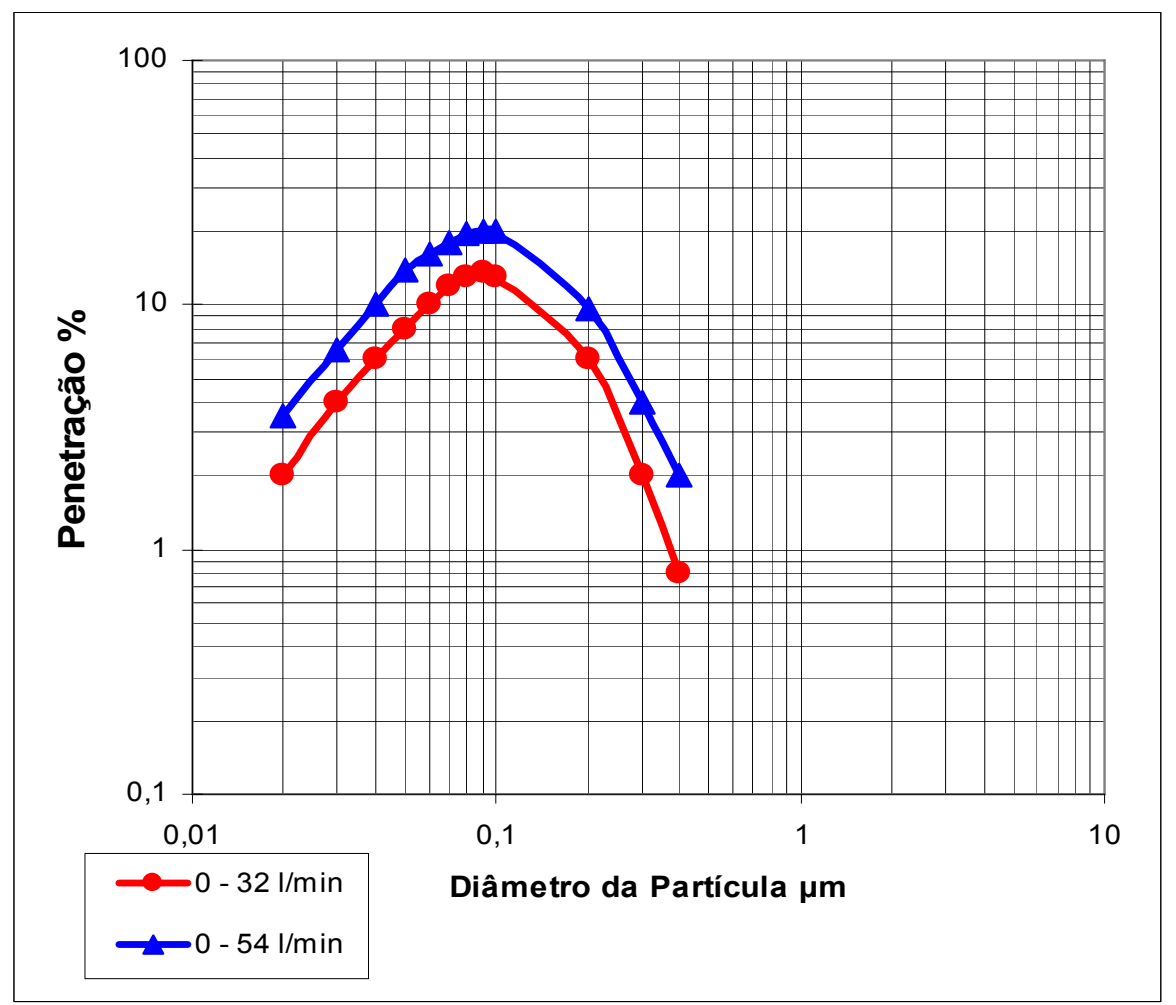

Figura 40 - Penetração em um filtro versus tamanho da partícula. Fonte: (adaptado TSI, 2008 - a).

O tamanho da distribuição do aerossol também exerce um efeito significativo na penetração (figura 41), onde a mesma diminui com o aumento da largura no tamanho da distribuição geométrica. Esta é geralmente medida e referenciada como desvio geométrico padrão (GSD). O aerossol polidisperso possui um GSD maior que 1,2 . 




Figura 41 - Penetração em um filtro versus desvio geométrico padrão. Fonte: (Adaptado TSI, 2008 - a).

A figura 40 mostra a importância do diâmetro da partícula versus a vazão e a figura 41 a importância da largura da distribuição GSD. Portanto estes parâmetros são muito importantes para uma maior repetibilidade.

\subsubsection{Estufa usada para condicionamento térmico}

Os filtros foram condicionados em uma estufa sem ventilação forçada da marca FANEN, modelo 311 - CG, escala de 0 a $250^{\circ} \mathrm{C}$, dimensões internas de $25 \times 25$ x $32 \mathrm{~cm}$ (figura 42). 


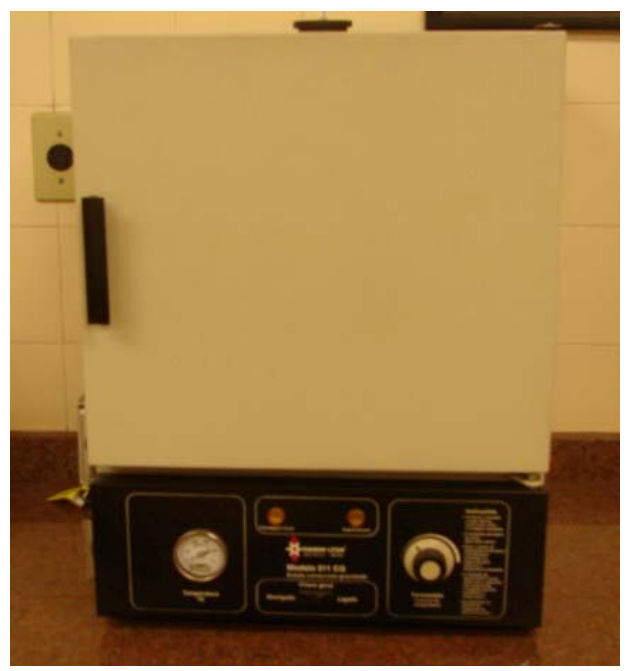

Figura 42 - Estufa utilizada para condicionamento dos filtros.

A temperatura foi ajustada conforme o controle disponível na estufa e o acompanhamento da temperatura foi realizado por meio do uso de um termômetro de bulbo, com faixa de medição de 0 a $200^{\circ} \mathrm{C}$.

O tempo de permanência dos filtros na estufa foi acompanhado pelo uso de um cronômetro.

Os filtros foram posicionados no interior da estufa empilhados sobre as prateleiras conforme figura 43.

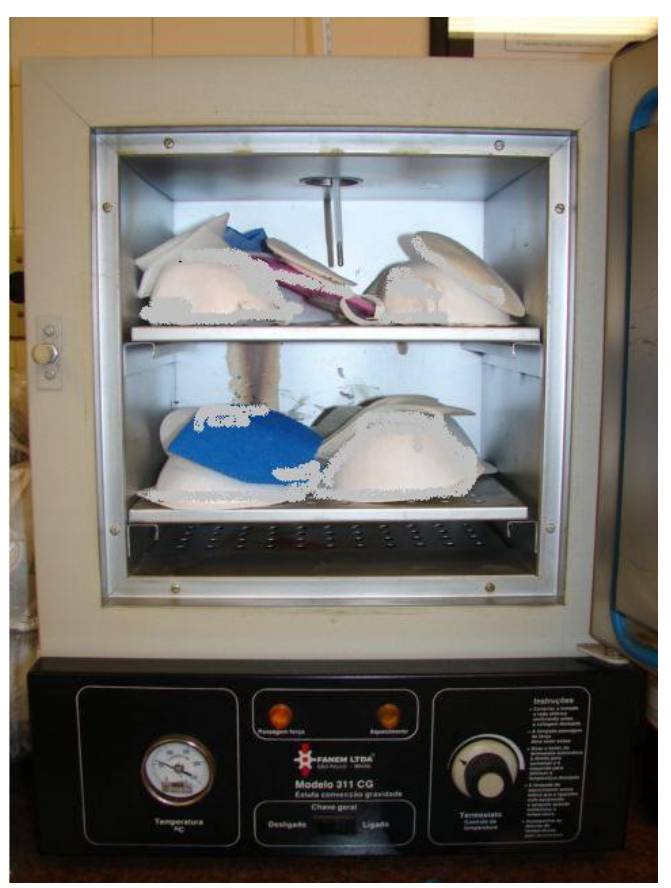

Figura 43 - Posicionamento dos filtros no interior da estufa. 
Com o objetivo de verificar quantificar as diferenças de temperaturas em diferentes pontos dentro da estufa, foram feitas 12 medições em pontos distintos do interior da estufa (figura 44).

As medições foram feitas utilizando - se um medidor de temperatura por infravermelho sem contato, modelo ST60 Pro Plus ${ }^{\mathrm{TM}}$ do fabricante Raytek.

As medidas das temperaturas foram feitas imediatamente após a abertura da porta, evitando deste modo o decaimento da temperatura devido a troca de calor com o ambiente a cada vez que a porta foi aberta. Os intervalos entre as medições foram de duas horas, garantindo assim a homogeneização da temperatura no interior da estufa após a abertura da porta.

As temperaturas medidas em cada ponto foram as seguintes:

Ponto $1=74,8^{\circ} \mathrm{C}$, Ponto $2=73,4^{\circ} \mathrm{C}$, Ponto $3=73,9^{\circ} \mathrm{C}$, Ponto $4=71,2^{\circ} \mathrm{C}$, Ponto $5=$ $70,8^{\circ} \mathrm{C}$, Ponto $6=71,8^{\circ} \mathrm{C}$, Ponto $7=72,8^{\circ} \mathrm{C}$, Ponto $8=71,8^{\circ} \mathrm{C}$, Ponto $9=72,3^{\circ} \mathrm{C}$, Ponto $10=69,8^{\circ} \mathrm{C}$, Ponto $11=67,8^{\circ} \mathrm{C}$, Ponto $12=67,7^{\circ} \mathrm{C}$.

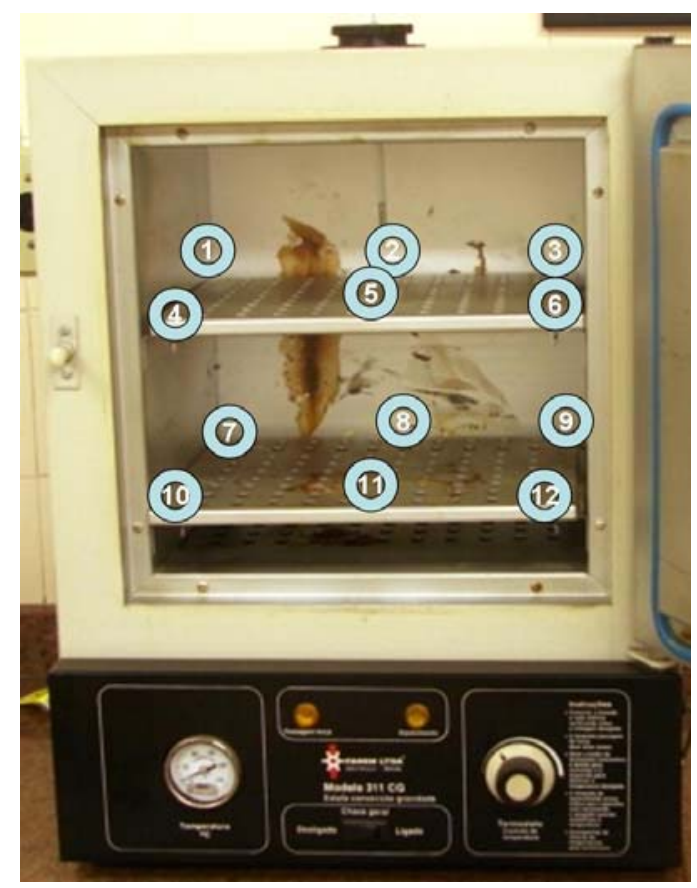

Figura 44 - Medição da temperatura em diferentes pontos no interior da estufa. 
O maior gradiente térmico encontrado foi de $7,1^{\circ} \mathrm{C}$, atendendo deste modo, no mínimo, a temperatura para condicionamento como definido nas normas brasileiras e européias (tabela 3 ). 


\section{RESULTADOS}

\subsection{ESTUDO PRELIMINAR}

Com o objetivo de determinar as faixas de temperatura a serem utilizadas na pesquisa e a aplicação ou não da umidade no experimento, foi conduzido um estudo preliminar onde as amostras foram submetidas à alta temperatura por pouco espaço de tempo e com alta umidade.

A consulta à bibliografia também norteou a decisão dos parâmetros que foram utilizados na pesquisa.

Vários pesquisadores, como segue, têm estudado e medido a eficiência de filtros mecânicos, sejam eles montados em um respirador ou sendo o próprio respirador constituído de um filtro. É o caso das peças faciais filtrantes (PFF).

Segundo Brown (1993), o efeito da temperatura e umidade em conjunto, aplicado sobre materiais sensíveis à umidade, pode ser consideravelmente maior do que quando aplicados separadamente. O autor também descreve que o estudo da influência da temperatura e umidade pode não ser completo, pois a natureza química dos polímeros pode alterar com a temperatura, afetando a taxa da perda da carga.

Estudos realizados em filtros novos expostos à névoa de óleo, alta umidade em temperatura ambiente e alta temperatura, demonstraram que alguns filtros expostos à alta temperatura e umidade simultaneamente, exerceram uma influência significativa na eficiência de filtração. Testes onde os filtros foram expostos à alta umidade somente, não representou variações significativas na penetração (Ortiz, et al.,1988)

Segundo Cheng, et al. (2006), a penetração de fibras de asbesto em filtros mecânicos armazenados durante uma semana à temperatura de $38^{\circ} \mathrm{C}$ e umidade de 
$90 \%$, aumentou de 0 a $3 \%$ para $20 \%$. Os únicos filtros que mantiveram a performance constante, independente das condições de teste, foram os filtros de alta eficiência High Efficiency Particulate Air (HEPA). Alguns filtros constituídos de material de baixa condutividade podem conter cargas eletrostáticas. Estas cargas podem ser perdidas sob condições de alta temperatura e alta umidade.

Os estudos de Motyl e Lowkis (2006) demonstram os resultados de testes comparativos entre amostras de mídias filtrantes tipo P1 e P2. Onde as amostras foram submetidas a diversas condições de umidade, medindo o decaimento da carga das mesmas, as mantas P2 apresentaram uma vida útil maior, em termos de manutenção das cargas eletrostáticas em comparação com a manta P1.

Estudos baseados na certificação americana, conforme a norma 42 CFR 84 (ESTADOS UNIDOS, 1995) que classifica os filtros mecânicos em função do tipo de aerossol a qual este será exposto, constatou que apesar de ser muito improvável que ocorra a degradação total da carga eletrostática do filtro exposto ao ambiente de trabalho, não dá para se descartar a possibilidade de um certo grau de degradação ocorrer em função do uso diário, armazenamento em condições adversas ou, mais importante ainda, a exposição a aerossóis industriais. Finalmente, concluem que estudos adicionais necessitam ser realizados nesta área para avaliar estas possibilidades (MARTIN e MOYER, 2000).

Outras publicações demonstram que variações da temperatura acima de $90^{\circ} \mathrm{C}$ e até $110^{\circ} \mathrm{C}$ tinham, como conseqüência, um aumento da penetração com uma estabilização da eficiência após períodos de aproximadamente 10 a 30 horas de exposição (BROWN, 1989)

As normas de aprovação americanas, européia e brasileiras para filtros para particulados, definem condições de pré-condicionamento dos filtros antes de testálos contra a penetração. A tabela 3 fornece uma comparação destas condições. 
Tabela 3 - Comparação entre normas EN 143/149, 42 CFR 84 e NBR 13697/13698 e requisitos de pré-condicionamento com relação à temperatura e umidade relativa (UR).

\begin{tabular}{|c|c|c|c|c|c|}
\hline Classe filtro & EN 143 & EN 149 & 42 CFR 84 & NBR 13697 & NBR 13698 \\
\hline P1, P2, P3 & $24 \mathrm{~h} \times 70^{\circ} \mathrm{C}$ & & & $24 \mathrm{~h} \times 65^{\circ} \mathrm{C}$ & \\
& $\begin{array}{c}24 \mathrm{~h} \times-30^{\circ} \mathrm{C} \\
\text { UR: seco }\end{array}$ & & & $24 \mathrm{~h} \times-15^{\circ} \mathrm{C}$ & \\
& & & & \\
UR: seco & \\
N95, P100 & & & $25 \mathrm{~h} \times 38^{\circ} \mathrm{C}$ & & \\
& & UR: 85\% & & \\
PFF1, PFF2, & & $24 \mathrm{~h} \times 70^{\circ} \mathrm{C}$ & & & $24 \mathrm{~h} \times 65^{\circ} \mathrm{C}$ \\
PFF3 & & $24 \mathrm{~h} \times-30^{\circ} \mathrm{C}$ & & & $24 \mathrm{~h} \times-15^{\circ} \mathrm{C}$ \\
& & UR: seco & & & UR: seco \\
\hline
\end{tabular}

Lowkis e Motyl (2001) concluem em seu estudo que a vida útil de elementos filtrantes fabricados com PP varia de acordo com o tipo de configuração e tipo de manta do material filtrante, constatando que a vida útil dos filtros classe P2 foi duas vezes maior que para o filtro P1.

Além dos resultados encontrados na literatura, foi constatado nos testes preliminares, evidências da degradação da carga eletrostática mediante a exposição à temperatura e/ou umidade. Isto foi observado testando-se a penetração inicial antes de submeter a amostra ao condicionamento específico e a cada período de exposição (tabela 4).

Foram pré-selecionados 6 fabricantes identificados na tabela 4 de "A" a " $F$ "; amostras do mesmo fornecedor mas de classe diferente foram identificadas com a letra correspondente do fabricante, acrescido do número 1, exemplo: "A1".

A umidade indicada como "ambiente" na tabela 4 é referente à umidade no ambiente do laboratório e variou durante o experimento entre 50 a 60\%. 
Tabela 4 - Medição da penetração em função da temperatura, tempo de exposição e umidade.

\begin{tabular}{|c|c|c|c|c|c|c|}
\hline Fabricante & Classe & $\begin{array}{c}\text { Penetração } \\
\text { inicial (\%) }\end{array}$ & $\begin{array}{c}\text { Temp. } \\
\left.\text { ( }{ }^{\circ} \mathbf{C}\right)\end{array}$ & Umidade \% & Tempo & $\begin{array}{c}\text { Penetração } \\
\text { após } \\
\text { exposição (\%) }\end{array}$ \\
\hline A & PFF2 & 0,203 & 110 & ambiente & 12 horas & 3,6 \\
A & PFF2 & 0,195 & 110 & ambiente & 12 horas & 10,3 \\
A & PFF2 & 0,924 & 100 & ambiente & 1 hora & 1,92 \\
A1 & PFF1 & 10,4 & 100 & ambiente & 1 hora & 13,8 \\
A & PFF2 & 0,12 & 22 & $*$ & 1 minuto & 16,7 \\
A & PFF2 & 1,94 & 22 & $*$ & 1 minuto & 36,9 \\
$A^{\star *}$ & PFF2 & 0,35 & 80 & 85 & 12 horas & 1,7 \\
$A^{\star *}$ & PFF2 & 0,35 & 80 & 85 & 32 horas & 2,16 \\
$A^{* *}$ & PFF2 & 0,35 & 80 & 85 & 64 horas & 2,68 \\
$A^{\star *}$ & PFF2 & 0,35 & 80 & 85 & 94 horas & 2,77 \\
B & P2 & 1 & 100 & ambiente & 1 hora & 1,04 \\
B1 & P1 & 8 & 100 & ambiente & 1 hora & 9,14 \\
B1 & P1 & 15,7 & 126 & ambiente & 1 hora & 16,9 \\
C & P1 & 7,2 & 100 & ambiente & 1 hora & 8,85 \\
D & P2 & 3,51 & 100 & ambiente & 1 hora & 9,67 \\
E & PFF2 & 0,182 & 118 & ambiente & 1 hora & 4,41 \\
E & PFF2 & 0.422 & 100 & ambiente & 1 hora & 1,67 \\
F & P2 & 0,462 & 113 & ambiente & 1 hora & 1,87 \\
F & P2 & 0,958 & 113 & ambiente & 1 hora & 1,39 \\
F & P2 & 0,624 & 113 & ambiente & 1 hora & 2 \\
F & P2 & 0,466 & 113 & ambiente & 1 hora & 0,356 \\
\hline
\end{tabular}

* Filtro foi mergulhado em álcool isopropílico (isopropanol).

** Mesmo filtro testado a cada intervalo de tempo como indicado na coluna "Tempo".

Os filtros foram condicionados em estufa com e sem a presença de umidade. A umidade foi criada mediante a colocação de beckers com água destilada no interior da estufa.

\subsection{DEFINIÇÃO DE PARÂMETROS PARA NOVOS TESTES}

Nos testes prévios, verificou-se uma diferença significativa na eficiência dos filtros após exposição à temperatura elevada, assim como, o efeito da isopropanol para remoção das cargas elétricas das fibras.

Tentou-se também manter um ambiente úmido e controlado dentro da estufa, porém, devido o tamanho reduzido da mesma e da grande dimensão do aparato 
necessário para manter a umidade, por exemplo, um dessecador, tornou-se muito difícil e até impraticável proceder com este condicionamento.

Outra dificuldade foi a de manter o monitoramento constante da unidade com o uso dos métodos de medição de umidade disponíveis, termohigromêtro digital e método do bulbo seco bulbo úmido, este último não foi possível usar também em função do tamanho da estufa. Deste modo, decidiu-se não se considerar a umidade como variável no estudo, ficando somente a variável temperatura versus tempo como base da pesquisa.

Os parâmetros e conduta na continuidade dos testes foram adotados com base nos resultados obtidos por outros pesquisadores, nas exigências normativas e na observação dos resultados dos testes preliminares e nas possíveis condições de temperatura encontradas em ambiente de mineração.

Devido à grande variação de resultados entre as amostras de fabricantes diferentes, decidiu-se coletar uma quantidade maior de amostras, com maior variação de fabricantes de filtros. Um total de 26 amostras de 8 fabricantes distintos foram submetidas ao condicionamento e teste de penetração. A tabela 5 detalha os tipos de amostras.

A temperatura inicial ficou definida em $75^{\circ} \mathrm{C}$ e o intervalo entre as medições, em 24 horas. O período total de testes teve a duração de 264 horas.

Após a constatação de uma tendência de estabilização, a temperatura deveria ser elevada para $90^{\circ} \mathrm{C}$ e novamente até $110^{\circ} \mathrm{C}$, seguindo a temperatura utilizada por Brown (1989) em seu experimento.

Foram separados 4 filtros para servirem de controle. As amostras de controle foram escolhidas após serem testadas todas as 26 amostras previamente selecionadas.

Após os primeiros testes, foram selecionadas três amostras que apresentaram os menores resultados de penetração inicial (do mesmo fabricante) e, mais três amostras de outro fabricante que apresentaram os maiores resultados de 
penetração inicial. De cada um desses grupos, retirou-se duas amostras que foram mergulhadas em isopropanol (álcool isopropílico), por 10 minutos, e secas ao ar livre. A última amostra de cada grupo era mantida como controle. Todas as amostras foram medidas quanto à penetração e resistência, antes e depois do procedimento. As amostras de controle passaram a ser testadas nos mesmos intervalos das outras, porém, não foram expostas à temperatura. As amostras mergulhadas em isopropanol, que representam os filtros mais e menos eficientes, também passaram a ser condicionadas em temperatura elevada, juntamente com as outras amostras.

\subsection{DESCRIÇÕES DAS AMOSTRAS USADAS NOS TESTES FINAIS}

As amostras enumeradas a seguir são referentes às indicadas na tabela 5.

1 a 4. PFF, onde o elemento filtrante é composto de uma camada interna e duas camadas externas de gramaturas diferentes, sendo que estas não influenciam na eficiência de filtração.

5 a 8 e 11 a 14. Filtro plano utilizado em máscaras elastoméricas O elemento filtrante é composto de uma camada interna e das camadas externas de gramaturas diferentes, sendo que uma delas influencia na eficiência de filtração.

9 a 10. Filtro plano utilizado em máscaras elastoméricas. O elemento filtrante é composto de uma camada interna e das camadas externas de gramaturas idênticas, sendo que estas não influenciam na eficiência de filtração.

15 a 16. PFF, onde o elemento filtrante é composto de uma camada interna e das camadas externas de gramaturas idênticas, as quais não influenciam na eficiência de filtração.

17 a 26. PFF, onde o elemento filtrante é composto de duas camadas internas de mesma gramatura e das camadas externas, também de gramaturas idênticas, e que não influenciam na eficiência de filtração. 
A tabela 5 detalha os tipos e quantidades de amostras de filtros comerciais utilizados no experimento.

Tabela 5 - Quantidades e tipos de filtros utilizados. Fonte: Arquivo pessoal.

\begin{tabular}{|l|c|c|c|c|c|}
\hline Fabricantel Amostras & Qtd. & Tipo & Descrição & Classe & Norma \\
\hline A - 1 e 2 & 2 & Dobrável & 1 & P1 & EN / NBR \\
B - - e 4 & 2 & Dobrável & 2 & P1 & EN / NBR \\
C-5 a 8 & 4 & Plano & 3 & N95 & 42 CFR \\
D - - e 10 & 2 & Plano & 4 & P1 & EN / NBR \\
C - 11 a 14 & 4 & Plano & 5 & N95 & 42 CFR \\
D - 15 e 16 & 2 & Moldado & 6 & P1 & EN / NBR \\
E - 17 a 21 & 5 & Moldado & 7 & P2 & EN / NBR \\
D-22 a 26 & 5 & Moldado & 8 & N95 & 42 CFR \\
\hline
\end{tabular}

\subsection{RESULTADOS DOS TESTES}

Amostras de diferentes fabricantes foram obtidas no mercado. Após a seleção e identificação, iniciaram-se os testes conforme planejamento pré-estabelecido. Os resultados dos testes podem ser observados nos gráficos 1 e 2 a seguir.

A repetibilidade do equipamento de teste e dispositivo de fixação das amostras foram verificados mediante a repetição completa dos testes nas mesmas amostras, por 10 vezes consecutivas, comparando-se a variação da penetração e da resistência (gráficos 1 e 2). Também se observou o aumento da resistência à inalação, o qual já foi estudado e indicado por Chen, et al. (1993), Barrett (1998), Moyer e Bergman (2000). Observou-se, também, um pequeno aumento da eficiência com o aumento significativo da resistência. 


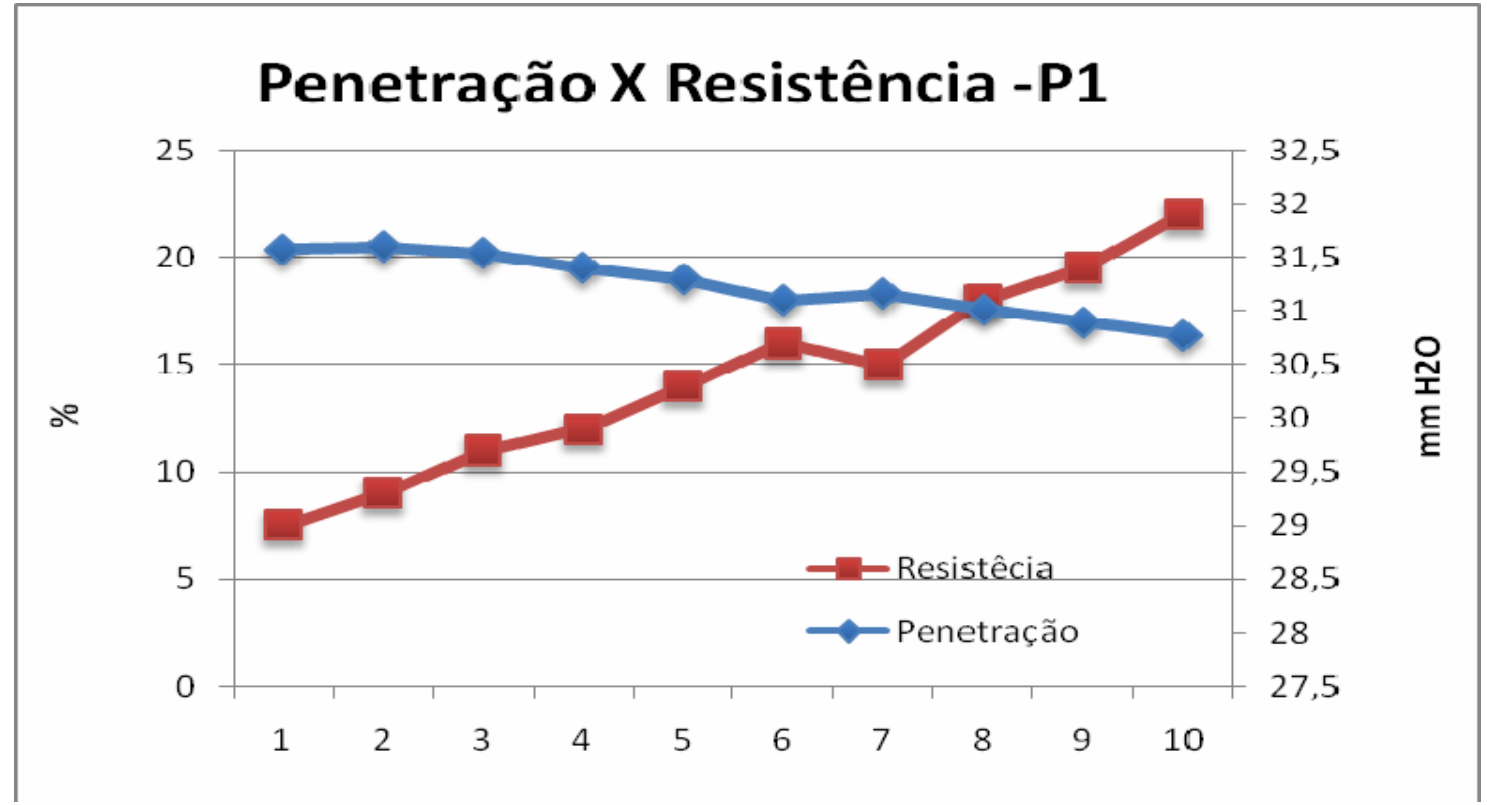

Gráfico 1 - Variação da penetração e perda de carga em amostras de filtros classe P1 testadas 10 vezes consecutivas.

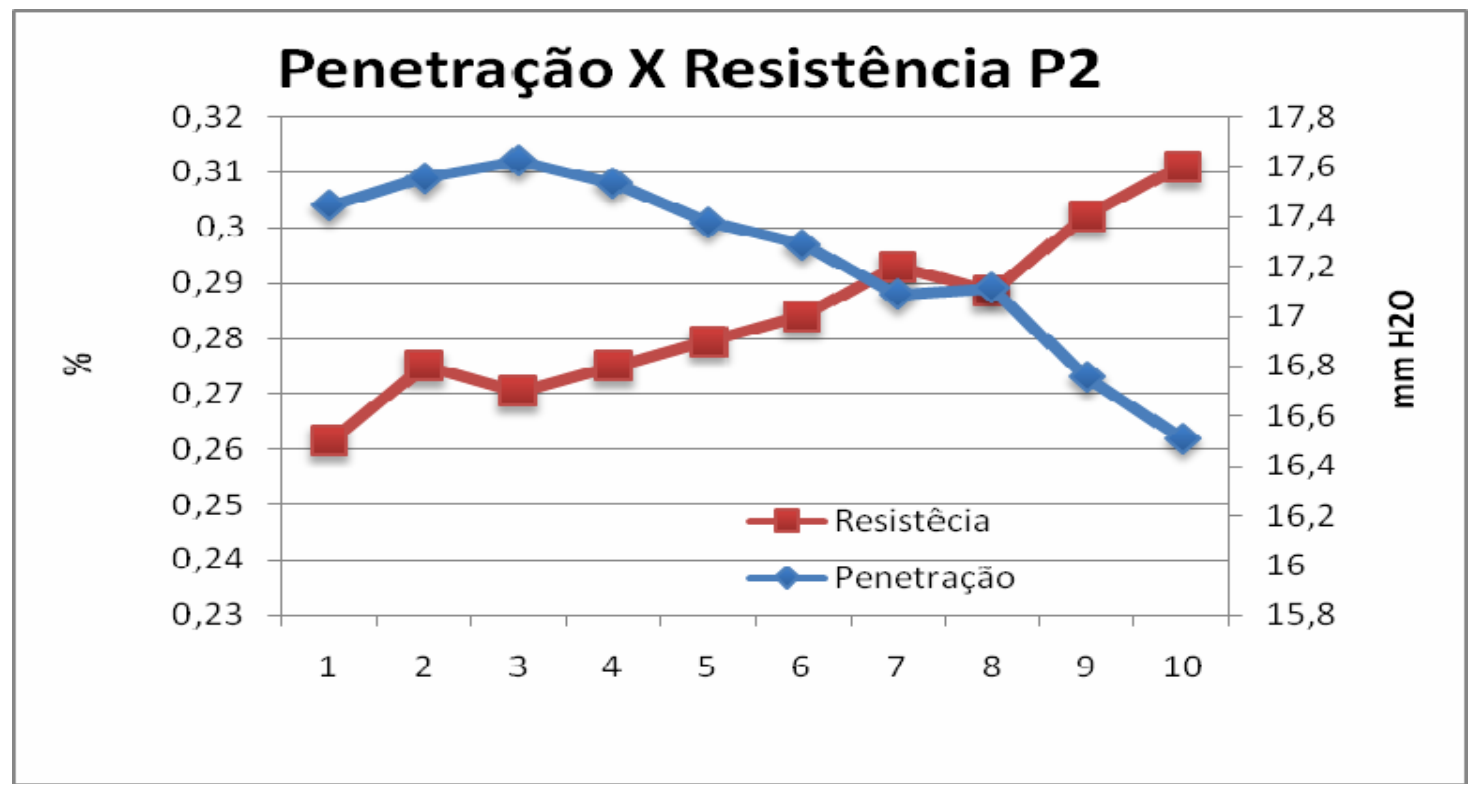

Gráfico 2 - Variação da penetração e perda de carga em amostras de filtros classe P2 testadas 10 vezes consecutivas.

Além deste procedimento, também foram utilizados dois filtros controle, testados nos mesmos intervalos das amostras expostas à alta temperatura (gráfico 3). A variação da penetração mostrou-se insignificante, confirmando a repetibilidade do equipamento de teste. 


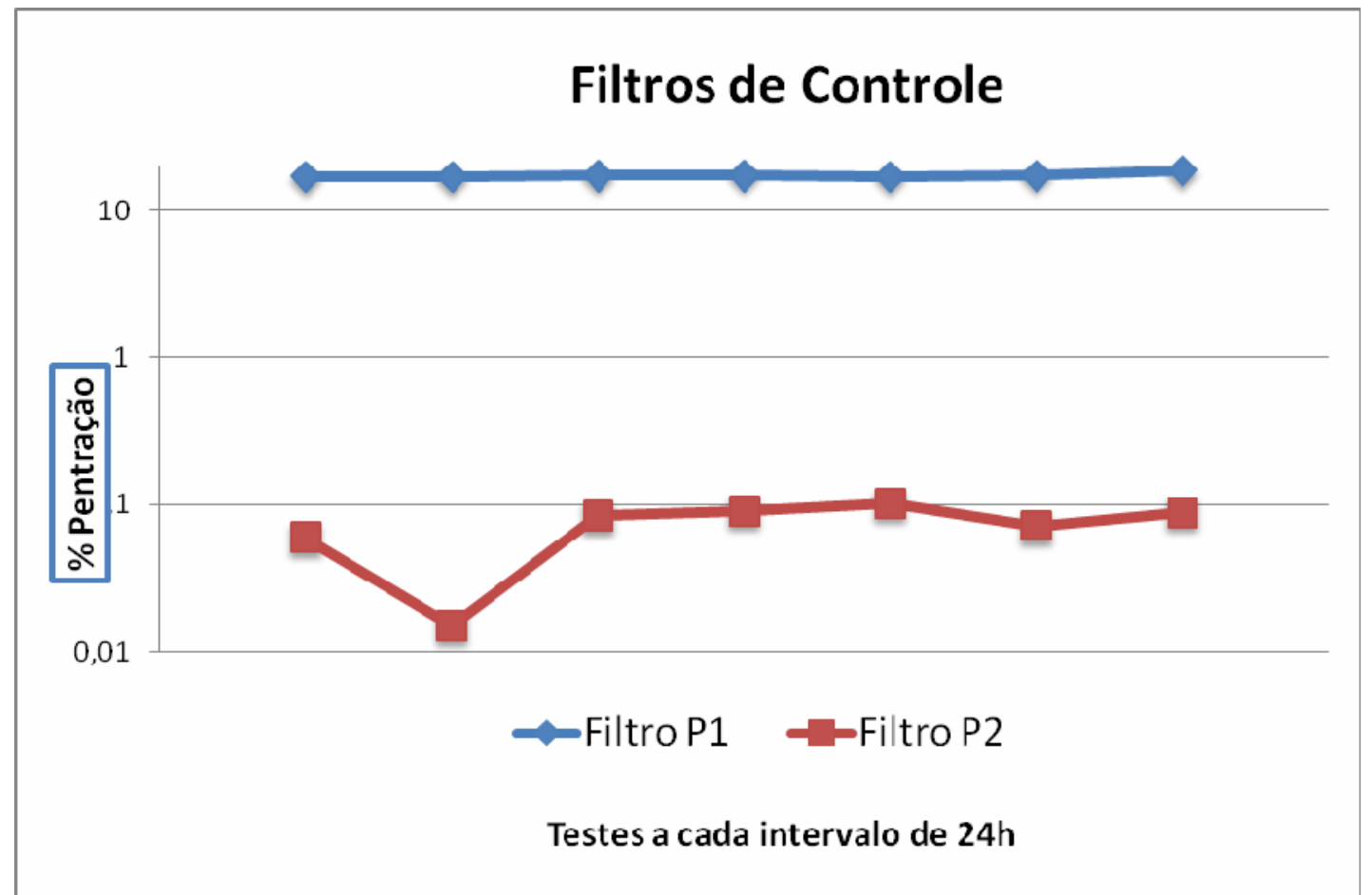

Gráfico 3 - Filtros de controle testados nos mesmos intervalos das primeiras 7 medições. Para melhor visualização foi utilizada escala logarítmica para a \% de penetração.

A penetração foi medida antes e depois da remoção da carga eletrostática com o uso do isopropanol. Após esta medição teste, as mesmas amostras foram expostas à temperatura de $75^{\circ} \mathrm{C}$ e passaram a ser monitoradas a cada 24 horas, num total de 168 horas. O objetivo era observar a variação da penetração com um filtro supostamente isento de carga eletrostática.

Outros estudos demonstram que o isopropanol possui a capacidade de remover as cargas eletrostáticas das fibras (CHEN, HUANG, 1998; MARTIN, MOYER, 2000). Este teste simples demonstra claramente o papel da carga eletrostática na captura das partículas.

Observou-se que o filtro classe PFF2 (amostras 1 e 2) do fabricante 8 (gráfico 4) apresentou maior dificuldade na remoção total das cargas eletrostáticas pelo uso do isopropanol. Constatou-se que, ao longo do tempo, o filtro mantido à temperatura de $75^{\circ} \mathrm{C}$ durante 48 horas apresentou um aumento na penetração de $0,2 \%$ para $23 \%$, variando ainda, nas 24 horas subseqüentes, em mais 13\% (gráfico 4). 
A preocupação em saber se a temperatura estaria interferindo na estrutura, ligação ou geometria das fibras e alterando o comportamento dos outros mecanismos de captura das partículas, foi sanada por meio deste experimento, visto que, após a remoção da carga eletrostática, a temperatura e o tempo não exercem influência significativa na eficiência dos filtros.

Jasper (2007), em seu estudo da influência do etil benzeno na degradação da performance de filtração de elementos filtrantes tipo eletreto carregados por efeito corona, observou que a degradação somente ocorre quando o etil benzeno, no estado líquido, entra em contato direto com as fibras. Não há variação significante na exposição a vapores deste. Segundo ele, a causa desta degradação é a criação de uma fina camada líquida do etil benzeno sobre a superfície das fibras carregadas do polímero, confirmando a perda da carga eletrostática por agente químico.

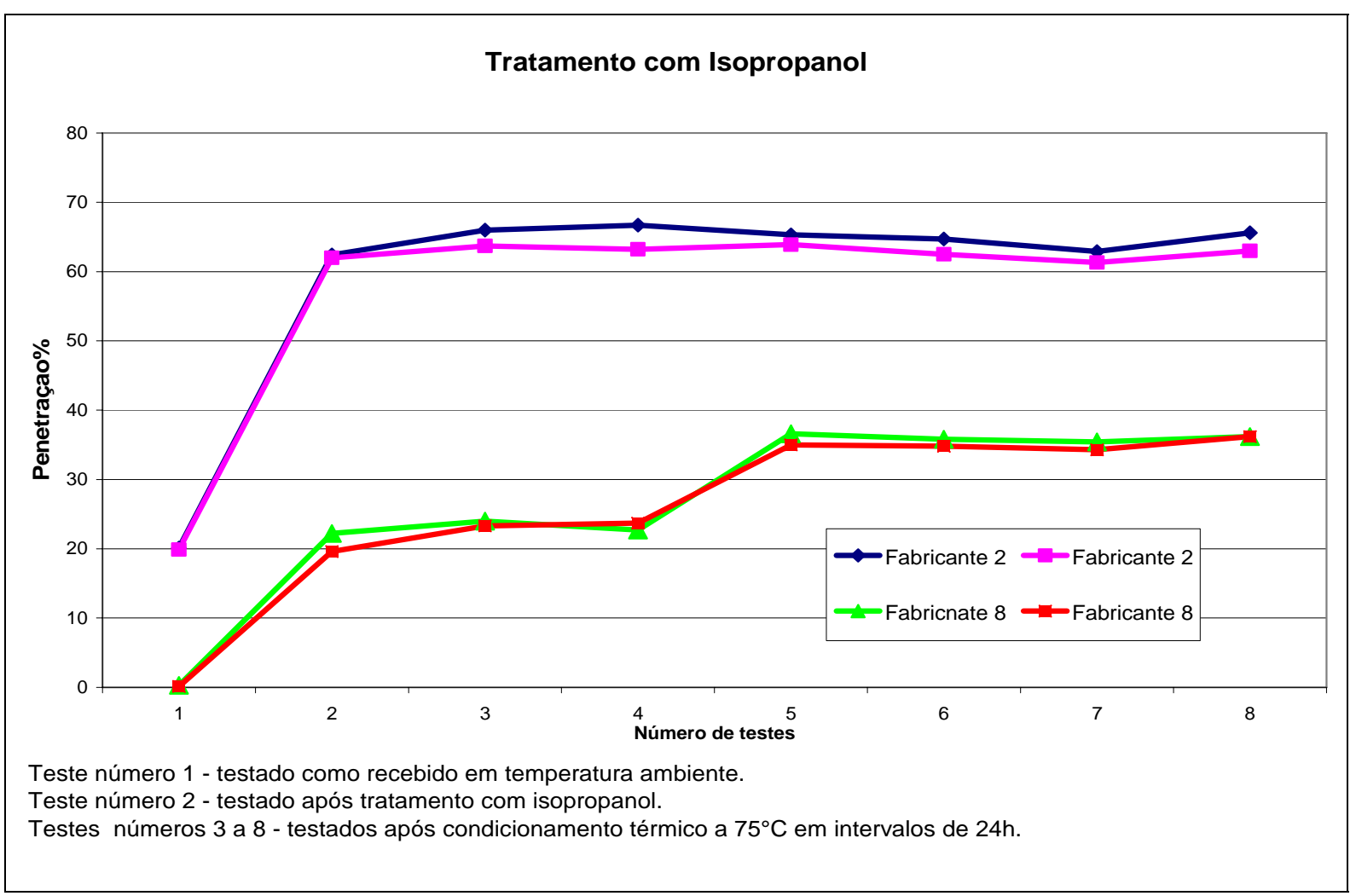

Gráfico 4 - Amostras condicionadas a $75^{\circ} \mathrm{C}$ depois de mergulhadas em isopropanol. Filtros do fabricante 2 são classe P1 e do fabricante 8 são classe P2. 
As 26 amostras selecionadas foram medidas antes e após condicionamento em temperatura elevada. Foram condicionadas e testadas em intervalos de 24 horas, em um período total de 264 horas, 11 dias.

Exceto as amostras de 1 a 4 que, devido à geometria, tiveram que ser cortadas para poderem ser montadas nos dispositivos de fixação, todas as amostras foram testadas utilizando-se dispositivos que permitiam uma exposição de $100 \%$ da área filtrante contra névoa de $\mathrm{NaCl}$.

A vazão utilizada nos testes foi de $85 \mathrm{l} / \mathrm{min}$.

Nos primeiros oito dias (168h) as amostras permaneceram a $75^{\circ} \mathrm{C}$ (gráfico 5). Após o décimo oitavo dia até o décimo primeiro dia a temperatura da estufa foi elevada em $25^{\circ} \mathrm{C}$ permanecendo em $90^{\circ} \mathrm{C}$. Após o décimo primeiro dia a temperatura foi elevada para $110^{\circ} \mathrm{C}$ permanecendo nesta temperatura por 24 horas (gráficos 6 e 7). 


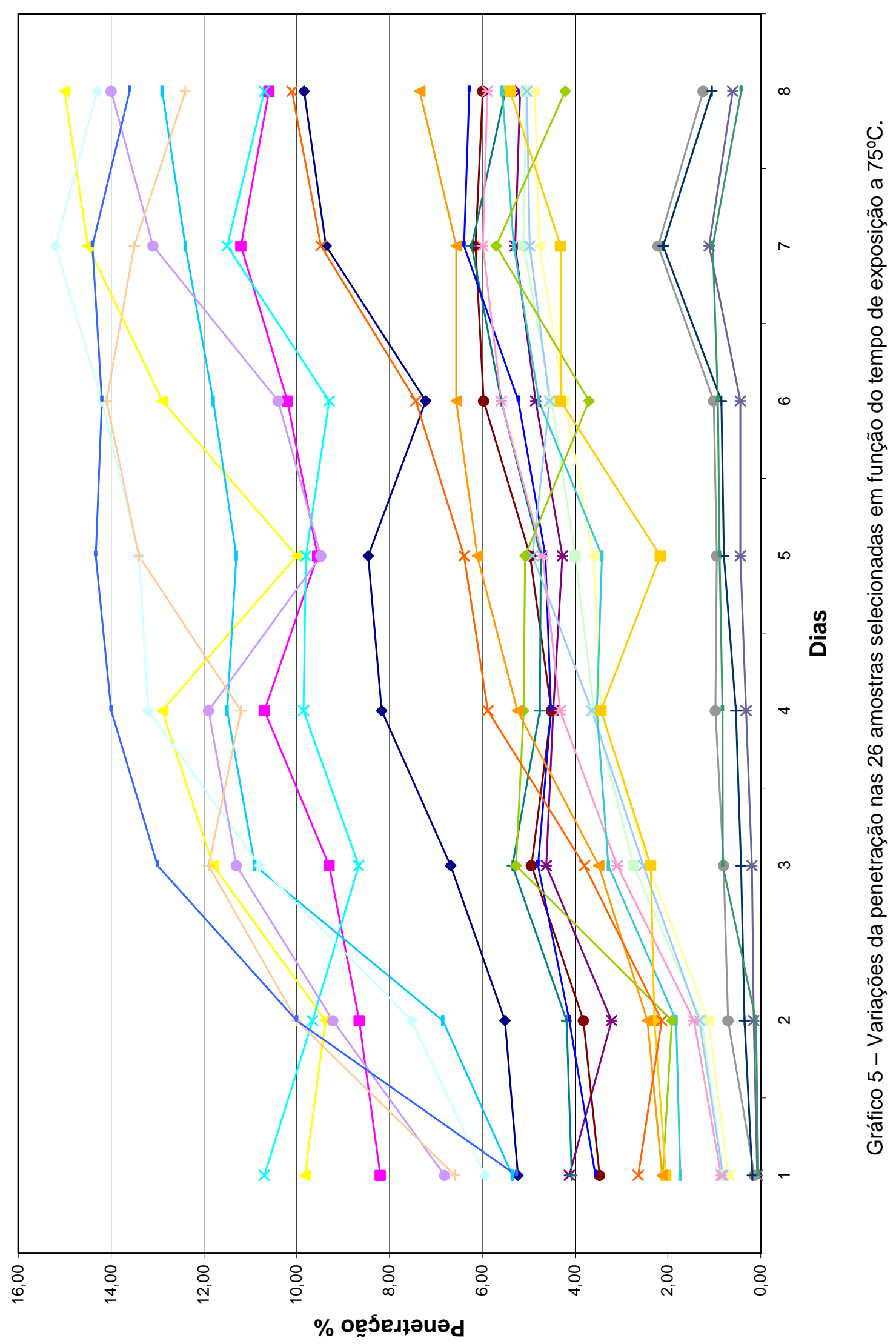




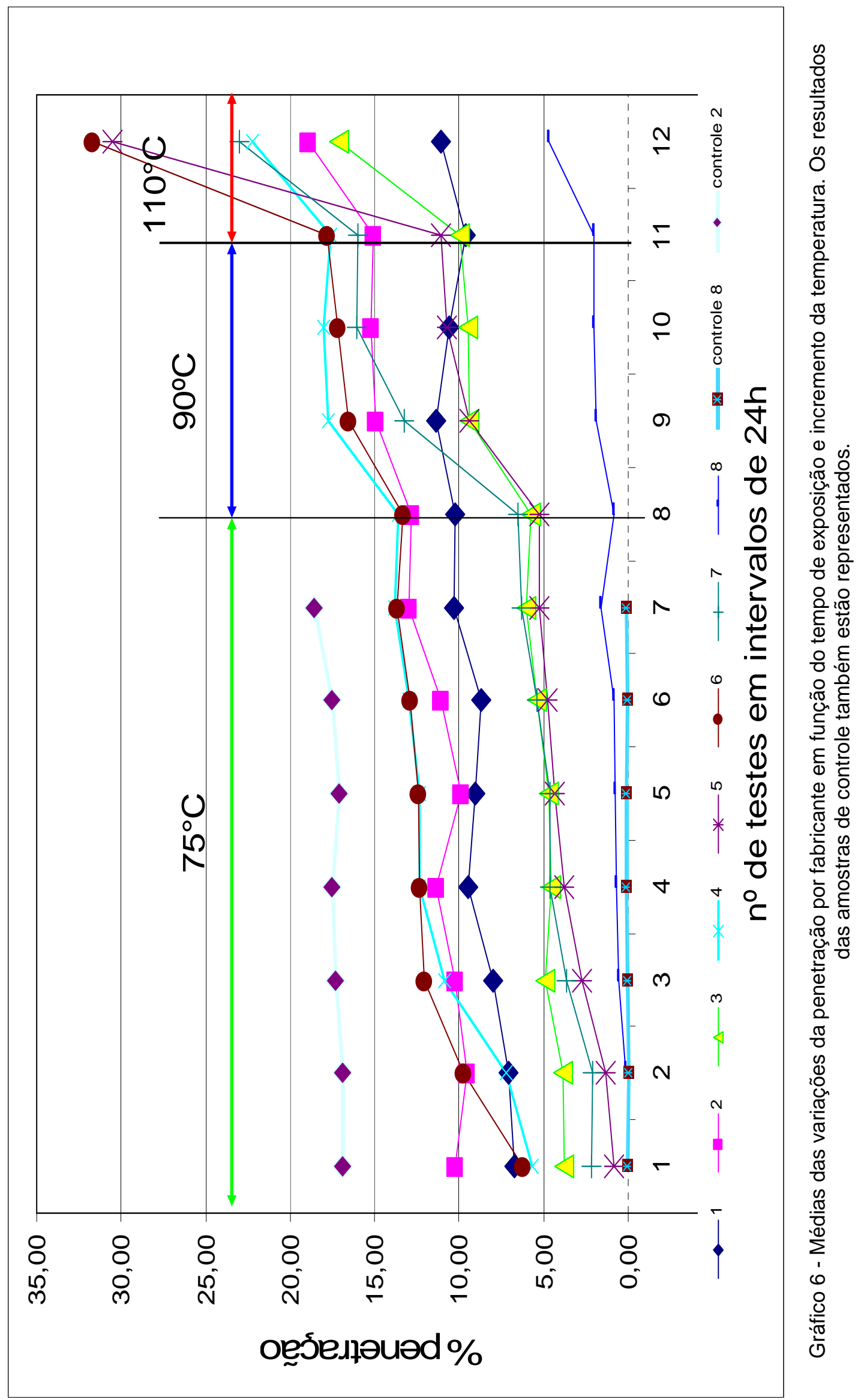




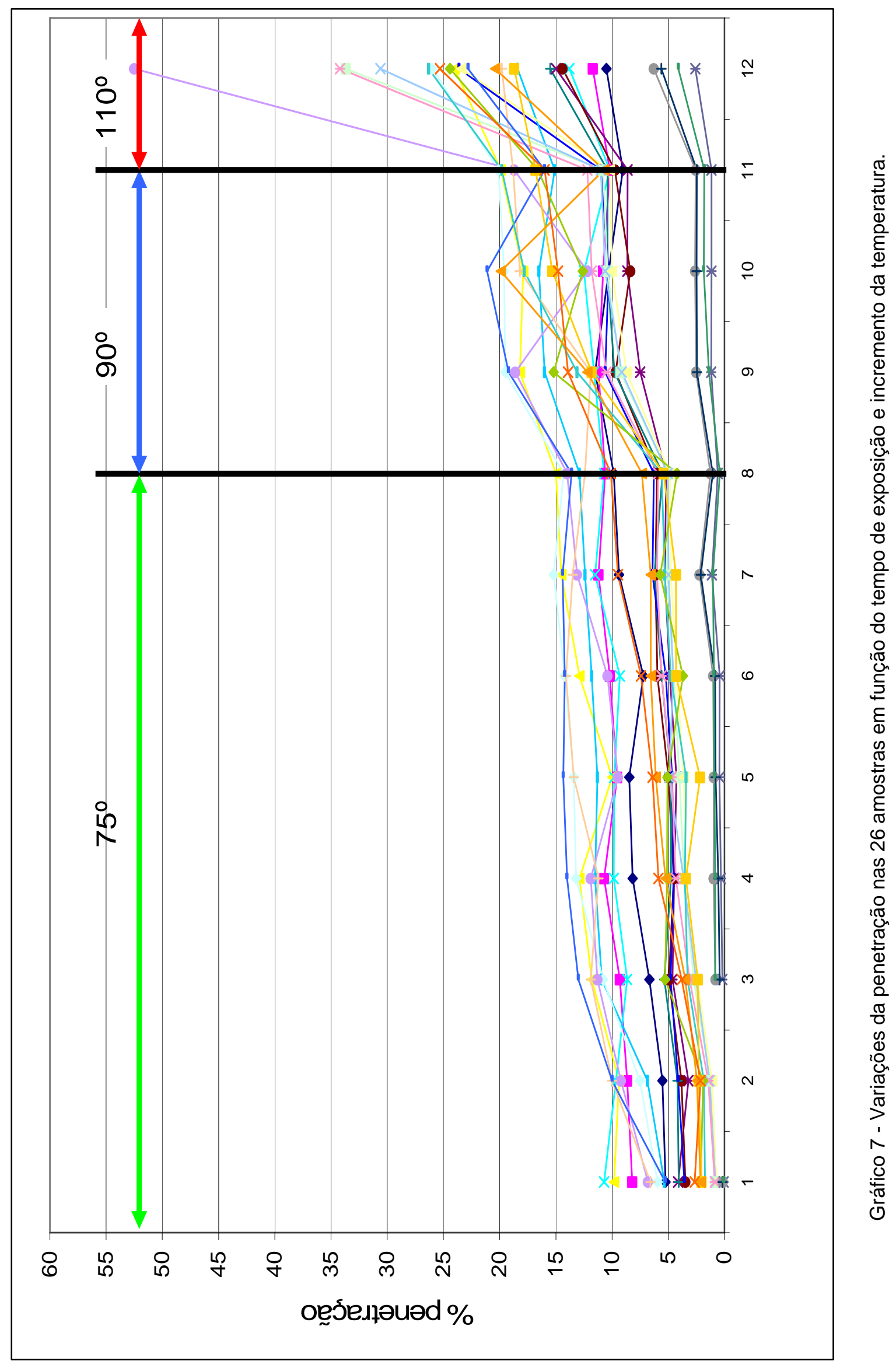


Simultaneamente às medições de penetração, foram também medidas as resistências a cada teste realizado. Como esperado, não houve variação significativa nos resultados ao longo do tempo, em temperaturas elevadas (gráfico 8).

A variação dos resultados de penetração foi de 2,53\% até 18\%, demonstrando uma variação considerável na eficiência de filtros de um para outro fabricante. A diferença entre o menor e maior valor foi calculada considerando a primeira medição de penetração de cada filtro testado antes do condicionamento e a última medição feita após o condicionamento à $90^{\circ} \mathrm{C}$ (gráfico 9). 


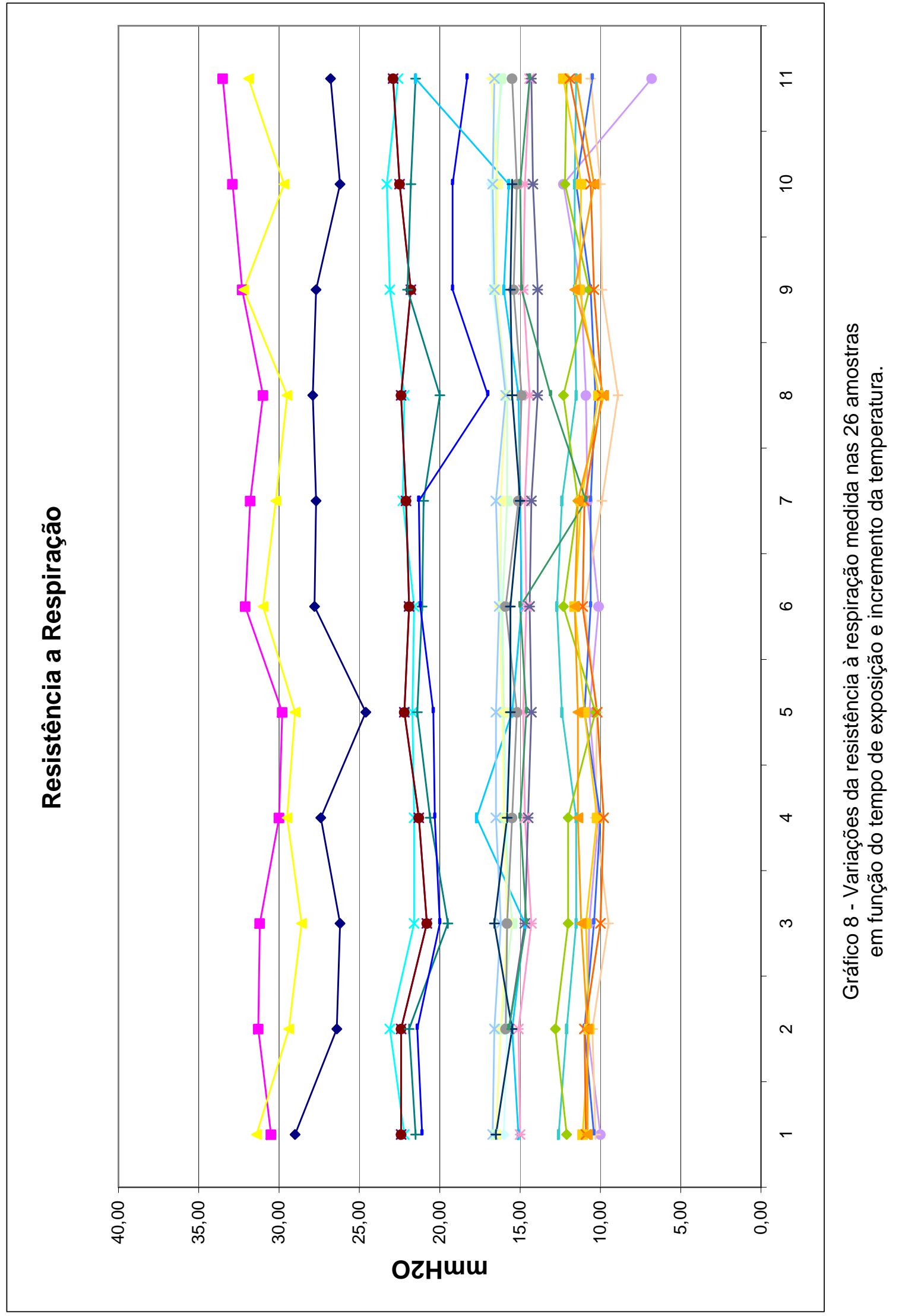




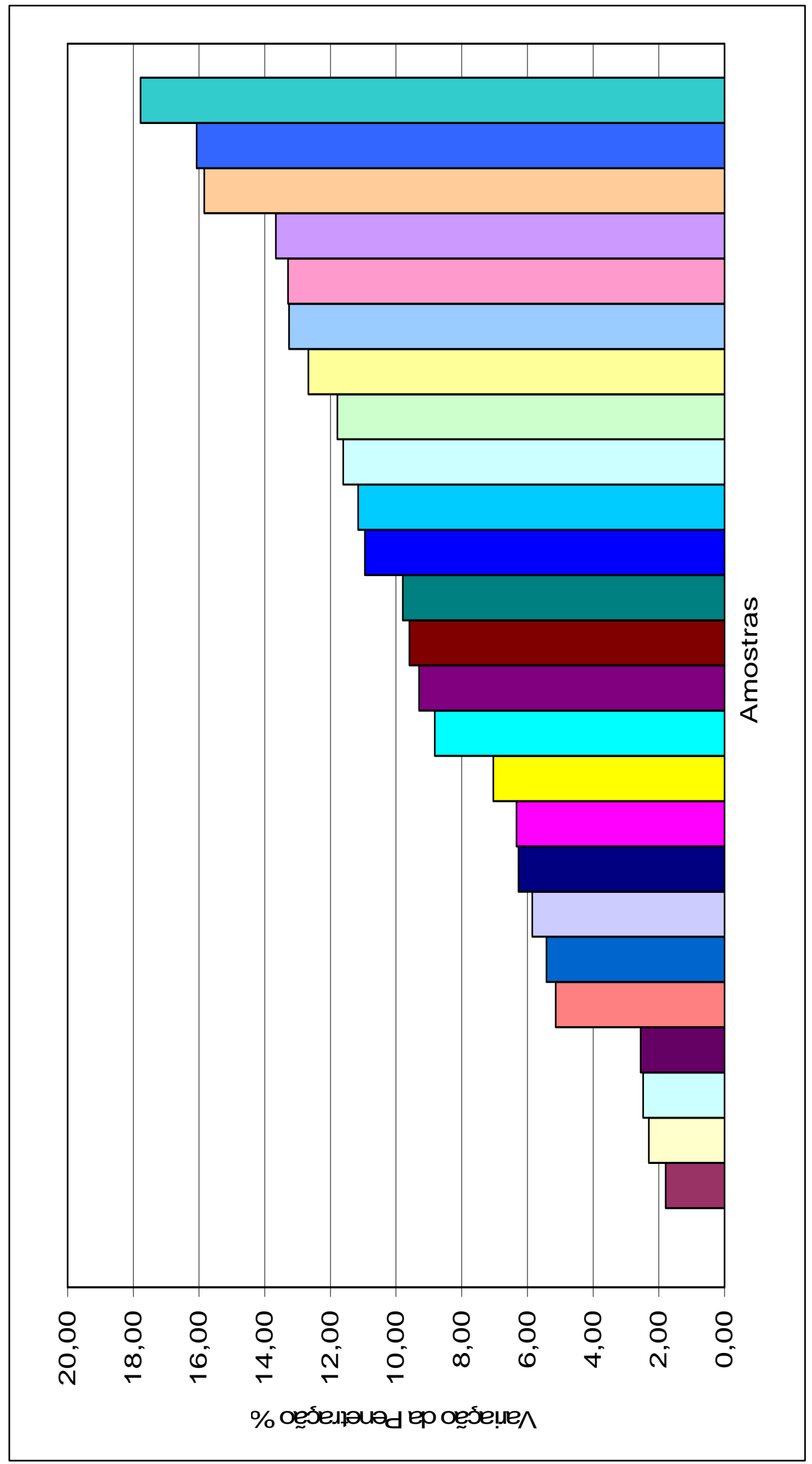




\section{DISCUSSÃO}

Buscando verificar a influência da temperatura na perda da eficiência dos filtros eletretos ou eletrostáticos, foram realizados testes simulando as condições térmicas possíveis de serem encontradas em ambiente de mineração.

Foram utilizadas as seguintes temperaturas: $75^{\circ} \mathrm{C}, 90^{\circ} \mathrm{C}$ e $110^{\circ} \mathrm{C}$.

As normas de aprovação, tanto nacionais como internacionais, prevêem o condicionamento térmico por períodos curtos (máximo 24 horas), visando verificar o efeito da temperatura na penetração dos filtros contra particulados e, conseqüentemente, definir a aprovação destes.

Contudo, segundo Brown (1993), com relação a testes rápidos, as taxas de perda de eficiência em curtos e longos períodos de tempo são bem diferentes, indicando que o ideal seria uma situação em que a vida útil da carga do filtro fosse avaliada com testes rápidos. Infelizmente, devido à complexidade do padrão da perda de carga, é difícil prever o comportamento do material exposto às condições moderadas durante um período prolongado, baseando-se em testes conduzidos em condições severas por um período curto de tempo.

Vários autores declaram, em seus estudos, a diminuição da capacidade de filtração em função da perda das cargas eletrostáticas, seja por efeito da temperatura, recobrimento da fibra por óleo, contato com substâncias químicas, exposição à radiação ionizante ou carregamento intermitente de $\mathrm{NaCl}$.

Todos os artigos referentes aos filtros ou elementos filtrantes, onde o principal mecanismo de captura das partículas se dá por atração eletrostática, afirmam que estes filtros possuem alta eficiência de filtração e baixa perda de carga. Isto ocorre devido ao grande espaço que existe entre as fibras que compõem o elemento fitrante, oferecendo, desta forma, uma baixa resistência à passagem do ar inalado. Esse fato gera mais conforto para o usuário e uma vida útil maior para a máscara. 
Com relação às partículas presentes em ambiente de mineração e seu risco ocupacional, Capitani (2006) declara que a silicose continua sendo a pneumoconiose mais prevalente no Brasil e no resto do mundo. Esta doença ocupacional ocorre, principalmente, nos ramos de atividade profissional como mineração em geral, metalurgia, cerâmica de porcelana e pisos. Isto se dá pela dificuldade da eliminação da exposição à poeira nestes ambientes de trabalho.

Camargo (2007) cita que grande parte da produção de carvão se dá em minas subterrâneas e que, devido à sua toxidade, muito tem se pesquisado a esse respeito em todo o globo. Esclarece ainda, com relação ao minério de ferro que, apesar deste ser muito comum na crosta terrestre e haver grandes jazidas no Brasil, praticamente não existem informações toxicológicas ou epidemiológicas sobre o mesmo.

Davies (2004) fez uma extensa pesquisa de campo medindo e comparando, com a legislação, as emissões de motores à Diesel, indicando os efeitos tóxicos e medidas de controle dos particulados provenientes destes.

As estatísticas do Brasil com relação a acidentes no trabalho são divulgadas pelo Ministério do Trabalho e Emprego, onde, infelizmente, não existe um detalhamento dos acidentes de trabalho por setor e tipo de exposição ocupacional. Apesar disto, muito se tem discutido com relação às doenças geradas por sílica, carvão e asbestos em trabalhadores de minas. Capitane (2006) ressalta a falta de dados confiáveis, no Brasil, sobre morbidade e mortalidade por silicose, chamando a atenção para a ocorrência de silicose em determinados tipos de processo de trabalho e de ocupação e, ainda, ressaltando a necessidade de investimentos na prevenção.

Ambientes de mineração podem apresentar condições de temperaturas elevadas, nas quais os filtros contra partículas podem ficar expostos por um longo período de tempo, podendo degradar a carga eletrostática neles existentes, afetando diretamente na capacidade de filtração. 
No ambiente de trabalho, apesar de pouco provável que os filtros ou respiradores fiquem expostos a temperaturas maiores do que $75^{\circ} \mathrm{C}$ por longo período de tempo, existe a possibilidade destes serem afetados durante o processamento, pois, a conformação e adesão das bordas de filtros planos são realizadas, predominantemente, por meio da aplicação de temperatura e pressão versus tempo.

Os moldes utilizados na fabricação dos filtros devem ser mantidos aquecidos em faixas de temperaturas que variam de 90 a $140^{\circ} \mathrm{C}$ e, o tempo de permanência das mantas, dependendo da processabilidade do material externo e tipo de acabamento pretendido, pode ser maior ou menor. Segundo recomendações, este tempo deve variar entre 9 a 15 segundos (informação verbal) ${ }^{1}$.

\footnotetext{
${ }^{1}$ Informação obtida pelo autor por meio de conversa com fabricante de material filtrante. Junho, 2007.
} 


\section{CONCLUSÕES}

Semelhantemente aos resultados encontrados por outros pesquisadores, constatouse uma forte influência da temperatura em função do tempo na eficiência dos filtros para particulados.

Também se constatou o efeito do uso do isopropanol na remoção das cargas eletrostáticas das fibras. Verificou-se ainda, com relação à remoção da carga eletrostática, que, para a amostra testada, um filtro N95 não foi possível remover totalmente a carga, pois ocorreu um aumento da penetração após o aumento da temperatura para $90^{\circ} \mathrm{C}$.

Ao comparar as variações de penetração encontradas, com os requisitos normativos, observou-se que $60 \%$ dos filtros, originalmente classificados como P1 ou N95, após 120 horas de exposição à $75^{\circ} \mathrm{C}$, apresentaram níveis de penetração superiores à faixa de aprovação.

As normas EN, 42 CFR 84 e NBR para PFF determinam pré-condicionamento entre 65 e $75^{\circ} \mathrm{C}$, por períodos de 24 horas Neste caso, nenhum dos filtros que foram testados seria reprovado, pois o tempo de exposição definido é muito curto.

Considerando as condições térmicas em ambiente de mina, é justo indagar se, os filtros testados continuariam a oferecer a proteção adequada ao usuário ao longo do tempo.

As amostras números 23 a 26 do fabricante número 8 apesar de visualmente serem muito parecidas com as amostras do fabricante $D$, mantiveram os resultados de penetração praticamente inalterados ao longo do tempo; comportamento totalmente diferente do observado nas amostras dos outros 7 fabricantes.

A influência da temperatura também variou conforme o fabricante do filtro/ respirador. Esta variação, muito provavelmente, está relacionada ao processo de 
fabricação da fibra, carregamento, capacidade de retenção da carga elétrica e material empregado pelo fornecedor do material filtrante. Outra possibilidade é a do processo de fabricação do filtro também ter afetado no desempenho deste, ou ainda, uma combinação das duas possibilidades, resultando na perda da carga elétrica.

A umidade é citada com freqüência em outros trabalhos como sendo um dos fatores que afetam a eficiência da filtração. Entretanto, Moyer e Stevens (1989) constataram, em um de seus estudos, que amostras de filtros eletrostáticos armazenados a $100 \%$ de umidade relativa e em temperatura ambiente não mostraram alterações significativas na penetração.

Deste modo, concluiu-se nesta pesquisa, que temperaturas de $75^{\circ} \mathrm{C}$ podem causar variações significativas na eficiência de filtração dos filtros (dependendo do fabricante), variando de 9,26\% até 12,55\% (gráfico 14). Para incremento da temperatura até $90^{\circ} \mathrm{C}$, houve variação da ordem 1,7 a 18\% (gráfico 14). O aumento da temperatura para a faixa de $110^{\circ} \mathrm{C}$, por $24 \mathrm{~h}$, causou danos estruturais em alguns filtros, não sendo possível prosseguir com os estudos Porém, os que não foram danificados tiveram um aumento da penetração em até 18\%.

Apesar de, neste estudo, não ter sido considerada a condição de fabricação dos filtros (onde o material do filtro é pressionado contra a parede aquecida do molde), a permanência dos mesmos em estufa, demonstrou claramente a influência da temperatura na eficiência dos filtros, podendo esta afetar na qualidade dos mesmos, logo no início da sua produção.

A extensão deste trabalho foi específica para áreas de mineração, contudo, condições semelhantes em que os filtros são expostos à altas temperaturas podem ocorrer em qualquer área onde seja necessário o uso de respiradores purificadores de ar para particulados.

Finalmente, um programa adequado de proteção respiratória, aliado ao uso de filtros eficientes e de qualidade, poderiam ajudar significativamente na redução das estatísticas de doenças ocupacionais relacionadas à parte respiratória. 


\subsection{DIFICULDADES ENCONTRADAS NA REALIZAÇÃO DA PESQUISA}

Como as amostras foram obtidas junto a revendas de EPI, não houve como obter as informações relativas ao processo e origem da matéria prima utilizada por cada fabricante e, mesmo que as amostras fossem coletadas junto aos fabricantes, dificilmente estes forneceriam tais informações, visto que são mantidas como segredo industrial. Deste modo, não foi possível usar planos de amostragem baseados em normas específicas para tal, durante a obtenção das amostras, assim como rastrear o tipo de matéria prima e processo utilizados na fabricação dos filtros.

Apesar de existir uma quantidade razoável de informações referentes a gradientes térmicos na mineração, as informações disponíveis são basicamente sobre a temperatura da rocha e foram levantadas e estudas principalmente com o objetivo do uso da energia geotérmica.

Sendo assim, outra dificuldade na realização da pesquisa foi a obtenção de artigos técnicos referentes aos gradientes térmicos em minas subterrâneas, para assim, se ter uma estimativa mais precisa das temperaturas presentes no ambiente de mineração subterrânea.

\subsection{PROPOSTAS PARA FUTUROS TRABALHOS}

Para uma melhor quantificação do problema da degradação de filtros eletreto, seria adequado fazer avaliações de filtros expostos a condições reais do ambiente de trabalho.

Os filtros novos poderiam ser testados após exposição no ambiente, simulando uma condição real de armazenamento de respiradores em temperatura elevada.

Poderiam ser realizados testes adicionais verificando a eficiência de filtros em uso em ambientes de mineração, com a presença de particulado. Embora existam 
recomendações normativas para o uso de respiradores descartáveis por no máximo um turno, existem usuários que utilizam por mais de um turno. O mais agravante é que alguns fabricantes indiretamente incentivam o uso de respiradores descartáveis por mais de um dia.

Vale observar que uma dificuldade que seria encontrada nestes testes seria a realização de um novo teste de penetração com o equipamento TSI, o qual mede a quantidade de partículas que passa pelo fotômetro, sendo elas de $\mathrm{NaCl}$ ou não. $\mathrm{Ou}$ seja, partículas do contaminante depositadas sobre o filtro podem chegar até o fotômetro, podendo este fornecer uma medida errada.

Minas subterrâneas apresentam alto índice de umidade, sendo interessante a condução de um estudo para verificar a influência da água líquida na penetração e perda de carga de filtros para particulados.

Realização de pesquisa sobre a estatística de doenças ocupacionais relacionadas ao uso inadequado de EPR. 


\section{REFERÊNCIAS}

AIR TECHNIQUES INTERNATIONAL. The TDA-100P Automatic Filter Tester. Owings Mills, 2008. Disponível em:

http://www.atitest.com/html/products/details/tda_100p.html. Acesso em: mar/2008.

ALMEIDA I. T. A poluição atmosférica por material particulado na mineração a céu aberto. São Paulo. Dissertação (Mestrado) - Escola Politécnica, Universidade de São Paulo, São Paulo, 1999.

ASSOCIAÇÃO BRASILEIRA DE NORMAS TÉCNICAS. NBR 12543: Equipamentos de proteção respiratória - Terminologia. Rio de Janeiro, 1999.

NBR 13697: Equipamentos de Proteção Respiratória - Filtros Mecânicos Especificação. Rio de Janeiro, 1996.

BARRETT L. W.; ROUSSEAU A. D. Aerosol loading performance of electret filter media. American Industrial Hygiene Association Journal, v. 59, p. 532-539, 1998.

BEHNAM P. B. M.; HOOMAN V. T. Simulation and analysis of unbonded nonwoven fibrous structures. Journal of Engineered Fibers and Fabrics, v. 1, n. 2, p. 47-65, 2006.

BRASIL. Ministério do Trabalho e Emprego. Portaria $n^{\circ} 25$, de 29 de dezembro de 1994, dando a redação final a Portaria GM no 3214, de 8 de junho de 1978. Normas Regulamentadoras de Segurança e Saúde no Trabalho. NR-9 - Programa de Prevenção de Riscos Ambientais. Disponível em:

http:www.mte.gov.br/legislação/normas regulamentadoras/nr 9.pdf. Acesso em: jan/2007.

BRASIL. Ministério do Trabalho. Secretária de Segurança e Saúde no Trabalho. Instrução Normativa nº 1, de 11 de abril de 1994.

BROWN, R. C. Modern concepts of air filtration applied to dust respirators. The Annals of Occupational Hygiene, v. 33, n. 4, p. 615-644, 1989.

Air filtration - an integrated approach to the theory and applications of fibrous filters. Sheffield, UK: Pergamon Press, p. 272, 1993. 
Filtration in industrial hygiene. American Industrial Hygiene Association

Journal, v. 62, n. 5, p.633-643, 2001.

CAMARGO, O. F. Estudo de desempenho de filtros para particulados e seleção de respiradores para uso em mineradoras. Ed. rev. São Paulo. 2007. 91 p. Dissertação (Mestrado) - Escola Politécnica, Universidade de São Paulo, São Paulo, 2007.

CAPITANI, E. M. A silicose ainda entre nós. Jornal de Pneumologia, v. 32, n. 6, p. 33-35, 2006.

CHEN, C. C.; HUANG, S. H. The effects of particle charge on the performance of a filtering facepiece. American Industrial Hygiene Association Journal, v. 59, n. 4, p. 227-233, Apr/1998.

CHEN, C. C. et al. Loading and filtration characteristics of filtering facepieces. American Industrial Hygiene Association Journal, v. 54, n. 2, p. 51-60, Feb/ 1993.

CHENG, Y. S. et al. Evaluation of respirator filters for asbestos fibers. Journal of Occupational and Environmental Hygiene, v. 3, n. 1, p. 26-35, 2006.

DAVIES, B. The control of diesel particulates in underground coal mining. 2004. Thesis (Master of Science). Victoria University of Technology, Centre for Environmental Safety and Risk Engineering, Victoria, 2004.

DROUIN, B. Triboelectric blend enhance air filtration. Filtration \& Separation, v. 37, n. 9 , p. 20-23, Nov/2000.

DRUCKETT, K. Nonwovens, Science and Technology II. 1999; Course Links, Material for Science and Engineering. Disponível em:

http://www.engr.utk.edu/mse/Textiles/index.html. Acesso em jul/2007.

EMI, H. et al. Collection mechanisms of electret filter. Particulate Science and Technology, v. 5, n. 2, p.161-171, 1987.

ESTADOS UNIDOS. Code of Federal Regulations. Department of Health and Human Services. Public Health Services. 42 CFR 84. Subpart K: non powered air purifying particulate respirator. [Rockville], 1995. 
FELTHAN, F. J. Second thoughts on the Hansen electrostatic filter. Filtration and Separation, v.13, p. 467-469, Sept-Oct/1976.

FJELD, R. A.; OWENS, T. M. The effect of particle charge on penetration in an electret filter. IEEE Transactions on Industry Applications, v. 24, n. 4, p. 725-731, Jul-Aug/1988.

HEGDE, R. R.; DAHIYA, A.; KAMATH, M. G. Olefin Fiber 2004; course links, material for science and engineering. Disponível em:

http://www.engr.utk.edu/mse/textiles/olefin\%20fibers.htm. Acesso em jul/2007.

INGLATERRA. Comissão Européia de Normalização. EN 143. Respiratory protective devices: particle filters. Requirements, testing, marking. [S.I.], 2006.

JASPER, W. J. et al. Degradation processes in corona-charged electret filter-media with exposure to ethyl benzene. Journal of Engineered Fibers and Fabrics, v. 2, n. 4, p. 1-6, 2007.

KRAVTSOV, A. et al. The Electret Effect in Polypropylene Fibers Treated in a Corona Discharge. Advances in Polymer Technology, v.19, n.4, p.312-316, USA, 2000.

LOWKIS, B.; MOTYL, E. Electret properties of polypropylene fabrics. Journal of Electrostatics, v.51-52, p.232-238, 2001.

MARTIN JUNIOR, S. B.; MOYER, E. S. Electrostatic respirator filter media: filter efficiency and most penetrating particle size effects. Applied Occupational Environmental Hygiene, v. 15, n. 8, p. 609-617, Aug/2000.

MOTYL E.; LOWKIS B. Effect of air humidity on charge and lifetime of PP electret nonwovens. Fibers and Textil in Eastern Europe, v. 14, 5, p. 39-42, Jan-Dec/2006.

MOYER, E. S.; BERGMAN, M. S. Electrostatic N-95 respirator filter media efficiency degradation resulting from intermittent sodium chloride aerosol exposure. Appl Occup Environ Hyg, v.15, n.8, Aug, p.600-8, USA, 2000.

MOYER, E. S.; STEVENS, G. A. "Worst case" aerosol testing parameters: II. Efficiency dependence of commercial respirator filters on humidity pretreatment. American Industrial Hygiene Association Journal, v.50, n.5, May, p.265-270. 1989. 
NETTO, L. F. Eletreto (O 'ímã' da Eletrostática). Instituto de Física - USP Laboratório de Demonstrações, 1994. Disponível em:

http://www.feiradeciencias.com.br/sala19/texto46.asp. Acesso em out/2007.

OBERTA, A. F. The truth about HEPA filters. 2008. Disponível em: www.asbestosguru-oberta.com. Acesso em: maio 2008.

ORTIZ, L. W. et al. Penetration of Respirator Filters by an Asbestos Aerosol. American Industrial Hygiene Association Journal, v.49, n.9, p.451-460, USA, 1988.

RIEF, S. et al. Computer simulation of air filtration including electric surface charges in three-dimensional fibrous micro structures. S.I.: Fraunhofer Institut für Technound Wirtschaftsmathematik.

ROMAY, F. J. et al. Experimental Study of Electrostatic Capture Mechanisms in Commercial Electret Filters. Aerosol Science and Technology, v.28, n.3, p.224234, 1998.

SANTOS, A. M. A. O tamanho das partículas de poeira suspensas no ar dos ambientes de trabalho. São Paulo: Fundacentro, 2001.

SFP SERVICES LTDA. Manufacturer and Supplies of Air Filter Test Instruments. Sodium Flame Photometrer Type 1100. Disponível em:

http://www.sfpservices.com. Acesso em: mai/2008.

STEVENS, G. A.; MOYER, E. S. "Worst case" aerosol testing parameters: I. Sodium chloride and dioctyl phthalate aerosol filter efficiency as a function of particle size and flow rate. American Industrial Hygiene Association Journal, v.50, n.5, May, p.257-64, 1989.

TORLONI, M. (Coord.). Programa de proteção respiratória: recomendações seleção e uso de respiradores. $3^{a}$ ed., São Paulo: FUNDACENTRO, 2002.

TORLONI, M.; VIEIRA A. V. Manual de proteção respiratória. São Paulo: ABHO, 2003. respirator standards EN 143 and 42 CFR part 84. 2003 (Filter Testing Seminar). 
$\overline{\operatorname{Jan} / 2004 .}$

TSI Model 8110 - A salt aerosol generator: instruction manual. Filter test media lot number - 50804. Jan/2001.

Automated filter tester operation and service manual P/N 1980207. Certitest ${ }^{\circledR}$ Model 8127/8130. 2008a.

Automated filter tester spec sheet. Certitest ${ }^{\circledR}$ Model 8127/8130. 2007.

WADSWORTH, L. C. Nonwovens, science and technology I - Nano Fiber Nonwoven. Tennessee: University of Tennessee, 2004. Disponível em:

http://www.engr.utk.edu/mse/Textiles/index.html. Acesso em: 9/jul/2007.

WILLEKE, K.; BARON, P. A. Aerosol measurement: principles, techniques and applications. New York: Van Nostrand Reinhold, 1993. 